\title{
ARCHITECTURE WITHOUT BARRIERS: \\ Designing Inclusive Environments Accessible to All
}

by

\author{
Hong-Li Wong \\ Interior Design, Sheridan College Institute of Technology and Advanced Learning, 2006 \\ Bachelor of Architectural Science, Ryerson University, 2011
}

\author{
A design thesis \\ presented to Ryerson University \\ in partial fulfillment of the \\ requirements for the program and degree of \\ Master of Architecture
}

Toronto, Ontario, Canada, 2014

(C) Hong-Li Wong 2014 


\section{AUTHOR'S DECLARATION}

I hereby declare that I am the sole author of this thesis. This is a true copy of the thesis, including any required final revisions, as accepted by my examiners.

I authorize Ryerson University to lend this thesis to other institutions or individuals for the purpose of scholarly research.

I further authorize Ryerson University to reproduce this thesis by photocopying or by other means, in total or in part, at the request of other institutions or individuals for the purpose of scholarly research.

I understand that my thesis may be made electronically available to the public.

Hong-Li Wong 


\title{
ARCHITECTURE WITHOUT BARRIERS: \\ Designing Inclusive Environments Accessible to All
}

\author{
By Hong-Li Wong \\ Master of Architecture Program, Ryerson University, Toronto \\ Master of Architecture Degree, 2014
}

In Canada, studies show there are changing demographics increasing the population, the disability rate, and the aging population. This significantly impacts people and their interactions within the built environment. Currently, there are many buildings meeting minimum accessibility standards, though they continuously create poorly designed and inaccessible buildings to all. Thus, integrating Inclusive Design (ID) allows for full participation within society. This prevents discrimination and stigmatization. ID is an intervention respecting differences, associated with gender, race, religion, as well as age and ability, by accommodating diverse needs of various groups of people. This approach incorporates three design strategies, including visual, nonvisual, and social aspects enhancing the concept of ID. They are accessible experience while traversing in architecture as communication, responsive and adaptable environment through multi-sensory experience, and secure architecture for social interaction. As a result, an inclusive environment is created addressing equity and equality, which benefit everyone enhancing selfdignity, independence, and well-being.

KEYWORDS: Inclusive Design (ID), barriers, built environment, accessible, usable, accommodate, diverse needs, experience, quality of life 


\section{ACKNOWLEDGEMENTS}

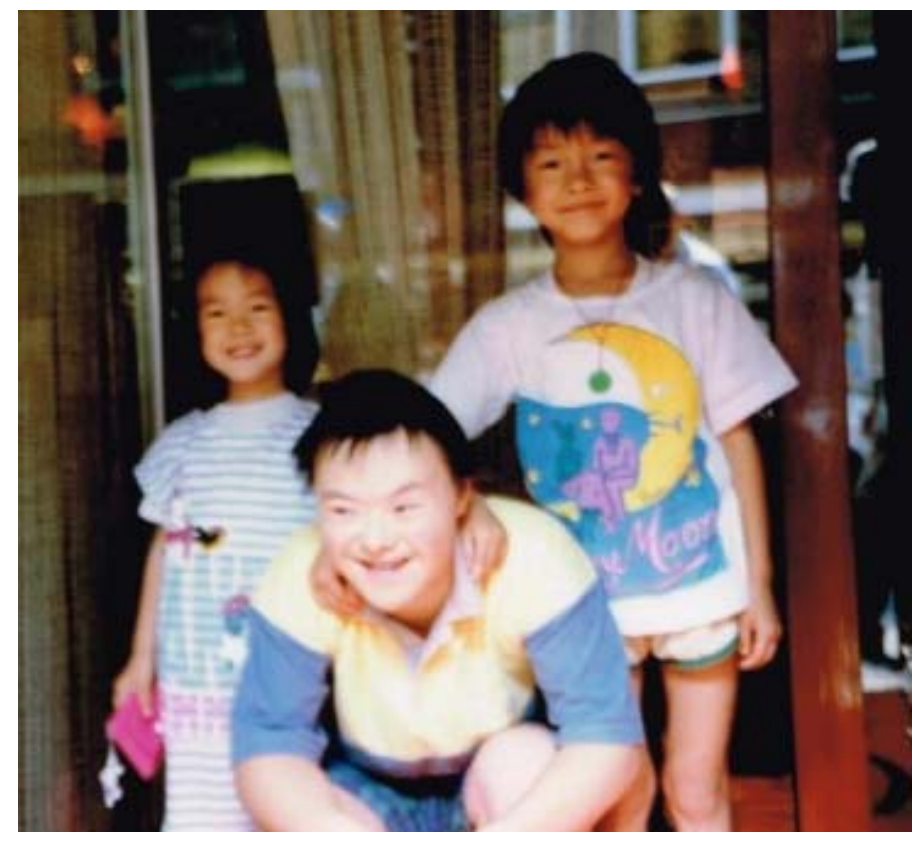

Author (left), uncle Akung (centre), and older brother (right)

I would like to acknowledge this dissertation to Paul Floerke for helping me with my thesis as my supervisor, Miljana Horvat as my very encouraging second reader, my mother and father for all their love and support, my friends for keeping me grounded and sane, and my uncle, Akung Wong, who has Down syndrome. Although he is different, I have memories from a young age of him playing with me, my siblings, and my cousins, like any other uncle. He is caring towards us and we respect him like an elder. Today, he is living in a communal Down syndrome facility in the Netherlands. He is currently 45 years old but has the body of a senior. His body is deteriorating and my family believes he may pass away before my grandparents. My uncle, Akung, led me to my thesis topic as I began to question the many issues related to architecture for people with physical and mental disabilities within Canada. Are these individuals being properly accommodated? What issues are affecting their overall quality of life and can these be improved through architecture? 


\section{DEDICATION}

I would like to dedicate this to my parents for their unconditional love and always believing in me, Peter Turner from Turner Fleischer Architects Inc. for supporting me, and Kelvin Lau for always being there for me during thesis crunch time. 


\section{TABLE OF CONTENTS}

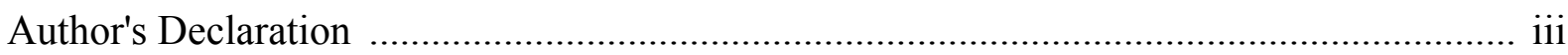

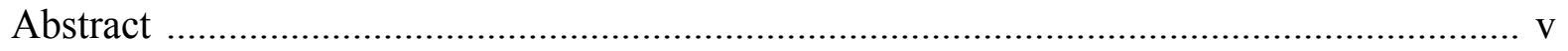

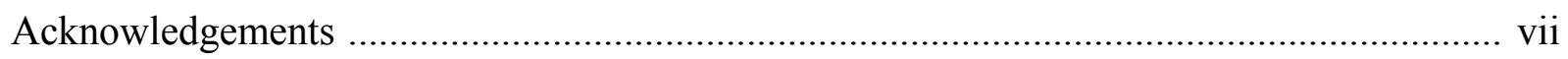

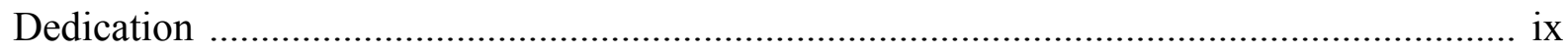

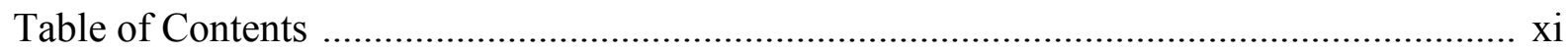

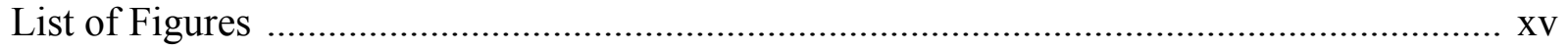

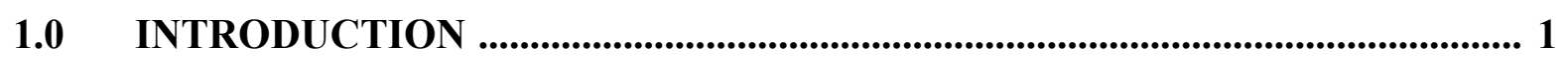

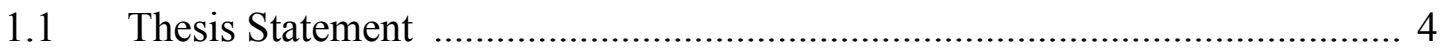

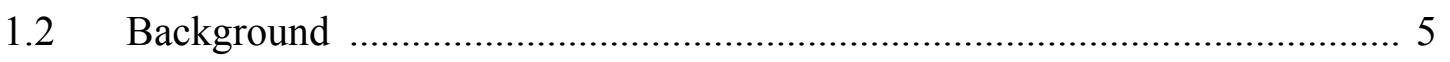

$1.3 \quad$ Target User Groups ........................................................................... 10

2.0 DESIGN WITHOUT BARRIERS ........................................................................... 11

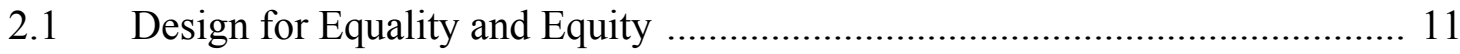

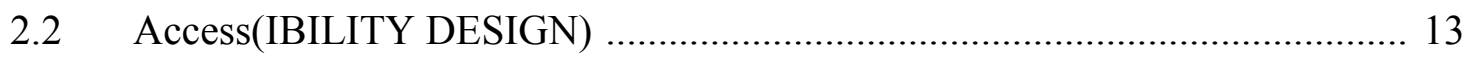

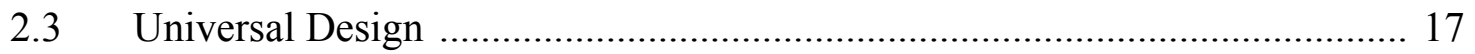

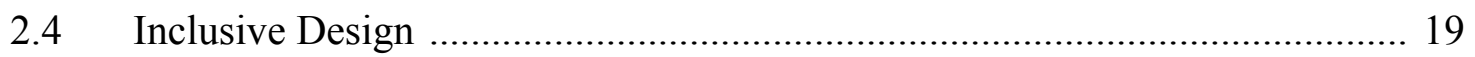

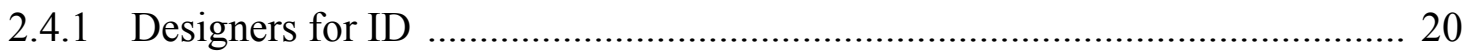

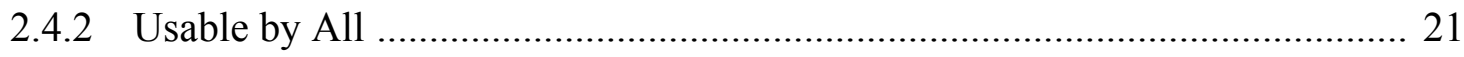

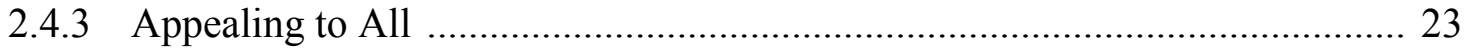


2.4.4 Collaborating with Users ........................................................................ 25

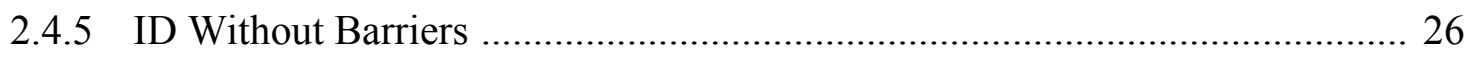

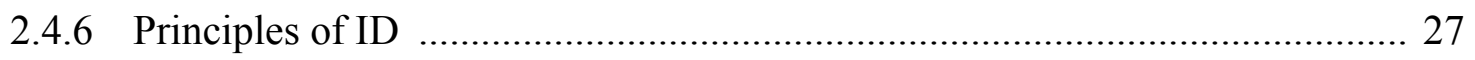

3.0 THEORETICAL FRAMEWORK _................................................................ 29

3.1 Accessible Architecture as Communication .............................................. 30

3.1.1 Communication Within Architecture …………………………………….. 31

3.1.2 Accessible Experience While Traversing in Architecture Design .................. 35

3.1.3 Integrate Communication Systems ……………............................................ 37

3.2 Responsive and Adaptable Architecture Through Multi-Sensory Experience 40

3.2.1 Integrate Non-Visual Information for Wayfinding ……………………....... 42

3.2.2 Soundscape Sensory ………………………....................................... 45

3.2.3 Illumination Within an Inclusive Environment ............................................... 47

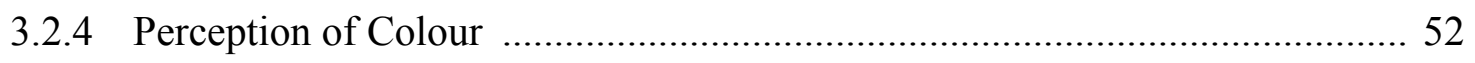

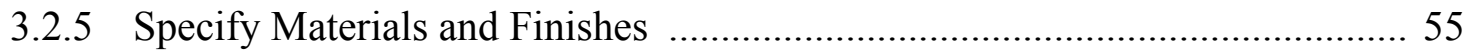

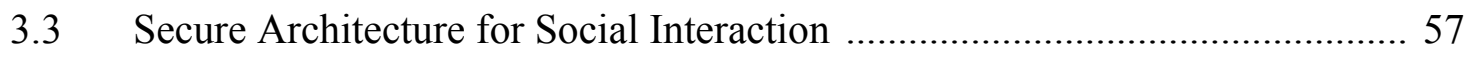

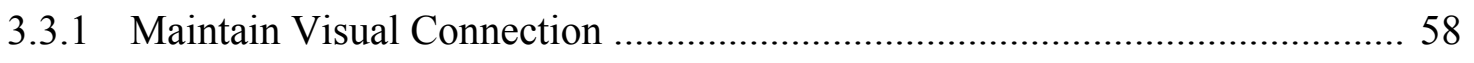

3.3.2 Integrate Circulation Spaces as Social Places ………..................................... 60

3.3.3 Social Places Define Human Behavior for Social Engagement ..................... 62 


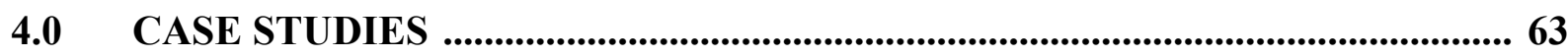

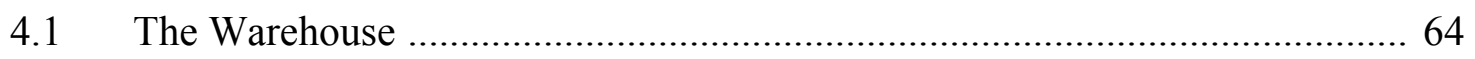

4.2 Hazelwood School for the Multiple Sensory Impaired .................................. 69

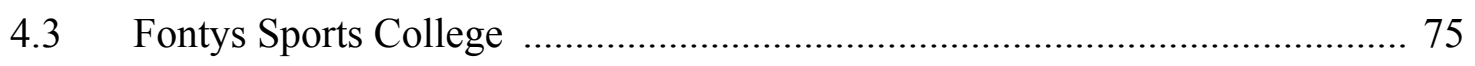

5.0 DESIGN PROPOSAL …….............................................................................................. 78

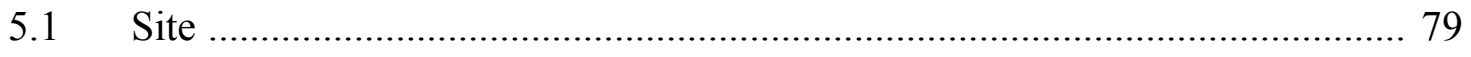

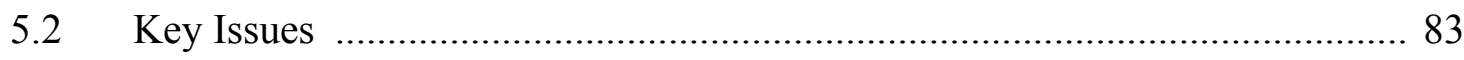

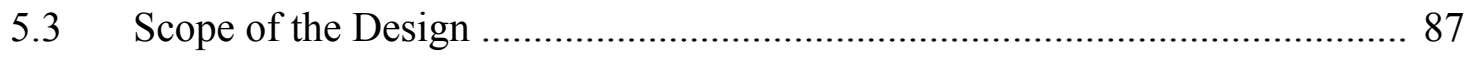

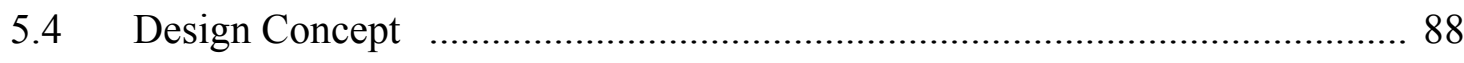

5.5 Strategies Implementing Three Design Interventions .................................... 93

5.5.1 Accessible Architecture as Communication ................................................. 93

5.5.2 Responsive \& Adaptable Architecture Through Multi-Sensory Experience .. 97

5.5.3 Secure Architecture for Social Interaction ................................................... 109

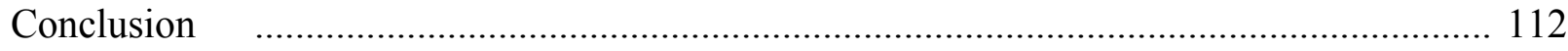

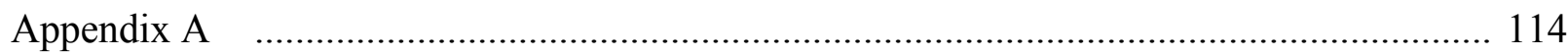

Appendix B

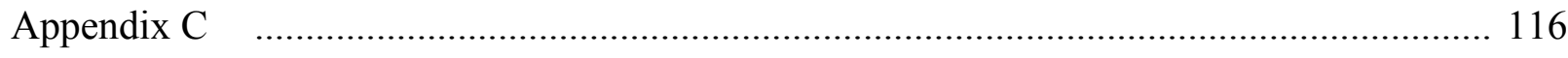

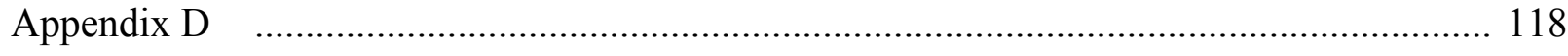

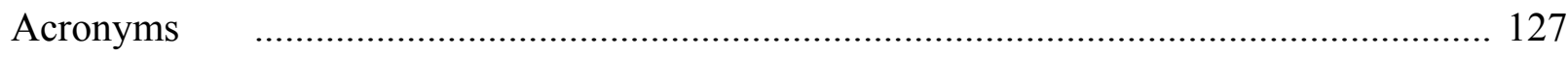

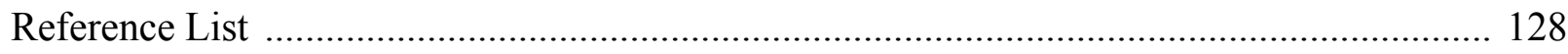




\section{LIST OF FIGURES}

Figure / Table Description and Source Page

Figure 1.2a Current buildings continue to exclude accessibility to all 5

Image by author taken on April 9, 2014.

Table 1.2b Population with and without disabilities in Canada, 2006

6

Image edited by author. Reference from PALS 2006: Analytical

Report. (2007). Statistics Canada (p. 16). Retrieved March 3, 2013, from http://www.statcan.gc.ca/pub/89-628-x/89-628-x2007002-

eng.pdf

Table 1.2c Comparison of Canada's disability rate in 2001 and 2006

$($ standardized $=$ expected $)$

Image edited by author. Reference from PALS 2006: Analytical Report. (2007). Statistics Canada (p. 20). Retrieved March 3, 2013, from http://www.statcan.gc.ca/pub/89-628-x/89-628-x2007002eng.pdf

Figure 1.2d Population age pyramids of Canada 1990, 2009, and predicted 2036

Image created by author. Reference from Age Pyramids of the Canadian Population, 2009, 2036 and 2061 (\#). (2012). Statistics Canada. Retrieved June 9, 2014, from http://www.statcan.gc.ca/pub/91-520-x/2010001/ct047-eng.htm

Image edited by author. Reference from Age Pyramid of Population of Canada July 1, 1901 - 2001. (n.d.). Statistics Canada. Retrieved June 9, 2014, from http://www12.statcan.ca/english/census01/products/analytic/compan ion/age/cda01pymd.cfm 
Figure 1.2e

Visible barriers (left) and invisible barriers showing attitudinal behavior towards PWD (right)

Bannert, S. (2013). The Architect and the Accessible

City. ArchDaily. Retrieved July 7, 2014, from

http://www.archdaily.com/364518/the-architect-and-the-accessible-

city-the-prize-winning-essay/

Image edited by author. Reference from Krupnick, E. (2013).

'Disabled' Mannequins Remind Us That Beautiful Doesn't Mean

'Perfect'. The Huffington Post. Retrieved July 20, 2014, from

http://www.huffingtonpost.com/2013/12/03/disabled-mannequins-

video_n_4379586.html

Figure 1.3a Enabler concept representing various functional limitations

Steinfeld, E., \& Maisel, J. L. (2012).Universal Design: Creating

Inclusive Environments (p. 50). Hoboken, NJ: Wiley.

Figure 2.2a Accessibility (top) vs. Universal Design or Inclusive Design (bottom)

Image created by author. Reference from Nussbaumer, L.

(2012). Inclusive Design: A Universal Need (p. 31). New York:

Fairchild Books.

Figure 2.2b Creative solutions to Accessibility Standards

Image created by author. Reference from Museum Map.

(n.d.). Solomon R. Guggenheim Museum. Retrieved June 12, 2014, from http://www.guggenheim.org/new-york/visit/plan-yourvisit/map

Figure 2.4.1a Michael Graves (left) and Chris Downey (right) are both advocates for change 
Abramovitch, I. (2014). Shortlist: Michael Graves. ELLE DECOR.

Retrieved June 19, 2014, from http://www.elledecor.com/celebritystyle/shortlist-michael-graves\#slide-8

Biography. (2009). Chris Downey Architect. Retrieved June 19, 2014, from http://www.arch4blind.com/bio.html

Figure 2.4.2a The pyramid of needs

Image edited by author. Reference from Universal Design Explained. (n.d.). Insta Blogs. Retrieved June 19, 2014, from http://www.instablogs.com/universal-design-explained.html.

Figure 2.4.3a MGDG creates aesthetic products for home and healthcare use Stryker Medical. (n.d.). Michael Graves Design Group. Retrieved June 19, 2014, from http://www.michaelgraves.com/design/project/stryker-medical.html

Figure 2.4.4a Inclusive design process

Image edited by author. Reference from Clarkson, J. (n.d.).

Designing a More Inclusive World. Centre for Excellence in Universal Design. Retrieved June 19, 2014, from http://www.universaldesign.ie/exploreampdiscover/conferenceproce edings/universallearningforthe21stcentury/designingamoreinclusive world

Figure 3.0a Theoretical framework created by three human experiences of the environment

Image by author.

Figure 3.1.1a Form (left with Crystal By Libeskind) vs. Function (right with TD Centre by Mies Van Der Rohe) 
Image edited by author. Reference from Bloor-Yorkville.

(n.d.). Royal Ontario Museum. Retrieved August 28, 2014, from

http://www.bloor-yorkville.com/directory/shops-

services.aspx?s=105

Reference from Toronto-Dominion Centre. (n.d.). $B+H$ Architects.

Retrieved June 27, 2014, from

https://www.bharchitects.com/en/projects/85\#8

Figure 3.1.1b Function vs. form

Image by author.

Figure 3.1.1c Internal functions express direction of movement

Image by author.

Figure 3.1.2a Kimbell Art Museum enhances human experiences visually and non-visually

Image edited by author. Reference from Kimbell Art Museum.

(2014, June 29).Wikipedia. Retrieved June 30, 2014, from

http://en.wikipedia.org/wiki/Kimbell_Art_Museum

Image edited by author. Reference from Louis Kahn and Texas

Modern. (n.d.).'Studio Forbes. Retrieved June 30, 2014, from

http://studioforbes.typepad.com/blog/2007/09/lighting-up-the.html

Image edited by author. Reference from Week 13: Function in

Architecture. (n.d.).ARCH 121 - Introduction to Architecture I .

Retrieved June 27, 2014, from

http://arch121.cankaya.edu.tr/uploads/files/Week\%2013-

lecture\%20notes-07-jan-2014.pdf 
Figure 3.1.3a Wayfinding integrates graphics with architectural elements as communication

Image edited by author. Reference from Cornfield, K. (n.d.). Behind the Big Doors at Ottawa's New IKEA Superstore. Girl About OTown. Retrieved August 28, 2014, from http://www.girlaboutotown.com/2011/12/06/behind-the-big-doorsat-ottawas-new-ikea-superstore/

Shopping, Wayfinding and Steering Behaviour. (n.d.). Wayfinding in Travel and Tourism. Retrieved August 28, 2014, from http://www.travelwayfinding.com/shopping-steering/

Figure 3.1.3b Functional signage showing direction of movement (left) vs. narrative signage system showing flow of movement up a building corresponds to different elevations of natural elements as wayfinding (two right images)

University of Applied Sciences Osnabrück Signage System

Osnabrück 2004. (n.d.).Büro Uebele. Retrieved June 30, 2014, from http://www.uebele.com/en/projekte/orientierungssystem/fachhochsc hule-osnabrueck.html\#i4

Image edited by author. Reference from Kreissparkasse Tübingen Signage System. (n.d.). L2M3 Kommunikationsdesign. Retrieved June 30, 2014, from http://www.12m3.com/index.php?lang=en\&key=projekttypLeitsyste me\&id $=44$

Figure 3.2a Multiple senses are fragments creating an overall image of the environment

Image by author 
Figure 3.2.1a Multiple senses connect to the brain to receive and interpret information about the environment

Image edited by author. References from Ceglio, C. (2011). How

Does Material Culture Shape our Sense of War?. War and the

Visceral Imagination. Retrieved July 1, 2014, from

http://warandvisceralimagination.wordpress.com/2011/08/03/hello-

world/

Imaged edited by author. Reference from Feeney, D. (n.d.).

Hierarchy of the Senses. Scottish Sensory Centre. Retrieved July 1,

2014, from

http://www.ssc.education.ed.ac.uk/courses/vi\&multi/vjun092ii.html

Figure 3.2.1b Senses provide information and enhance our experiences within architecture design

Giancarli, D. (n.d.). Sensory Architecture.WordPress. Retrieved

September 3, 2014, from

http://davegiancarli.wordpress.com/2012/10/

Figure 3.2.1c Various non-visual wayfinding techniques to assist in orientation for diverse users

Image from author. Reference from Sensory Mapping.

(n.d.). Information Design. Retrieved July 9, 2014, from

http://datadesign.wordpress.com/2012/01/30/sensory-mapping/

Figure 3.2.3a Emergency lighting for safety using LED (left) and photo-

luminescent tape (right)

Mathews, L. (2013). Philips LED carpet turns floors into incredibly helpful dynamic signage. Geek. Retrieved September 3, 2014, from http://www.geek.com/news/philips-led-carpet-turns-floors-intoincredibly-helpful-dynamic-signage-1577552/ 
Cintas Fotoluminicentes. (n.d.). Tape Solutions. Retrieved

September 3, 2014, from http://www.tape-

solution.com/cintas\%20fotoluminicentes.html

Figure 3.2.3b Anchor Centre for Blind Children uses lighting to guide children

Sokol, D. (n.d.). Extra Sensory Perception.Architectural Record.

Retrieved September 3, 2014,

from http://archrecord.construction.com/schools/08_Extra_Sensory .asp

Bright, K., \& Egger, V. (2008). Using Visual Contrast for Effective, Inclusive, Environments. Information Design Journal, 16(3), 178189.

Figure 3.2.3c Tadao Ando's Church of Light (left) creates different experiences compared to his $4 \times 4$ House (right)

Digital Design Foundations 2011. (n.d.).WordPress. Retrieved September 3, 2014, from http://ddfblog2011.wordpress.com/page/4/

Del Co, F. (n.d.). 4 x 4 House by Tadao Ando. Architecture Week.

Retrieved September 3, 2014, from

http://www.architectureweek.com/2011/0727/design_4-2.html

Figure 3.2.4a Enhancing behavior through colour psychology Image by author.

Figure 3.2.4b Different levels of colour blindness and primary colours for contrast Image by author. Reference from Web Design and Colour Blindness. (2007). AKA Marketing. Retrieved June 9, 2014, from http://www.akamarketing.com/blog/83-web-design-and-colourblindness.html 
Figure 3.3.1a House of Disabled People's Organization

Image edited by author. Reference from HDPO. (n.d.). ArchDaily.

Retrieved August 29, 2014, from

http://www.archdaily.com/495736/house-of-disable-people-s-

organization-cubo-force4/

Figure 3.3.2a Definition of social place

Reference from http://www.mindtangle.net/2009/04/03/designingsocial-websites/

http://blogs.brandeis.edu/city/2012/09/10/placemaking-inspired-byjane-jacobs-eyes-on-the-street-concept/place_diagram-2/

Figure 3.3.2b Social spaces cut through the middle vs. tangent

Image by author. Reference from Alexander, C., Ishikawa, S., \&

Silverstein, M. (1977). A Pattern Language: Towns, Buildings,

Construction (p. 619). New York: Oxford University Press.

Figure 3.3.2c Circulation space as social space

Image by author.

Figure 3.3.3a Three spaces affecting human behavior for social engagement Image by author.

Figure 4.1a Front view as one approaches the site and the building reminds Graves of Italian farmhouses

Michael Graves. (2014).Slideshare (p. 9). Retrieved July 17, 2014, from http://www.slideshare.net/vikashsaini78/michael-graves30129579

Figure 4.1b Architectural expression of an industrial warehouse vs. a residential home 
Michael Graves. (2014).Slideshare (p. 4). Retrieved July 17, 2014, from http://www.slideshare.net/vikashsaini78/michael-graves-

30129579

Figure 4.1c

Renovations with additions to an existing building to make it fully accessible

Image edited by author. References from Michael Graves.

(2014).Slideshare (p. 7\&8). Retrieved July 17, 2014, from

http://www.slideshare.net/vikashsaini78/michael-graves-30129579

Image edited by author. References from Michael Graves

Warehouse, Princeton, USA. (n.d.). Atlas of Interiors. Retrieved

July 17, 2014, from http://atlasofinteriors.polimi-

cooperation.org/2014/03/20/michael-graves-warehouse-princeton-

usa-1977/

Image edited by author. References from Nussbaumer, L.

(2012). Inclusive Design: A Universal Need (p. 259). New York:

Fairchild Books.

Image edited by author. References Michael Graves for Dwell.

(n.d.). Vimeo (5:25). Retrieved July 17, 2014, from

http://vimeo.com/39458609

Figure 4.1d Brightly lit interiors and interesting qualities of spaces

Best Of Home Interior. (n.d.). : At Home with Architect Michael

Graves. Retrieved July 17, 2014, from

http://bestofhomeinterior.blogspot.ca/2012/10/at-home-with-

architect-michael-graves.html

Figure 4.1e Enfilade and landmarks for wayfinding 
Best Of Home Interior. (n.d.). : At Home with Architect Michael

Graves. Retrieved July 17, 2014, from

http://bestofhomeinterior.blogspot.ca/2012/10/at-home-witharchitect-michael-graves.html

The Warehouse. (n.d.). Michael Graves and Associates. Retrieved July 17,2014 , from http://www.michaelgraves.com/architecture/project/thewarehouse.html

Figure $4.2 \mathrm{a}$

Hazelwood School uses sensory cues to promote independence and sense of dignity

Hazelwood School Sketchbook . (n.d.).Alan Dunlop Architect

Limited (p. 2). Retrieved July 17, 2014, from

http://www.alandunloparchitects.com/wp-

content/uploads/2011/03/Hazelwood-Sketchbook.pdf

Figure $4.2 \mathrm{~b} \quad$ Orientation within the building through various senses

Hazelwood School. (2009). Institute for Human Centered Design .

Retrieved July 18, 2014, from

http://www.dev.ihcdstore.org/?q=node/128\#top

Figure 4.2c Floor plan of Hazelwood School

Image revised by author. Reference from Hazelwood School

Sketchbook . (n.d.).Alan Dunlop Architect Limited (p. 16).

Retrieved July 17, 2014, from

http://www.alandunloparchitects.com/wp-

content/uploads/2011/03/Hazelwood-Sketchbook.pdf

Image revised by author. Reference from Design Appreciation Special Institutes. (n.d.). Issuu. Retrieved July 18, 2014, from 
http://issuu.com/sivakumar.1/docs/design_appreciation_special_inst itutes

Figure 4.2d Building section through 1) the street 2) \& 3) classrooms

Sokol, D. (n.d.). Pavilion in a Park .Architectural Record. Retrieved

July 17, 2014, from

http://archrecord.construction.com/schools/08_Hazelwood.asp

Figure 4.2e Nursery classrooms use yellow and primary use red storage boxes for colour coding

Sokol, D. (n.d.). Pavilion in a Park .Architectural Record. Retrieved July 17, 2014, from

http://archrecord.construction.com/schools/08_Hazelwood.asp

Hazelwood ASN School. (n.d.). Scotland (p. 5). Retrieved July 18, 2014, from

http://www.scotland.gov.uk/Resource/Doc/920/0066326.pdf

Figure 4.2f Material selection for external building uses timber and slate

Hazelwood School. (2009). Institute for Human Centered Design .

Retrieved July 18, 2014, from

http://www.dev.ihcdstore.org/?q=node/128\#top

Figure 4.3a Open ground floor and visual connections between various spaces to the sports hall

Fontys School of Sport Studies. (n.d.).Mecanoo. Retrieved July 18, 2014, from

http://www.mecanoo.nl/Default.aspx?tabid=116\&DetailId=834\&pc ode $=\mathrm{A} 489$

Fontys Sports College. (n.d.). World Buildings Directory. Retrieved July 18, 2014, from 
http://www.worldbuildingsdirectory.com/project.cfm?id=5025

(good images)

Figure 4.3b Interactive spaces in the exterior and interior along circulation routes

Fontys Sports College Eindhoven Scores With Bolidt.

(n.d.). Archello. Retrieved July 18, 2014, from

http://www.archello.com/en/project/fontys-sports-college

Fontys Sports College. (n.d.). World Buildings Directory. Retrieved

July 18, 2014, from

http://www.worldbuildingsdirectory.com/project.cfm?id=5025

(good images)

Figure 5.1a Community centre in Alexandra Park neighbourhood (marked in red)

Image by author. Reference from Toronto Neighbourhood Guide.

(n.d.).Alexandra Park. Retrieved July 10, 2014, from

http://www.torontoneighbourhoods.net/neighbourhoods/downtown/ alexandra-park

Figure 5.1b Site selection and neighbourhood

Image by author.

Figure 5.1c Urban renewal plan for Alexandra Park along Bathurst Street

Image edited by author. Reference from Myrvold, B. (1993).

Historical Walking Tour of Kensington Market. Toronto Public

Library (p. 14). Retrieved July 10, 2014, from

http://static.torontopubliclibrary.ca/da/pdfs/loc_his-w-16.pdf

Image edited by author. Reference from Dundas Street West Final 
Design Report. (2011). regionalArchitects + Corban and Goode + ERA Architects + planningAlliance + Poulos and Chung (p. 97 \& 101). Retrieved July 10, 2014, from

http://www1.toronto.ca/city_of_toronto/policy_planning_finance administration/public_consultation_unit/transportation_office/dunda s_west/files/pdf/dundas_5.pdf

Figure 5.1d Current condition of urban farming, Market 707, and public patios for seating

To Green Thumbs and Golden Ladles. (n.d.). Talkin Trash With UHN. Retrieved July 10, 2014, from http://talkintrashwithuhn.com/2013/08/01/to-green-thumbs-andgolden-ladles/

Check out what's popping up! Container Markets. (n.d.). RSS.

Retrieved July 10, 2014, from

http://www.supercubes.com/blog/2012/07/check-out-whats-

popping-up-container-markets

Market 707's New Public Patio. (n.d.).Projexity. Retrieved July 10, 2014, from https://projexity.com/projects/view/Market-707\%E2sNew-Public-Patio/2\#/main/designs

Figure 5.2a Scadding Court Community Centre is considered a partially accessible building

Facility Listing and Permits. (n.d.). FUN Guide Fall 2013/Winter

2014. Retrieved July 9, 2014, from

http://www1.toronto.ca/parks/pdf/facility_map.pdf 
Figure 5.2b Key issues with SCCC

Image by author. Reference from Scadding Court Community

Centre. (n.d.).Google Maps. Retrieved July 10, 2014, from

https://www.google.ca/maps/@43.652297,-

79.405053,3a,47.7y,163.54h,86.53t/data=!3m4!1e1!3m2!1sP-

HmJm3D10Qdk0fIjOc2rQ!2e0

Photographs taken by the author during site visit.

Figure 5.2c Existing site conditions to consider

Image by author.

Figure 5.3a Scope of work from approach, entrance, central commons, destination point, to egress

Image by author.

Figure 5.4a Design concept involves a spiral ramp that extends outwards

Image by author. Reference from The Designing of Squirrel

Cottage. (n.d.).Chambers McMillan architects. Retrieved July 14, 2014, from http://www.cmcmarchitects.com/the-ramp-house/the-

blog/

Figure 5.4b Cartesian orientation to access the public plaza

Image by author.

Figure 5.4c Interior concept creating break-out spaces while connecting different programs and services

Image by author.

Figure 5.5.1a Form follows function for SCCC

Image by author. 
Figure 5.5.1b Communicating accessibility through visual experience Image by author.

Figure 5.5.1c Signage system within SCCC

Image by author.

Figure 5.5.2a Multi-sensory experience to access public plaza

Image by author.

Figure 5.5.2b Experiencing sound within SCCC

Image by author.

Figure 5.5.2c Interior lighting with recessed light strips (main circulation), and recessed LED (destination pts). For means of egress, linear wall mounted light fixtures and photo-luminescent tape are used Fluorescent Strip Light. (n.d.). She777. Retrieved July 15, 2014, from http://she777.com/resessed-flouresent-light/1/fluorescent-striplight-240v-flush-recessed/

Recessed LED. (n.d.). Sistemalux. Retrieved July 15, 2014, from http://www.sistemalux.com/en/products/version/punto-led-withfrosted-diffuser-for-insulated-ceiling-large-frosted-diffuser/9211$00 / 19 / 176 / 3$

Sucre Lighting. (n.d.). Halo Lighting. Retrieved July 15, 2014, from http://www.halolighting.com.au/product/interior/wallmounted/sucre-fluorescent

Cintas Fotoluminicentes. (n.d.). Tape Solutions. Retrieved September 3, 2014, from http://www.tapesolution.com/cintas\%20fotoluminicentes.html 
Figure 5.5.2d External lighting in public plaza enhancing safety and usability

Silka-Max. (n.d.). Illuminated Bollards Lighting. Retrieved July 15,

2014, from

http://www.dwwindsor.com/products/illuminated+bollards/silka-

$\max$

Ledia by Hess. (n.d.). Products. Retrieved July 15, 2014, from

http://www.architonic.com/pmsht/ledia-hess/1052621

400 Nano by Platek Light. (n.d.). Products. Retrieved July 15, 2014, from http://www.architonic.com/pmsht/400-nano-platek-

light/1220011

LED Underwater Light Fountain Light Swimming Pool Light.

(n.d.). Retrieved July 15, 2014, from

http://www.fmlights.com/underwater-light.html\#led-under-water-

lights

Figure 5.5.2e SCCC uses Pilkington anti-reflective glass system with thermochromic film for welcome wall only

Image by author. Reference from Pilkington. (2013).

Pilkington. Anti-reflective Glass OptiView, pg. 2.

Figure 5.5.2f Colour contrast and colour co-ordination provide visual information

102 in exterior (left) and interior (right) environments

Image by author.

$\begin{array}{ll}\text { Interior } & \text { Interior Materials and Finishes } \\ \text { materials and } & \text { TechZone Optima Technical Panels. (n.d.).Armstrong. Retrieved } \\ \text { finishes } & \text { August 29, 2014, from } \\ & \text { http://www.armstrong.com/commceilingsna/products/ceilings/techz }\end{array}$

$104-$

106 
one-optima-technical-panels/_N-cZ1z141qu

$\begin{array}{ll}\begin{array}{l}\text { Exterior } \\ \text { materials and }\end{array} & \text { Exterior Materials and Finishes } \\ \text { finishes } & \text { Red Square Penny Payer 12x12. (n.d.). Decor Precast. Retrieved } \\ \text { July 15, 2014, from http://www.homedepot.ca/product/red-square- } & \text { penny-paver-12-inch-x-12-inch/917798 } \\ & \text { Reference from Curbstone. (n.d.). Decor Precast. Retrieved August } \\ & \text { 29, 2014, from } \\ & \text { http://www.decorprecast.com/edgerDetails.php?page=curbStone } \\ & \text { Charcoal Cobble - Lite Paving. (n.d.). Decor Precast. Retrieved } \\ & \text { July 15, 2014, from http://www.homedepot.ca/product/charcoal- } \\ & \text { cobble-lite-paving-stone/917799 } \\ & \text { Hospital Courtyard Seating. (n.d.). Boex. Retrieved August 29, } \\ & \text { 2014, from http://www.boex.co.uk/project/hospital-outdoor- } \\ & \text { furniture/ } \\ & \text { Ipe Wood. (n.d.). SwiftDeck. Retrieved July 15, 2014, from } \\ & \text { http://www.easydeckbuilding.com/decking_material_styles_swiftde } \\ & \text { ck.html }\end{array}$

$\begin{array}{lll}\text { Figure 5.5.3a Secure environment for taking action and reaching destination pts. } & 109\end{array}$ Image by author.

Figure 5.5.3b Interior view of the central commons space 110 Image by author.

Figure 5.5.3c Interior view of the library (intermediate space) 111 Image by author. 
xxxii 


\subsection{INTRODUCTION}

Today, there are many poorly designed environments that continue to be inaccessible to children, families, people with disabilities (PWD) and seniors preventing their full participation within society. Thus, Canada needs to improve accessibility for many reasons, one of them being the changing demographics. Studies show demographics are shifting due to longer life expectancies, healthier living, better medicine, and advanced technology (Story, Mueller, \& Mace, 1998, p. 6). All of these cause an increase in the number of the Canadian population, thus increasing the disability rate. Furthermore, reduced birth rates and the baby-boomer generation now approaching retirement will increase the aging population as seniors are aging longer. Thus, this will have an immense impact on how the built environment and products are designed.

People with different abilities, sizes, and ages should be able to fully participate with the built environment independently as they all have opportunities and obligations in all aspects of society. Accessibility should be provided for people with diverse disabilities, including mobility, mental, and sensory (hearing and vision loss), and various user groups of children, families, and the elderly. When designing products and environments, various users require different needs. It is important to consider everyone since some people depend on other abilities for creating awareness of their surroundings.

Therefore, Inclusive Design (ID) should be integrated within our built environment using

both concepts of equality and equity. Everyone should be treated the same while ensuring equity is there first. This general notion relates to Accessible Design (AD), Universal Design (UD), and Inclusive Design (ID). AD is about equity, designing specifically to meet the needs of PWD. However, creating separate entrances do not provide equality. UD is about equality, with a 
one-size-fits-all concept while integrating equity by creating flexibility and adaption. However, UD does not acknowledge diversity. ID incorporates both concepts of equality and equity in the design of products and environments which can be used by everyone, respecting differences and meeting diverse needs. This is through responsive, adaptive, accessible, and secure design applications. This thesis focuses on inclusive environments accessible to all. The theoretical framework supports three major design interventions. They enhance the purpose and meaning of ID by first creating accessible architecture as communication by focusing on form follows function, accessible experience, and other communication systems. Secondly, responsive and adaptable architecture is achieved through multi-sensory experiences using non-visual information including sound, light, colour, and finishes. Finally, there is secure architecture for social interaction by maintaining visual connection and integrating circulation spaces as social places. These three strategies are selected because people experience buildings as a whole visually, non-visually, and socially.

A community centre located at the Alexandra Park neighbourhood in Toronto is selected to test these ideas. It represents a community for social gathering, social support, holds important public functions, and represents diversity within a community. Designing a fully inclusive community centre promotes equal access and usability by various groups of people, regardless of age and abilities. This benefits diverse needs by creating accessible equipments, programs, and policies to all.

Redeveloping the community centre involves many people within the design process creating an accessible building used by all. In doing so, it is essential to address existing and emerging needs in order to design for the future. Based on the diverse culture and history of Alexandra Park, there is a need to break down barriers while preserving the identity of the neighbourhood. The building's identity will also be preserved since everyone uses various 
programs and services there. The plan is to re-design public spaces within the Scadding Court Community Centre (SCCC) site supporting existing recreational and educational programs, while enhancing community life through inclusion, social interaction, and creating a venue for neighboring communities for engagement. The scope of the design concentrates on how people approach the site, enter the building, the central commons space, which directs people to their destinations points, and finally to the means of egress. The intent is not to design the entire building because once people can easily approach and enter the building independently, the rest just follows if they are designed inclusively.

Thus, this thesis topic is simply not an architectural issue. It also encompasses political, economic, social, and technological aspects. This concept is still relatively new in Canada. Any changes made to our built environment are considered small-scale and moving incrementally slow. Though, it accommodates diverse needs, including children, families, PWD, and older adults. It also offers innovation within design, increases productivity, marketability, and provides usability and access to buildings. Overall, ID enhances people's sense of dignity, self-esteem, independence, and quality of life. 


\subsection{THESIS STATEMENT}

Inclusive Design (ID) removes barriers in political, economical, social, and technological aspects. Today, our society continues to have poorly designed buildings and environments creating exclusions for all. Thus, ID should be more integrated within the built environment to allow people to fully use and access the surrounding preventing discrimination and stigmatization. ID is an intervention respecting differences by accommodating diverse needs of various groups of people. 


\subsection{BACKGROUND}

Inclusive Design (ID) is making environments and products more usable, safer, and healthier in response to the needs of an increasingly diverse population (IDeA, 2013)

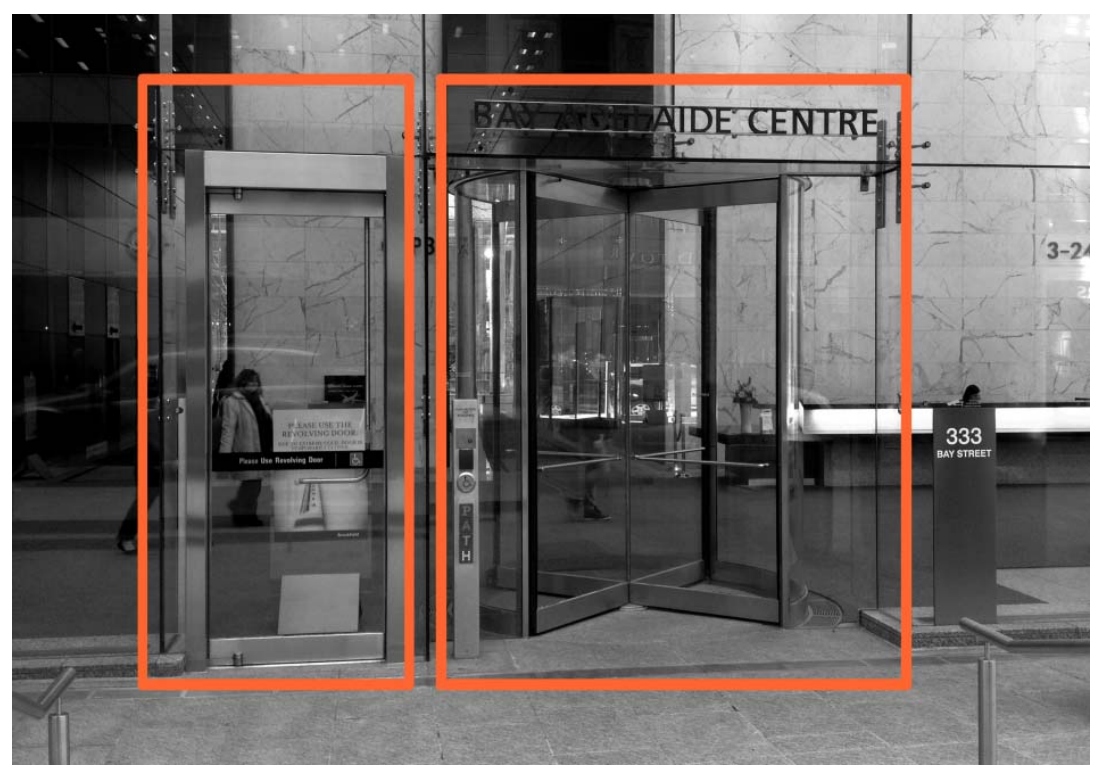

Figure 1.2a - Current buildings continue to exclude accessibility to all, such as Bay Adelaide Centre

Today, there are many poorly designed environments that continue to exclude access to all preventing people's full participation within society, including women with strollers, people with disabilities (PWD), and seniors with assistive devices. To illustrate, the newly constructed Bay Adelaide Centre in Toronto contains a major entrance with revolving doors (Figure 1.2a). This entrance restricts a variety of user groups. To make situations worse, an alternative entrance is adjacently provided with a sign blocking the door, excluding full access for everyone into the building. This scenario can be prevented using larger revolving doors, such as those used at a hospital accommodating strollers, wheelchairs, and contemporary assistive devices. 


\begin{tabular}{|l|r|r|r|r|}
\hline \multirow{2}{*}{ Geographic name } & $\begin{array}{r}\text { Total } \\
\text { population }\end{array}$ & $\begin{array}{r}\text { Persons } \\
\text { with } \\
\text { disabilities }\end{array}$ & $\begin{array}{r}\text { Persons } \\
\text { without } \\
\text { disabilities }\end{array}$ & $\begin{array}{r}\text { Disability } \\
\text { rate }\end{array}$ \\
\cline { 2 - 5 } & \multicolumn{3}{|c|}{ number } \\
\hline Canada (excluding territories) & $30,793,810$ & $4,408,470$ & $26,385,340$ & 14.3 \\
\hline Canada (including territories) & $30,893,640$ & $4,417,870$ & $26,475,770$ & 14.3 \\
\hline
\end{tabular}

Table 1.2b - Population with and without disabilities in Canada, 2006

\begin{tabular}{|l|r|r|r|}
\hline \multirow{2}{*}{ Province } & 2001 & $\begin{array}{r}2006 \\
\text { standardized }\end{array}$ & $\begin{array}{r}2006 \text { non } \\
\text { standardized }\end{array}$ \\
\hline Canada & \multicolumn{3}{|c|}{ percentage } \\
\cline { 2 - 4 } & 12.4 & 13.5 & 14.3 \\
\hline
\end{tabular}

Table 1.2c - Comparison of Canada's disability rate in 2001 and 2006 (standardized = expected)

Canada needs to improve accessibility for many reasons, one of them being the changing demographics. The demographics are shifting due to longer life expectancies, healthier living, better medicine, and advanced technology (Story, Mueller, \& Mace, 1998, p. 6). All of these cause an increase in the number of the Canadian population, thus increasing the disability rate. Based on the Participation and Activity Limitation Survey (PALS) of 2006, the entire population of Canada including territories was 30,893,640 people in total (Table $1.2 \mathrm{~b}$ ), with $14.3 \%$ of them being disabled (PALS 2006: Analytical Report, 2007, p. 16). PALS is a post-census national survey collecting information on people with differing abilities, such as hearing, mobility, communication, and learning to assess their impacts within society. Disability is a universal human experience and a natural part of aging. The disability rates are just the minimum and more actually exist within our nation. Thus, the results collected in the survey do not truly reflect the number of PWD in Canada because many of them, especially older adults, deny having a disability because of the perceived shame identified with being disabled (Story, Mueller, \& Mace, 1998). Therefore, the population increase will raise the disability rate, which will have an immense impact on how the built environment and products are designed. 


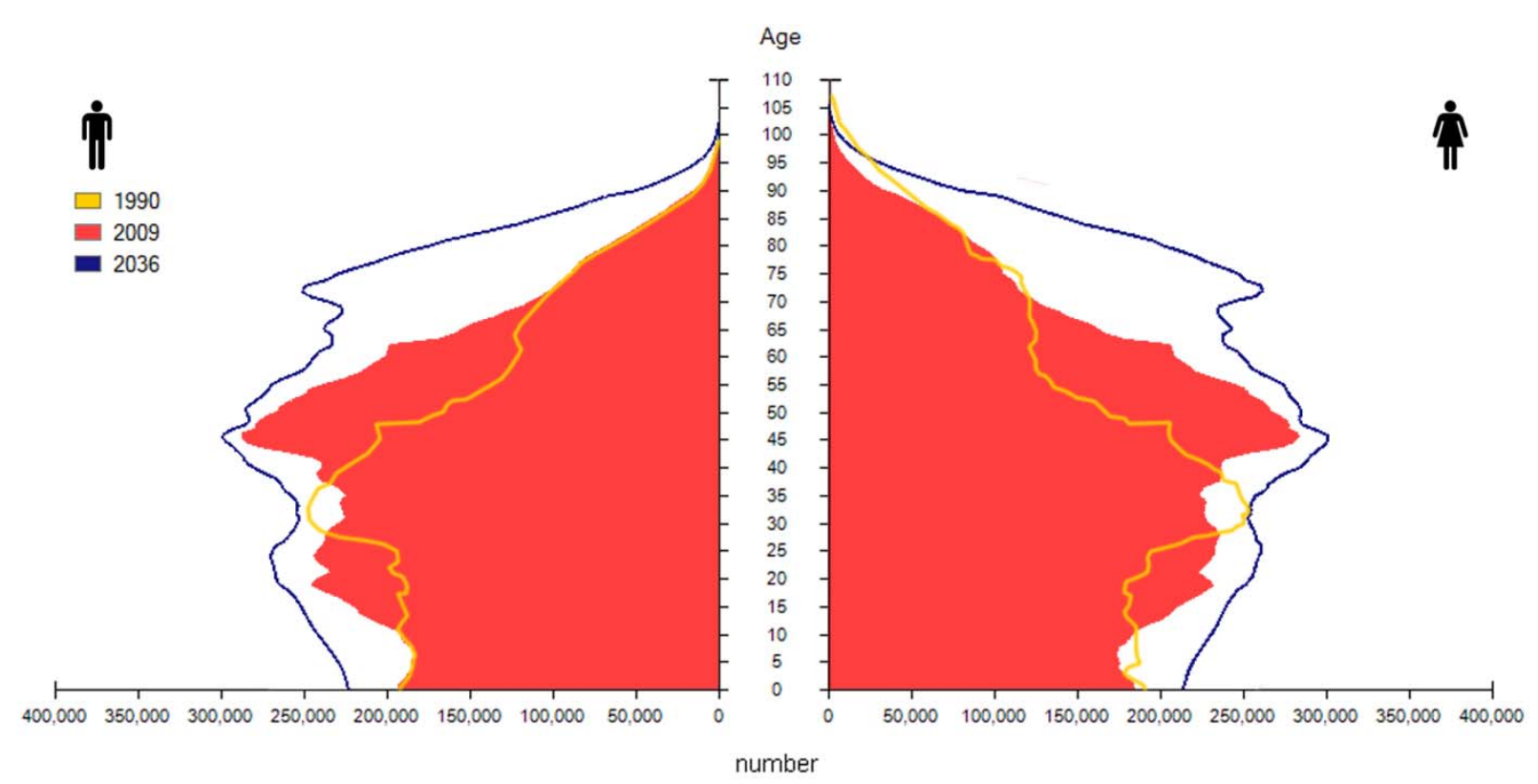

Figure 1.2d - Population age pyramids of Canada 1990, 2009, and predicted 2036

Furthermore, reduced birth rates and the baby-boomer generation now approaching retirement will increase in the aging population. Therefore the overall disability rate naturally increases substantially as the population ages. As shown in PALS 2006 survey, the "standardized" or expected disability rate explained by population aging between 2001 and 2006 shows an increase that should have been $1.1 \%$ (Table 1.2c), when in reality, there is an increase of 1.9\% (PALS 2006: Analytical Report, 2007, p. 13 \& 20). Although these are past survey results, these numbers help with future predictions. Canada's population aging pyramids for both male and female in three different years (Figure 1.2d) in 1990, 2009, and predicted 2036 indicate that the senior population is aging longer (Age Pyramids of the Canadian Population 2009, 2036, and 2061 (\#), 2012). Therefore, it is evident that the demographics are changing. Designers must respond to the needs of individual differences and their impacts on inclusion within the built environment, such as housing, workplaces, and public facilities. 

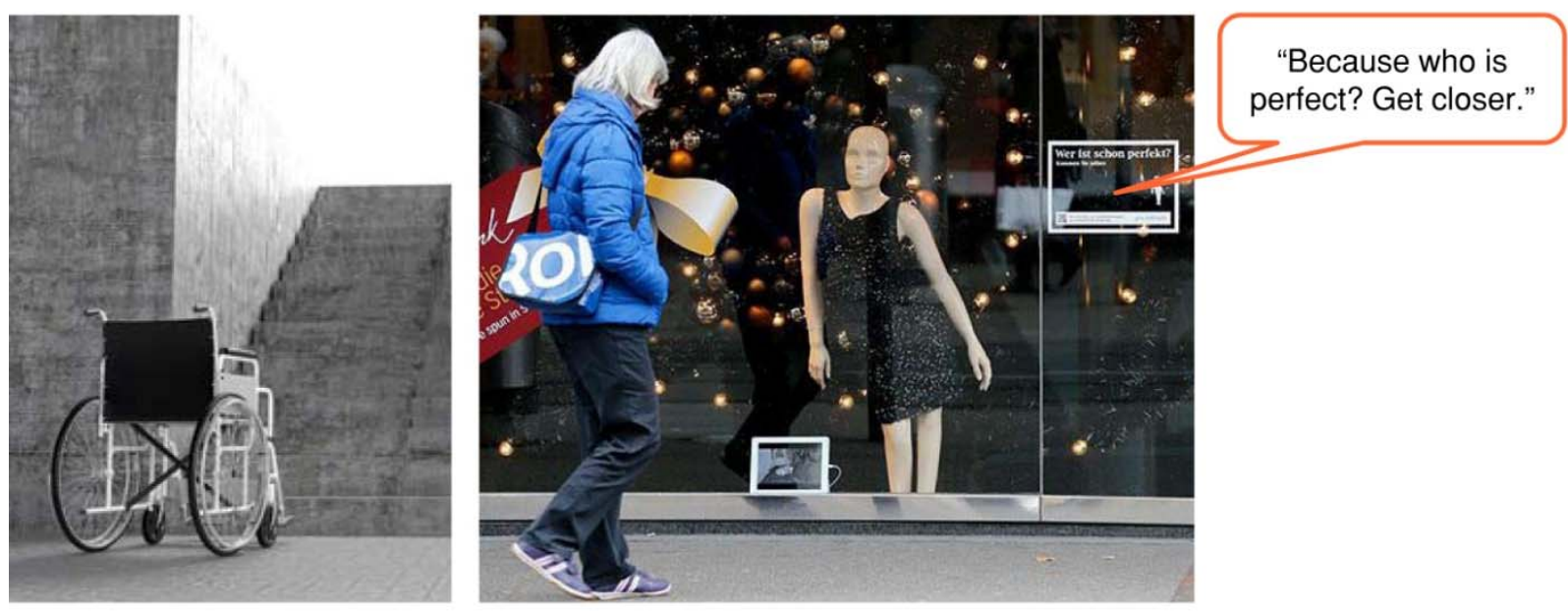

Figure 1.2e - Visible barriers (left) and invisible barriers showing attitudinal behavior towards PWD (right)

Every organism, including human beings, interacts with its physical environment. Our built environment refers to buildings and public spaces. Many people, including mothers with strollers, seniors, and PWD, experience barriers within the built environment due to environmental restrictions. Barriers mean any obstacles that prevent them from fully participating in all aspects of society and their abilities to move independently (Steinfeld \& Maisel, 2012, p. 4). These barriers are visible and invisible (Figure 1.2e). Visible barriers include architectural barriers, such as stairs which prevent people with mobility devices from using them and seniors who have a fear of slipping and falling from using stairs. Invisible barriers include attitudinal barriers, such as behaviors and perceptions that discriminate against PWD (MAH, 2005, p. 7). For instance, a successful project called "Because Who is Perfect? Get Closer" by Pro Infirmis causes shock for many shoppers passing by the storefront after creating mannequins of real people with physical disabilities (Krupnick, 2013). The goal is to raise awareness and this demonstration proves that it is normal to be different, hence diversity. It is a discrimination to associate perfection as normal when all mannequin figures are tall and slender. 
Along with barriers, there are other causes of exclusions that prevent people from fully participating within society. They are employment, wealth, education, housing, violence, abuse, gender, ethnicity/race, age, languages, disabilities, and location to services. These mainly refer to underrepresented groups of people or the visible minority, including Aboriginal people, youth, seniors, PWD, women, and immigrants. ID prevents discrimination, accommodates diverse needs, provides opportunities, and changes values and attitudes of society. This presents a major challenge, especially for the disabled community. An inclusive environment is barrier-free promoting equal opportunities and participation to all. Through design, we can change the environment to be as enabling as possible. Design is more than form and function. Its other purpose is to change the attitudinal perceptions and how people interact with the environment. 


\subsection{TARGET USER GROUPS}

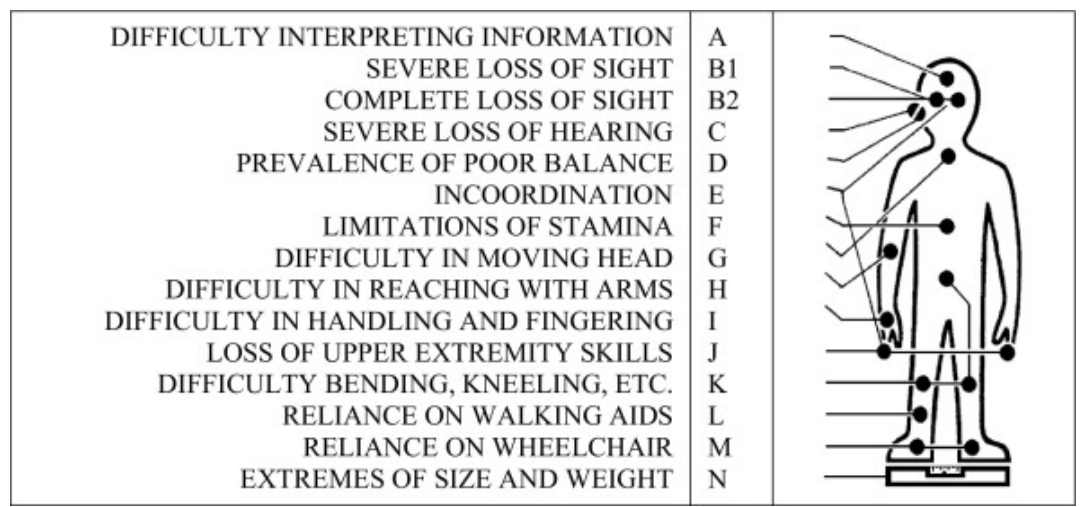

Figure 1.3a - Enabler concept representing various functional limitations

People with different abilities, sizes, and ages should be able to fully participate within society independently. An inclusive environment provides access for people with diverse disabilities, including mobility, mental, and sensory (hearing and vision loss), and various user groups from children, families, and the elderly (Appendix C). For instance, children's cognitive capabilities are still being developed. The way they see and remember the environment are different compared to adults (Creating a Sense of Adventure, 2009). Therefore, specific wayfinding, such as the use of landmarks, are effective navigational techniques for children, which are also helpful for adults and the elderly. Overall, fully accessible environments do not necessarily mean everyone experiences and uses the product equally. It actually means everyone is considered and the design of spaces and products do not draw attention to a specific target user group (Nussbaumer, 2012, p. 282). As mentioned before, a barrier preventing them from fully participating within society is based on interactions between the individual and the built environment. Thus, the Enabler concept (Figure 1.3a) by Steinfeld et al. (1979) is a representation of the target population with various functional limitations which helps designers enhance specific details of the built environment in order to create inclusive designs to all user groups (Steinfeld, 2012, p. 50). 


\subsection{DESIGN WITHOUT BARRIERS}

This chapter discusses the development of Accessibility Design (AD), Universal Design (UD), and Inclusive Design (ID) creating a fully inclusive environment. All of these different concepts and philosophies vary in terms equality and equity. Each of these will be examined carefully providing theoretical information and criticizing the effectiveness of meeting diverse needs.

\subsection{DESIGN FOR EQUALITY AND EQUITY}

Equality and equity actually have different meanings. Many people believe that equality means treating everyone exactly the same in status, rights, and opportunities (Policy \& Projects Officer Community Services Division, 2013, p. 13). Generally, the white heterosexual male ablebodied is the frame of reference established as a benchmark (Nielsen, 2008, p. 5). It has been widely understood that in order to have equality between the able-bodied and PWD, they need to be more like the able-bodied. Conversely, the able-bodied do not need to be more like them. This is a false understanding or concept of equality as it is perceived that when individuals with disabilities demand to be treated like mainstream society, it means they demand to be treated like them in general. In reality, individuals with disabilities are demanding for equity that enhances their enjoyment without discrimination through inclusion. Equity includes diversity because it is a discrimination to treat differentness as identical and it is impossible to eliminate all forms of discrimination against them without taking into account their differences (Respecting Differences, 2009). However, equality between them can never be achieved. Replacing equality with equity will also not correct the problem and it is politically incorrect (Facio \& Morgan, 2009, p. 1156). Equity, on the other hand, is about being treated fairly and meeting their individual needs (Facio \& Morgan, 2009, p. 1136). It is a subjective concept that means different 
things to different people. Everyone is different in terms of education, gender, skills, and personalities.

Therefore, ID uses both concepts of equality and equity. Everyone should be treated the same but ensure that equity is there first. We must remember that what is equal is not always fair, and what is fair is not always equal. This way, everyone gets exactly the same outcome through inclusion, regardless of their differences. This general notion relates to AD, UD, and ID. AD is about equity, designing specifically to meet their needs. However, creating separate entrances do not provide equality. UD is about equality, with a one-size-fits-all concept while integrating equity by creating flexibility and adaption. However, UD does not acknowledge diversity. ID incorporates both concepts of equality and equity in the design of products and environments which can be used by everyone, respecting differences and meeting diverse needs. 


\section{$2.2 \operatorname{access(IBILITY~DESIGN)~}$}

Access, Accessibility Design (AD), Universal Design (UD), and Inclusive Design (ID) must all be discussed first to provide background understanding of this thesis topic. They are often used when discussing in many ID literature. In particular for this thesis, UD and ID have similar but different meanings. In Canada, ID is used and is the ultimate goal to describe equitable access to all within our built environment. Nonetheless, there are various design theories and movements around the world that are similar to ID. They are barrier-free, designfor-all, life span design, and trans-generational design that have been discussed in many literature prior to ID (Ormerod \& Newton, 2005, p. 104).
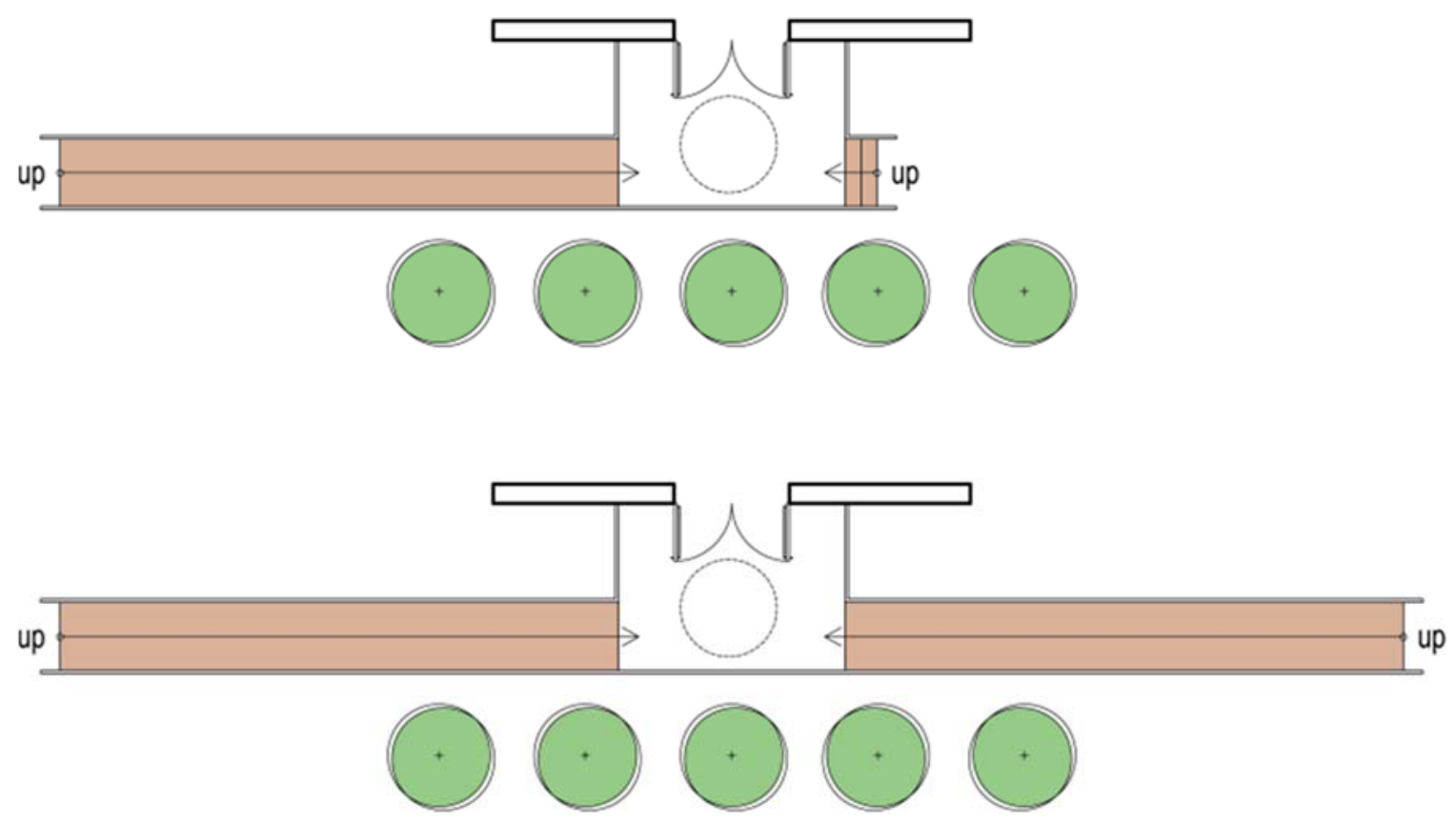

Figure 2.2a - Accessibility (top) vs. Universal Design or Inclusive Design (bottom)

Accessibility has different meanings depending on the context of the term. Access used within ID refers to having the right and freedom to use and enjoy as others in buildings, employment, and communication (Nussbaumer, 2012, p. 4). ID is always accessible and AD is accessible but not always inclusive. For instance, a main entrance with stairs and a ramp 
addresses accessibility (Figure 2.2a). Since everyone cannot use the stairs, a ramp is provided to offer access for mothers with strollers and people with mobility impairments. According to ID, these are equality issues of usability and their dignity. On the other hand, a ramp on both sides of the building provides access to all, making the design truly inclusive (Figure 2.2a). Therefore, inclusive environments provide access for everyone, regardless of their age and abilities. In this case, access within the context of ID is positive. Conversely, literature about ID always discusses $\mathrm{AD}$ as the opposite definition of ID. Molly Follette Story describes AD as:

Design to accommodate specific individuals or groups of individuals with disabilities. Because it is the ONLY solution for some problems and some users, accessible design will always be necessary, at least in certain situations. Specialized design is usually more expensive than universal design and because it is atypical, accessible design may segregate and stigmatize the users it is designed to accommodate (as cited in Ormerod \& Newton, 2005, p. 104).

$\mathrm{AD}$ emerged out of the disability rights movement which typically responds to people in wheelchairs (Nussbaumer, 2012, p. 106; Story, Mueller, \& Mace, 1998, p. 6). However, this is a form of discrimination as it does not address the diverse needs of the population having access to the built environment, such as those with sensory impairments and those using motorized scooters today. Selwyn Goldsmith is a father figure within accessibility. He is a disabled architect and disability rights campaigner who has influenced many architects and other professions to apply barriers diverse people experience into a guidance manual on architectural planning (Selwyn Goldsmith, 2011). His books are one of the reasons the accessibility standards are created.

Secondly, AD seeks solutions to retrofit existing building designs to become fully accessible. Therefore, designers only need to meet minimum standards to regulations and building codes (Ormerod \& Newton, 2005, p. 104). This results in the minimums to become the new maximums. These standards do not push designers and architects to think beyond them. For 
instance, let us return to the example of the main entrance design with the stairs and ramp. It is considered legal by the accessibility design guidelines. However, some observations further suggest that the design for PWD creates a separate or segregated access route, which draws too much attention to a person's impairment (Imrie, 2012, p. 875). This is an issue for AD and is prevented in ID.

In addition, there is a misconception that $\mathrm{AD}$ creates poorly designed environments that are unattractive and institutional (Nussbaumer, 2012, p. 44). Though in reality, creativity can still occur even though strict guidelines exist. It simply depends on how designers approach them since all buildings must be to code. They exist as important architectural elements in order for buildings to be safe and usable to all. An example is the Guggenheim Museum in New York designed by Frank Lloyd Wright (Figure 2.2b). He takes the notion of a ramp, which people most often perceive it as connecting two levels together, and expresses it throughout the entire building. He was inspired by the experiences of museums and a shell. He allows visitors to experience the building by taking an elevator up to the top of the building and spiraling down the ramp while observing artworks along their path of travel (Steinfeld, 1998, p. 23-24). 


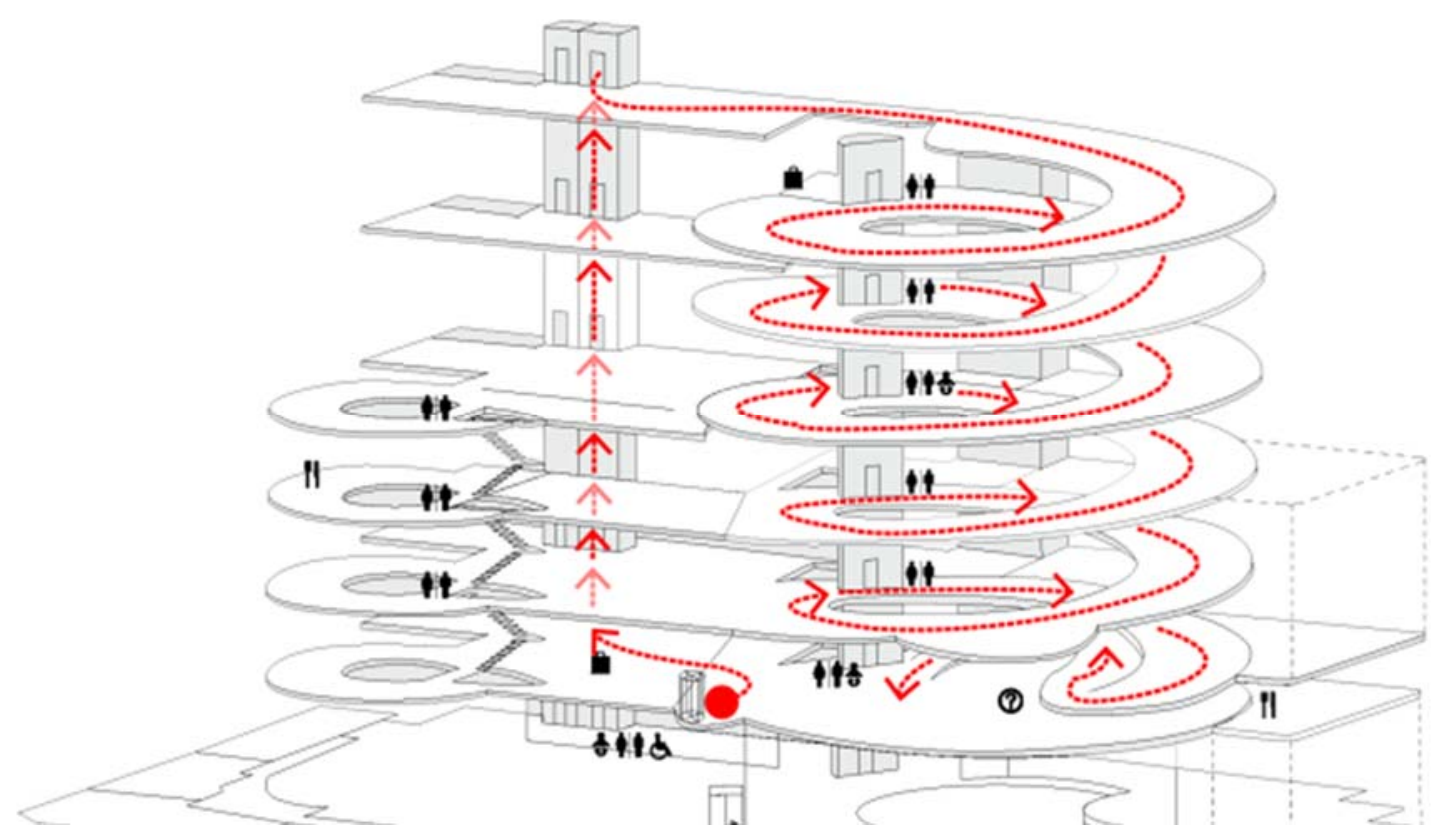

Figure 2.2b - Creative solutions to Accessibility Standards

Today, our nation is in the process of meeting the needs of diverse group of people by implementing and enforcing accessibility standards into the built environment. The City of Toronto Accessibility Design Guidelines has been in place since 2003 and today, it is considered an outdated document (Appendix A). The Accessibility for Ontarians with Disabilities Act (AODA) became law in 2005. Their aim is to provide access for all Ontarians with disabilities by January 1, 2025 (Overview of Updated Accessibility Requirements, n.d.). As part of their initiative, AODA has recently amended the Ontario Building Code 2012 to enhance accessibility within buildings in December 27, 2013 (Overview of Updated Accessibility Requirements, n.d.). New accessibility requirements will come into force on January 1, 2015 to include enhancements to accessibility in buildings, such as power door operations, wider door widths and path of travel, elevator to be accessible to all floors, universal washrooms, and tactile warning surface indicators, which will improve the built environment to be accessible to all (Overview of Updated Accessibility Requirements, n.d.). 


\subsection{UNIVERSAL DESIGN}

Universal Design (UD) is a philosophy widely used in United States involving micro to macro scale designs from door levers to the entire building (Nussbaumer, 2012). For this thesis, ID is similar to UD but have different meanings. According to many literature, some researchers use them interchangeably, while others believe ID is a more appropriate term than UD when discussing about equality and equity (Nussbaumer, 2012, p. xii). In this case, UD relates to the entire world that is used by everyone everywhere (Nussbaumer, 2012, p. 34). Ronald Mace from the Center for Universal Design defines the widely accepted term as "...the design of products and environments to be usable by all people, to the greatest extent possible, without the need for adaptation or specialized design" (Imrie, 2012, p. 873). This concept started as a social movement in the late 1960s to allow any person, regardless of their age and abilities to use them with no or little extra modification (Imrie, 2012, p. 874; Steinfeld, 2012, p. 15). Though, it has been criticized by many sources that the word "universal" means one solution accommodating everybody. In reality, UD can only be designed for the greatest percentile of people who will most likely use the product and environment, because everyone has different abilities and needs (Nussbaumer, 2012, p. 29\&33). This explains why ID, which is further explained in the next section, is more appropriate than UD. Furthermore, according to Imrie and Hall, they criticize Mace's definition to be too utopian and does not reflect the nature of inclusion (as cited in Steinfeld, 2012, p. 29). As mentioned by Steinfeld and Tauke, they believe the term should be "universal designing" to reflect the evolutionary process to becoming more inclusive (Steinfeld, 2012, p. 29). Therefore, some adaptations and choices are necessary in order to accommodate a diverse group of people. These are further described in detail regarding the seven UD principles by the Center for Universal Design at North Carolina. They are: 
Principle 1: Equitable The building is usable by anyone. It does not disadvantage, Use stigmatize or privilege any group of users.

Principle 2: Flexibility in Use

The building accommodates not only a wide range of individual user preferences but also users' varying functional abilities.

Principle 3: Simple and Intuitive

How to use the building is easy to understand regardless of the user's experience, knowledge, language skills or concentration level.

Principle 4:

The building communicates all necessary information effectively to Perceptible Information all users regardless of ambient conditions or the users' varying intellectual or sensory abilities.

Principle 5: Tolerance The building minimizes hazards and adverse consequences of for Error accidental or unintended actions by all users.

Principle 6: Low

Everyone can use the building efficiently, comfortably and with Physical Effort minimal fatigue.

Principle 7: Size and The building provides appropriate size and space for approach, reach, manipulation and use regardless of the users' body size, posture, or functional abilities (Universal Design New York, 2001).

These principles are used voluntarily for designers compared to AD. However, these guidelines will find their way into accessibility codes, particularly those with little or no cost having benefits to all users. In addition, UD is more concerned with democracy and equity with a goal to move towards social inclusion (Ormerod \& Newton, 2005, p. 104). This further leads to the creation of ID as a concept by revising these principles. 


\subsection{INCLUSIVE DESIGN}

Inclusivity is a better approach to design which developed from UD. As mentioned earlier, they are similar but have different purposes. UD has a more architectural and industrial origin where the goal is to design one size fits all (Inclusive Design Research Centre OCAD University, 2013). ID, conversely, refers to including rather than excluding. Though, according to Dr. Scott Rains (2009) who is a consultant and researcher on UD, he believes the major difference is that ID is broader than UD because it embraces diversity in social and economic situations, protecting PWD for instance (as cited in Nussbaumer, 2012, p. 4\&34). Diversity refers to various ages, abilities, and limitations. Therefore, ID evolved as an intervention through UD and is more appropriate for a diverse group of people accessing products and environments with equality and equity.

ID began in the United Kingdom and is an approach that is used widely in Europe, UK, Canada, and other countries (Nussbaumer, 2012, p. xii\&30). ID is defined as:

A way of designing products and environments so that they are usable and appealing to everyone regardless of age, ability or circumstance, by working with users to remove barriers in the social, technical, political, and economic processes underpinning building and design (Ormerod \& Newton, 2005, p. 104).

This definition will be taken apart for further analysis in better understanding the term.

They include designers for ID, usable by all, appealing to all, collaborating with users, and designing without barriers. 


\subsubsection{DESIGNERS FOR INCLUSIVE DESIGN}
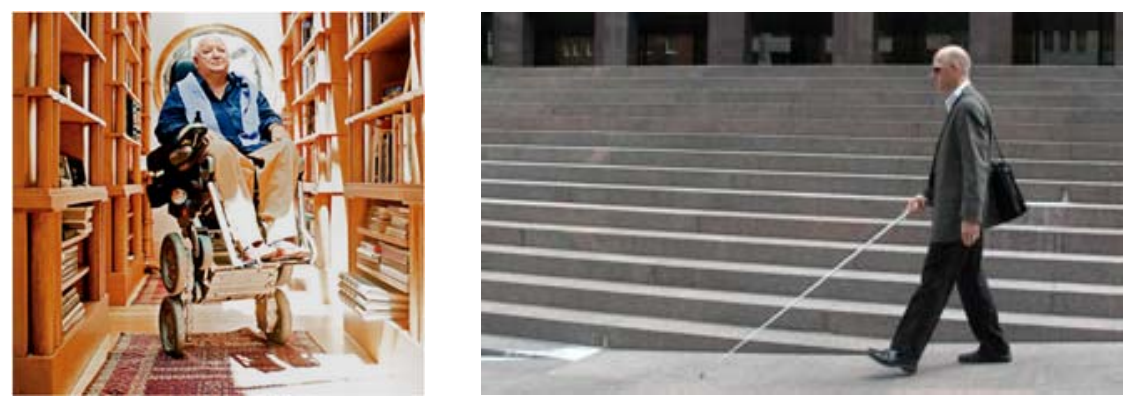

Figure 2.4.1a - Michael Graves (left) and Chris Downey (right) are both advocates for change

Firstly, Inclusive Design is about designing, referring to various design professionals creating products and environments accessible to all. The Digital Accessibility Team (DAT) (2009) reveals that ID consists of responsibility, including those who are involved in designing for inclusivity (as cited in Nussbaumer, 2012, p. 34). This refers to architects, interior designers, graphic designers, landscape architects, industrial designers, etc. Designers must understand the users in order to meet their needs. This means that they must design for everyone in mind, regardless of their contextual situation and abilities. No single user is excluded or considered as an alternative. Thus, this shows the important roles of an architect because their designs are not only intended for the average citizen. Furthermore, since barriers are created by us, we can also create enabling environments for people through various designers who act as advocates for accessible and inclusive environments. They include Michael Graves (Figure 2.4.1a), who is wheelchair-bound creating empathetic architecture and products for everyone to use (Scutti, 2013), and Chris Downey, who is a blind architect designing buildings for the visually impaired (Biography, 2009). Since these two recognizing architects personally experience a disability, they realize that ID is more than meeting the minimums. This concept encourages them to create aesthetically pleasing spaces and more spacious designs, which is a different perspective compared to AD (Ormerod \& Newton, 2005, p. 108). 


\subsubsection{USABLE BY ALL}

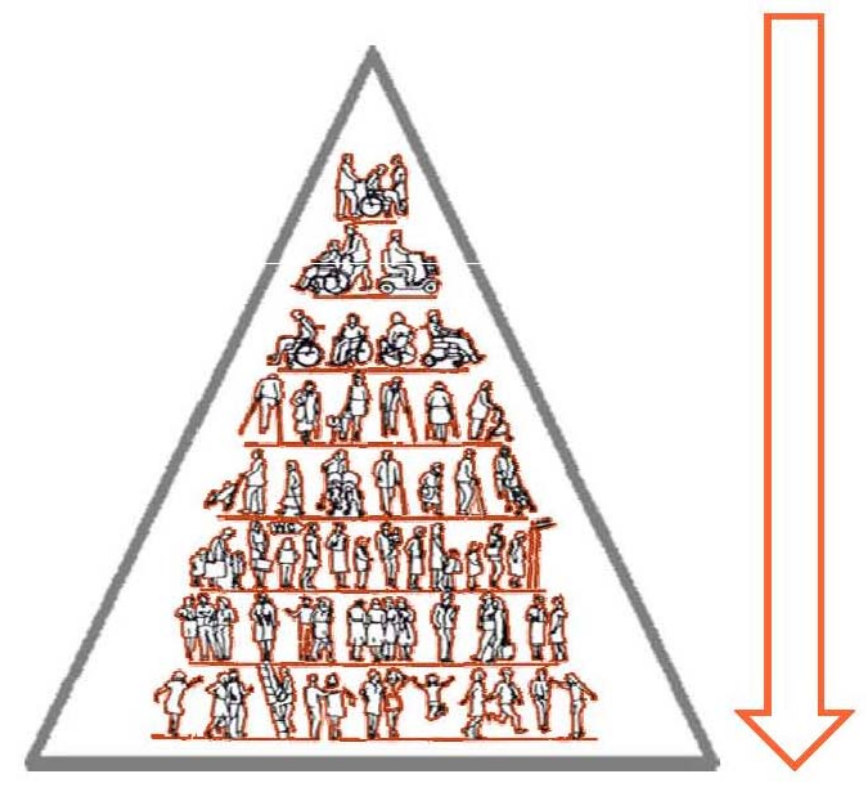

Figure 2.4.2a - The pyramid of needs

Inclusive Design refers to products and spaces that are usable by all. There is a misconception that ID is often associated with accessibility for PWD or the aging population. In reality, ID is not a specialized design and does not only cater to their needs. It also includes children, families, and the aging population as various target groups (Imrie, 2012, p. 875). According to the pyramid of needs (Figure 2.4.2a) developed by Maria Benktzon and Sven-Erich Juhlins, it divides users by their varying degrees of impairment from fully capable at the bottom to people with disabilities who rely on assistance at the top of the pyramid (Clarkson et al., 2003, p. 17). The pyramid is to be read from a top-down approach and represents ID solutions for meeting individual needs. By catering to those most in need first or those experiencing worst case scenarios at the top of the pyramid, will naturally accommodate and be used by mainstream society at the bottom of the pyramid. 
Furthermore, there will always be $5 \%$ of the people who are unable to access buildings and environments (Steinfeld \& Maisel, 2012, p. 99\&100). A single design solution cannot accommodate everyone because it cannot meet diverse needs. Therefore, the aim of ID is to design for the average with accommodations by providing choices and flexibility. In doing so, everyone can benefit from an inclusive environment in many ways. For example, a standingheight counter can accommodate most adults. Though, by offering varying heights provide options for people to use, accommodating children and those in wheelchairs as well. 


\subsubsection{APPEALING TO ALL}
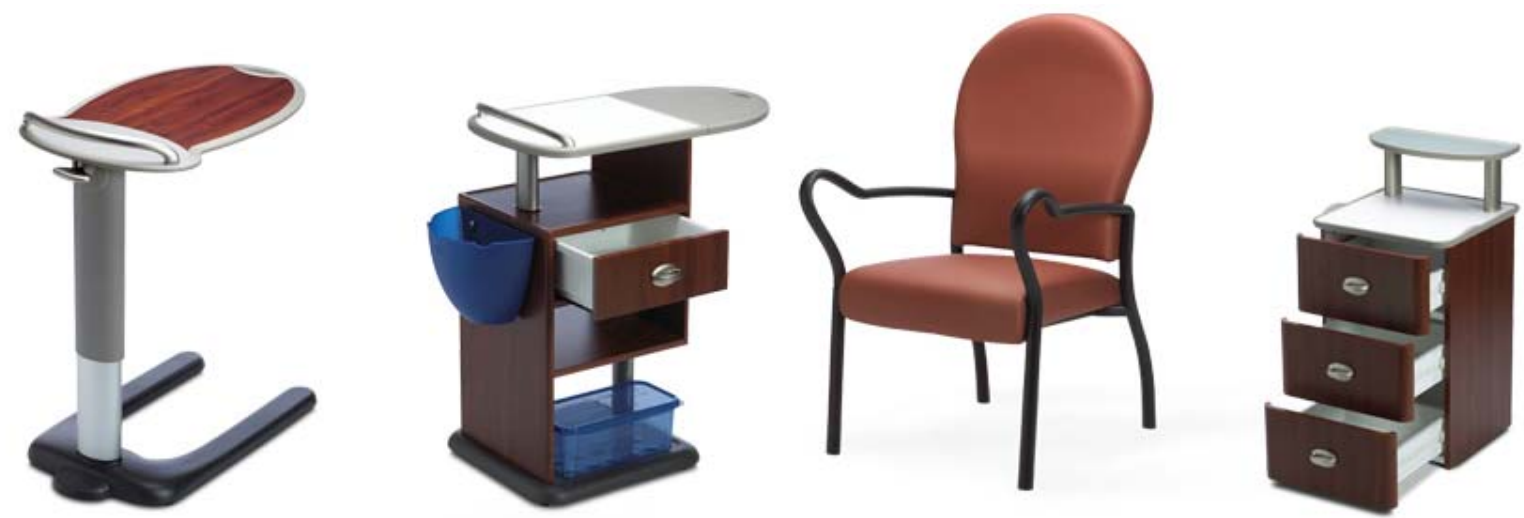

Figure 2.4.3a - Michael Graves Design Group creates aesthetic products for home and healthcare use

Inclusive Design refers to aesthetics. If inclusion is only about accessibility, it may have an institutional look. However, this is not the case. It is an advantage when inclusive products are attractive because when everyone can use it, it is more marketable. Thus, it becomes more economical since it benefits everyone (Nussbaumer, 2012, p. 43\&44). Null and Cherry (1996, p. 31) reveal inclusively designed products must be integrated and unified within architecture with the appearance that spaces are designed for people without disabilities (as cited in Nussbaumer, 2012, p. 44). For instance, Michael Graves Design Group creates functional and aesthetically pleasing accessible products (Figure 2.4.3a), while Michael Graves \& Associates is a counterpart firm designing interiors and architecture buildings (Our Mission, n.d.). They represent appealing products without emphasizing that they are designed for a specific user and avoids a medical look, making products more usable and marketable. Furthermore, it is not economically and practically feasible to design specifically for each different target user group because they are too small to be addressed individually (Steinfeld \& Maisel, 2012). Specialized product designs create segregation, thus forming discrimination for specific target user groups. In addition, many baby boomers are retired or almost retiring. Their current and future needs to maintaining 
independence when living at home (aging in place) is achieved by gearing aesthetically pleasing products and environments for them to use, making them the target market (Nussbaumer, 2012, p.44). Finally, designing appealing products and environments become more convenient and enjoyable to use for everyone. These include entrances, parking, lighting, signage, materials, etc. Thus, ID is a global need and makes practical business sense when providing access for everyone. 


\subsubsection{COLLABORATING WITH USERS}

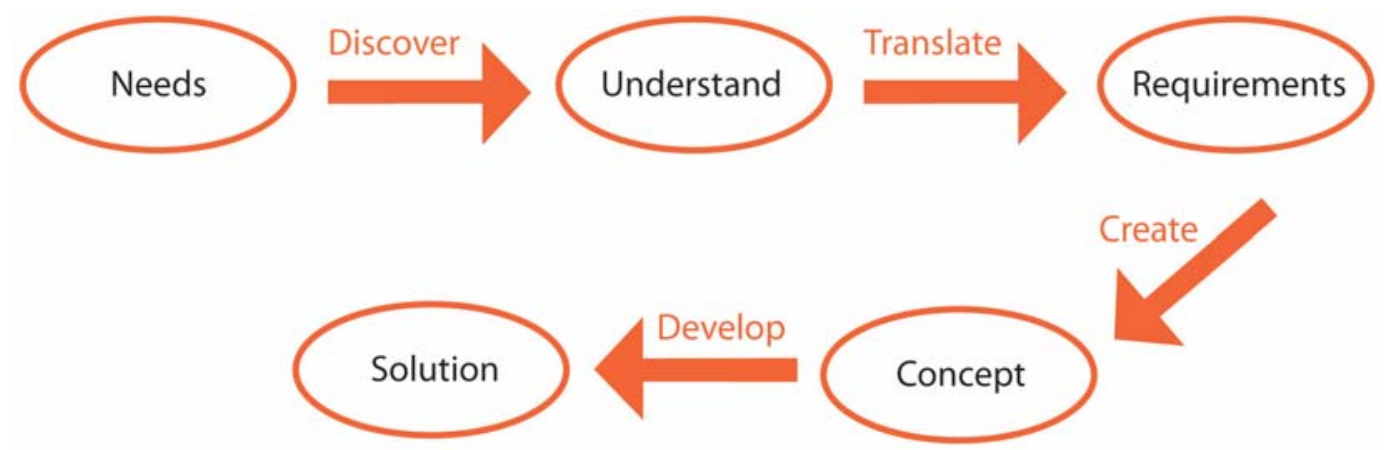

Figure 2.4.4a - Inclusive design process

The definition of Inclusive Design is about working with users of various products and environments. In order to accommodate for diverse needs, everyone should be involved early in the design and decision-making process from pre-design to post-occupancy evaluation (POE) stages (Figure 2.4.4a) (Nussbaumer, 2012, p. 32\&36). During the design process, it involves a multidisciplinary team of various designers, as mentioned earlier, along with users to create inclusive accessible environments. This is accomplished by receiving input from users either through interviews, surveys, and focus groups. Guerin and Dohr (2005) discuss the importance of making observations from past experiences or performing visual inspections through behavioral mapping (as cited in Nussbaumer, 2012, p. 67). When the building is occupied, behavioural mapping determines how people use certain spaces, where movement occurs, and possible congestion locations. After a project is complete, a POE is performed of the entire building to determine the success of the project through client satisfaction, assess overall design process, and design solutions (Nussbaumer, 2012, p. 143). As a result, various users should be integrated into the design process in order to create more accessible environments from the beginning, while learning and enhancing past design solutions. 


\subsubsection{INCLUSIVE DESIGN WITHOUT BARRIERS}

Inclusive Design is simply not just an architectural issue. It affects four areas in political, economical, social, and technological aspects as well. According to Commission for Architecture and the Built Environment (CABE), the purpose of ID is to:

remove the barriers that create undue effort and separation. It enables everyone to participate equally, confidently, and independently in everyday activities. An inclusive approach to design offers new insights into the way we interact with the built environment. It creates new opportunities to deploy creative and problem-solving skills (Nussbaumer, 2012, p. 32).

By identifying specific barriers, they become opportunities for inclusion. Designers, or architects in particular, are socially responsible for creating environments that provide social justice and empowerment for people including PWD, mothers with strollers, and the aging population (Ormerod \& Newton, 2005, p. 103). In doing so, it provides change in values, attitudes, offers dignity, and allow a sense of belonging for them (Nussbaumer, 2012, p. 31). It acknowledges diversity and differences that accommodate a larger population. Thus, ID is for everyone since they all have opportunities and obligations in all aspects of society. 


\subsubsection{PRINCIPLES OF INCLUSIVE DESIGN}

Like any concept, they have their own set of principles to follow. CABE (2006) developed five key principles of ID and they are:

Principle 1: People Place people at the heart of the design process.

Principle 2: Diversity Acknowledge diversity and differences.

Principle 3: Choice $\quad$ Single design solution cannot accommodate all users.

Principle 4: Flexibility Flexibility in use.

Principle 5: Convenient Provides buildings and environments that are convenient and enjoyable to use for everyone (Principles of Inclusive Design: They Include You, n.d.).

All of these principles have been discussed previously when breaking down the definition of ID. They do not represent standards like AD. As mentioned earlier, the concept of ID developed from UD. Therefore, many of these principles are similar and different than UD (Nussbaumer, 2012). They are simply revised to enhance the meaning and purpose of ID. It is also clear that many of these UD principles correspond with the principles of ID. Below is a list that identifies how the seven UD principles fit within the five ID principles.

\begin{tabular}{|c|c|}
\hline ID & UD \\
\hline Principle 1: People & $\begin{array}{l}\text { All seven principles. Though for ID, the focus is to incorr } \\
\text { users and designers into the entire design process. }\end{array}$ \\
\hline Principle 2: Diversity & Principle 1: Equitable Use \\
\hline Principle 3: Choice & $\begin{array}{l}\text { Principle 3: Simple and Intuitive } \\
\text { Principle 6: Low Physical Effort }\end{array}$ \\
\hline Principle 4: Flexibility & Principle 2: Flexibility in Use \\
\hline Principle 5: Convenient & $\begin{array}{l}\text { Principle 4: Perceptible Information } \\
\text { Principle 5: Tolerance for Error } \\
\text { Principle 7: Size and Space for Approach and Use (p. 35) }\end{array}$ \\
\hline
\end{tabular}


However, it is obvious that both these concepts overall emphasize similar ideas of responsive, adaptable, accessible, and secure (p. 37). These criteria are applied when discussing both ID and UD principles. They are:

Criteria 1: Responsive Relate to people's needs and wants

a) People are involved in the design process from pre-design to POE

b) Daily user's needs

c) invisible accessibility

Criteria 2: Adaptable Relates to diversity and differences in people

a) Easy to use and understand, flexible, convenient, and enjoyable

b) provide options

Criteria 3: Accessible Relates to the accessibility standards

Criteria 4: Secure Relates to health, safety, and welfare

a) Physical health: ergonomics, indoor air quality, safety, security

b) Psychological health: feelings of security and safety (p. 37)

Therefore, when these criteria are integrated into products and environments, they become more usable by everyone, which is the purpose and meaning of ID. These four criteria enhance the theoretical framework for this thesis. 


\subsection{THEORETICAL FRAMEWORK}

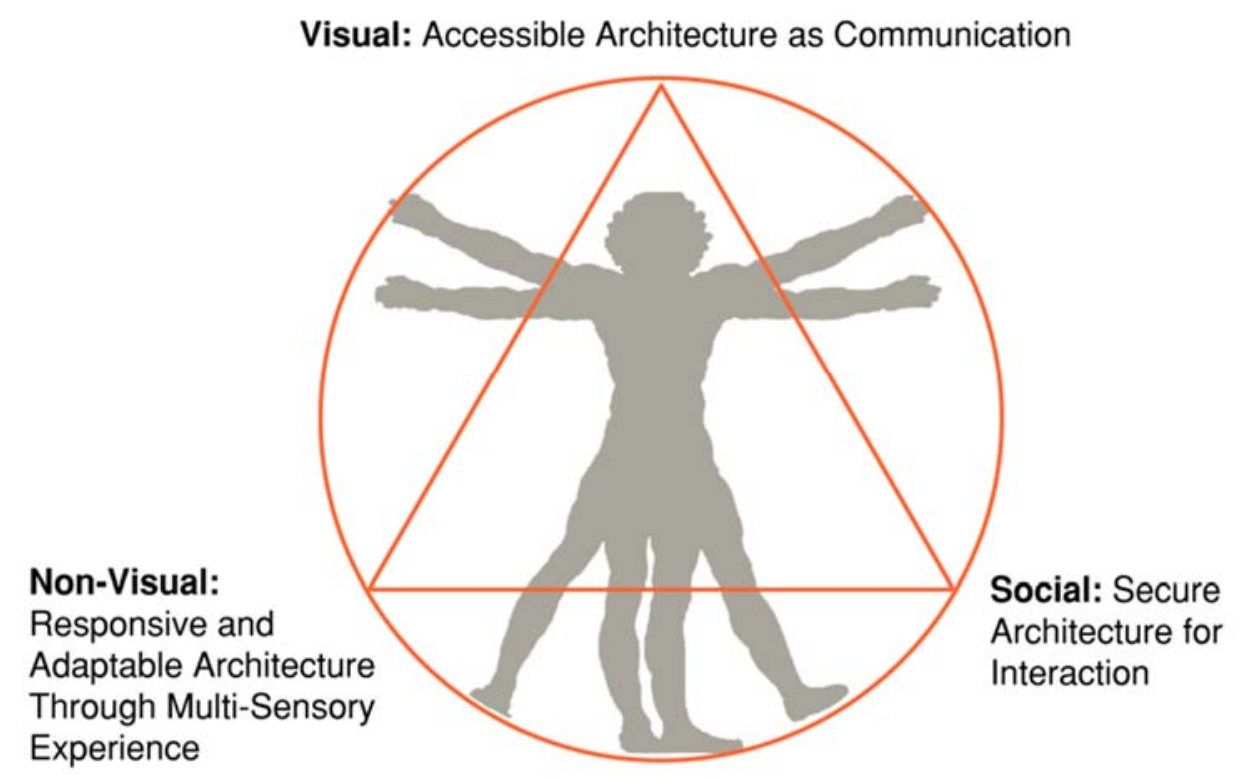

Figure 3.0a - Theoretical framework created by three human experiences of the environment

The theoretical framework supports three major design interventions for this thesis topic on inclusive environments accessible for all. For each theory, additional themes are introduced to expand the idea. These three theories support the four criteria as mentioned earlier, which are derived from the seven principles of UD and five principles of ID. They are responsive, adaptive, accessible, and secure. For this thesis, the three design strategies to be integrated with ID are creating accessible architecture as communication, responsive and adaptable architecture through multi-sensory experience, and secure architecture for social interaction. These three strategies are selected because people experience buildings as a whole visually, non-visually, and socially (Figure 3.0a). Thus, these three areas become the focus for exploring the following design strategies. 


\subsection{ACCESSIBLE ARCHITECTURE AS COMMUNICATION}

Architecture is experienced from the moment one approaches from the street, to the site, and into the building. The most obvious way to determine accessibility is by seeing. Vision is the most primary sense as Plato insists that ethical universals are accessible to the mind's eye (Pallasmaa, 2012, p. 18). Form is visible to the eye providing knowledge about the physical environment. Therefore, inclusively designed buildings must be fully accessible architecturally for people to use, regardless of their age and abilities. Architecture within inclusion is used as communication when people traverse and experience the building. These ideas are further described in communication within architecture, accessible experience while traversing in architecture design, and integrate communication systems. 


\subsubsection{COMMUNICATION WITHIN ARCHITECTURE}

Within architecture, buildings communicate through visual perception conveying both function and aesthetics. Achieving functionality is important to help people use the building easily depending on the arrangement of spaces and rooms. On the other hand, if architecture is not attractive to use, it does not make sense and is not considered architecture. Therefore, both functional necessity and aesthetic appeal represent good architecture.
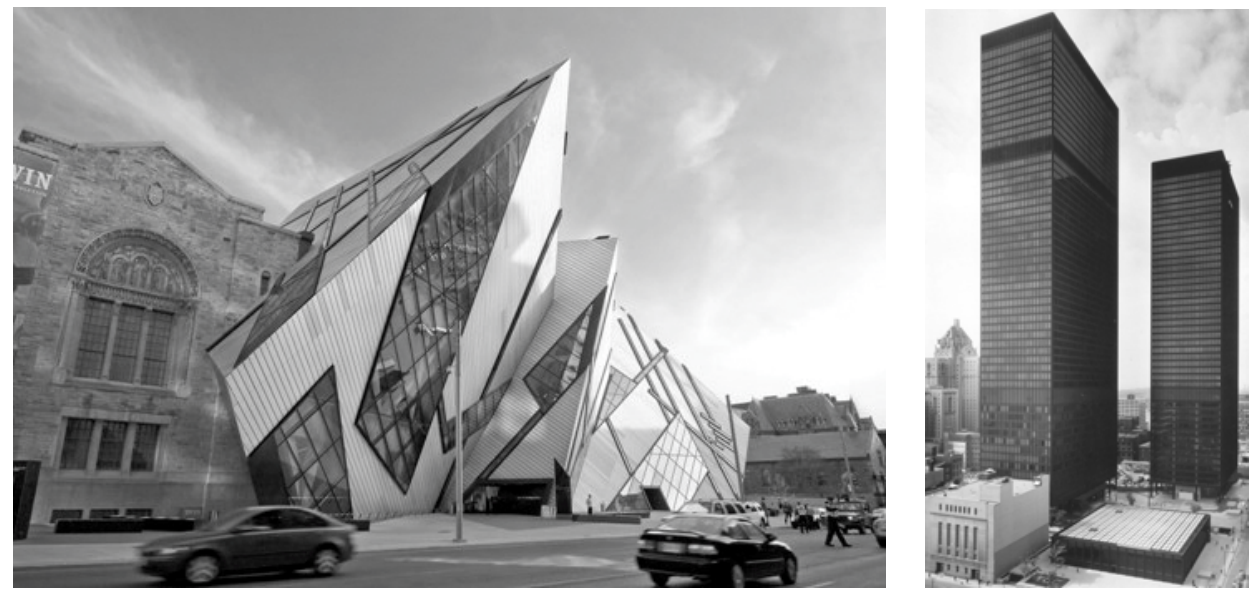

Figure 3.1.1a - Form (left with Crystal By Libeskind) vs. Function (right with TD Centre by Mies Van Der Rohe)

Within architecture design, form and function are dealt with simultaneously. However, some buildings emphasis on form more compared to functional operations. The result of these two differ aesthetically and functionally, though they do not represent right or wrong approaches to architecture design. Two images illustrate this idea with the Crystal by Daniel Libeskind expressing form and the TD Centre by Mies Van Der Rohe representing function (Figure 3.1.1a). The intent of the Crystal is to design an iconic landmark within the city of Toronto creating contrast to a historical museum. Once inside the building, the typical functions of a museum is ignored, casting daylight into the interiors and creating awkward corners when viewing artifacts. Form in general refers to size, contours, complexity of shape and style of the building (Arthur \& 
Passini, 2002, p. 37). Conversely, TD Centre is designed to function as an office maximizing and controlling daylight for occupants, maximizing square footage for various tenants, and obtaining corner offices for views.

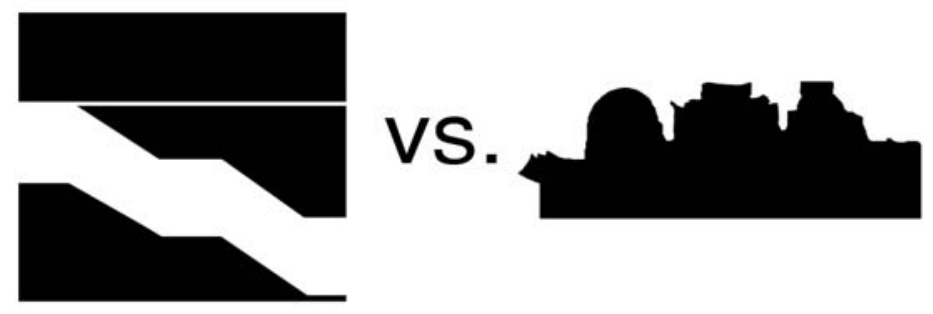

Figure 3.1.1b - Function vs. Form

In the case of creating inclusively designed buildings, two goals must be achieved for representing communication within architecture for various occupants. They are 'form follows function' to provide situational awareness and expressing circulatory function creating spatial awareness for all. Firstly, it is more effective that inclusive built forms are not determined using historic ornamentation and aesthetic appeal. The approach should be that 'form follows function' since inclusive buildings serve a purpose which is to accommodate diverse needs (Figure 3.1.1b). 'Form follows function' is a design principle that is coined by Louis Sullivan meaning that the shape of the building is determined by internal activities or purpose (Week 13: Function in Architecture, n.d., p. 7). In doing so, it provides them with situational awareness which benefits all users when entering unfamiliar surroundings. According to Smith and Hancock (1995), they describe that people's cognitive minds do not search for knowledge and instead, they are provided with the perception and understanding of the environment which are guided by motivation and through previous experiences (as cited in Steinfeld, 2012, p. 109\&150). Thus, the architecture of inclusively designed buildings should convey the purpose of the building in order to provide information benefiting mainstream society. 
Secondly, within inclusively designed buildings, the built form should communicate accessible circulation as function because they facilitate safety and usability for everyone. This increases satisfaction, provides independence, sense of dignity, reduces stigma, and isolation for people (Center for Inclusive Design and Environmental Access, 2010, p. 1). Buildings generally have rooms with interrelated functions. According to Roth (1993), there are four types of functions in architecture and they are pragmatic, circulatory, symbolic, and psychological. Inclusive buildings should convey psychological function and circulatory function, which is the making of appropriate spaces to accommodate and direct movement from one area to the next (Roth, 1993, p. 11).

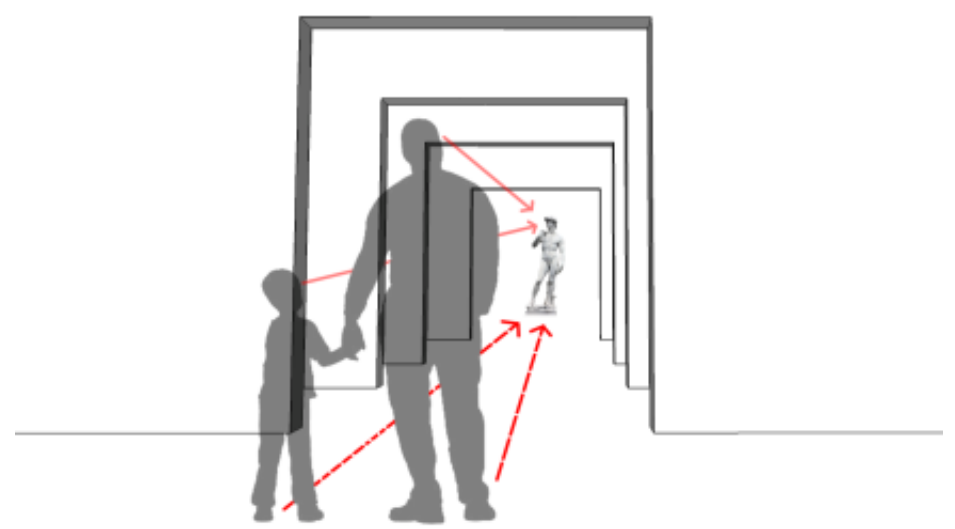

Figure 3.1.1c - Internal functions express direction of movement

As shown in the diagram, this is an example that expresses flow of movement using the concept of enfilade, a row of openings which line up between various rooms to guide people (Figure 3.1.1c). The spaces are easy to access, providing a sense of safety for people with diverse abilities. This provides a clear understanding and experience for users. In doing so, it assists with spatial awareness, which is the ability to be aware of their location in relation to space. People with diverse abilities tend to avoid unpredictable environments. According to Jerry Weisman (1981), a designer, notes that “the ability to find one's way into, through, and out of a building is 
clearly a prerequisite for the satisfaction of higher goals" (as cited in Center for Inclusive Design and Environmental Access, 2010, p. 1). When the built form conveys circulation for visitors, it reduces confusion for them, saves time and money for designers, reduces mistakes by employees, and prevents accidents (Center for Inclusive Design and Environmental Access, 2010, p. 1). These routes provide information to guide them to their destination point. Thus, communication through architecture by expressing the built form integrating ID directs movement by providing spatial awareness of the surrounding. This makes buildings easier to remember by expressing the important function to increase usability. This is effective especially for seniors when they are aware of historical and cultural meanings associated with the building (Arthur \& Passini, 2002, p. 37). Though, this is beneficial to a diverse group of users. 


\subsubsection{ACCESSIBLE EXPERIENCE WHILE TRAVERSING IN ARCHITECTURE DESIGN}

Previously, visual perception discusses how internal function determines the built form, which provides users with information in advance of the built environment for taking action or making decisions for orientation. Good architecture uses a mixture of functions including pragmatic, circulatory, symbolic, and psychological (Roth, 1993, p. 14).
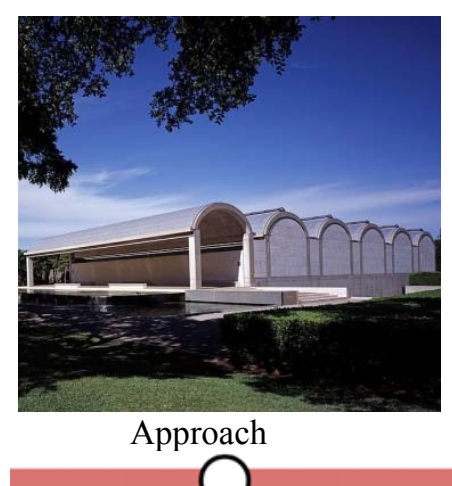

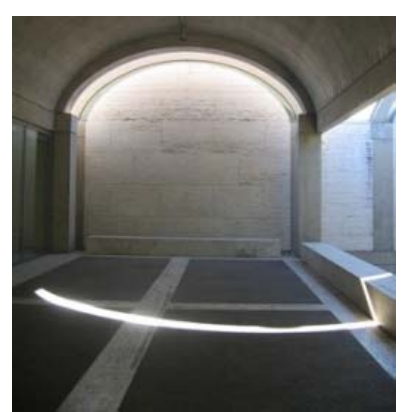

Entrance

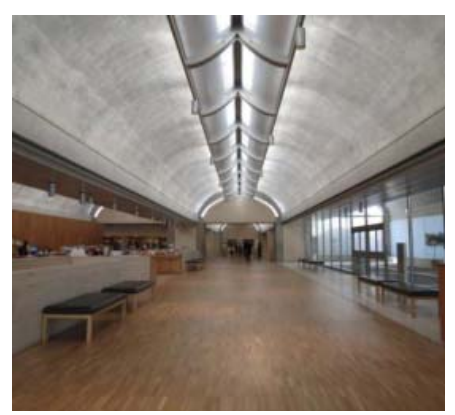

Gallery

Figure 3.1.2a - Kimbell Art Museum enhances human experiences visually and non-visually

Since architecture combines function with aesthetic and in order to communicate to diverse users, inclusively designed buildings deal with two functions: circulatory (function) and psychological (impact of aesthetic design) because people with diverse ages and abilities experience buildings physically and psychologically. Aesthetic refers to beauty including visual and non-visual attributes such as experiencing architecture. The Kimbell Art Museum by Louis Kahn represents a building that enhances visitor's experiences (Figure 3.1.2a). His concept focuses on how various spaces are used and how people should feel as they traverse the galleries (Kahn Building, 2014). His design is based on many factors including proportion, scale, repetition, materials, variation, and light and how they have an effect on the quality of the architecture impacting people's experiences (Schittich, 2013, p. 41). Similar to classical 
buildings, the basic plan consists of sixteen cycloid vaults enabling visitors to easily understand the form and is used for orientation. The solid concrete cycloid vaults give the impression of monumentality without overpowering the visitors. Although solid forms repeat, there is also variation using void porticos once they approach the museum. White oak is used in contrast to the concrete vaults, which is a warm material creating intimate spaces for viewing artworks. He also plays with light cleverly serving many purposes: providing a sense of wayfinding for visitors to follow the light having a psychological effect on touch, for illumination with diffused natural daylight while protecting artworks, producing a soft ambiance against the concrete vaults, and using natural light to relate people back to nature within a contained museum (Kahn Building, 2014). Therefore, it is clear that the design of buildings in regards to form and function communicate to people visually and non-visually while traversing in architecture design. It is important for inclusively designed buildings to apply this concept in order to set the ambiance and provide a sense of welcoming for people of diverse age and abilities. 


\subsubsection{INTEGRATE COMMUNICATION SYSTEMS}
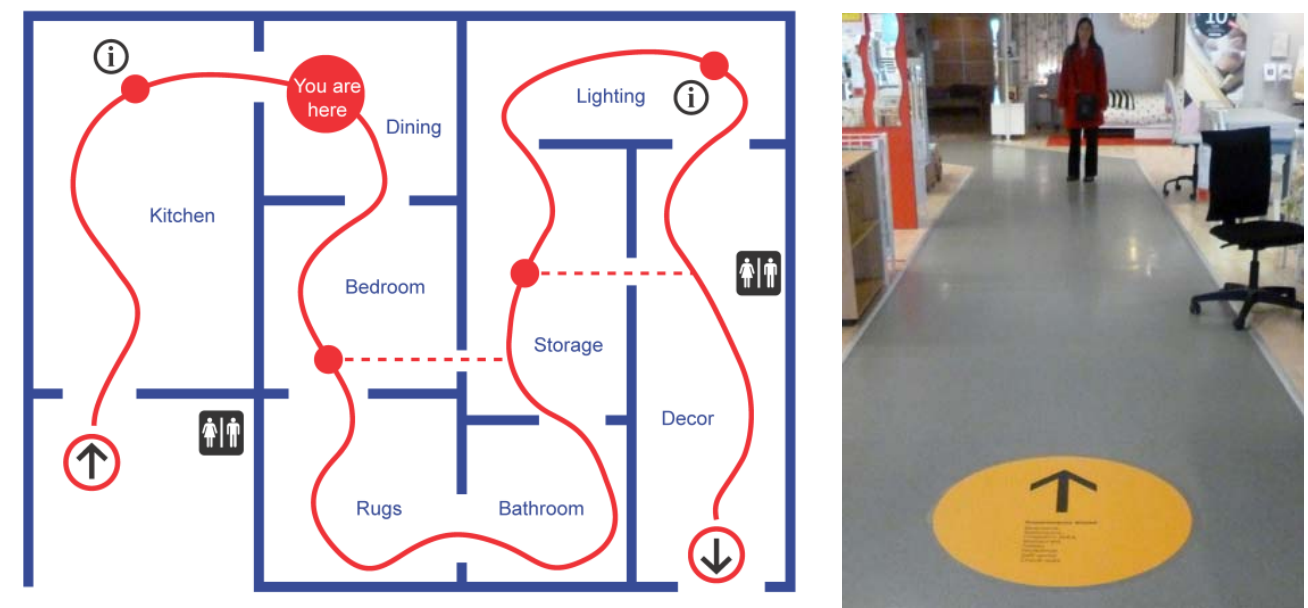

Figure 3.1.3a - Wayfinding integrates graphics with architectural elements as communication

Besides architectural design in providing communication, wayfinding is effective to accommodate diverse needs. According to Salma (2007), wayfinding is described as various methods people use to navigate in order to become familiar with their surrounding (as cited in Nussbaumer, 2012, p. 49). Wayfinding is considered another form of communication system integrated within inclusively designed buildings (Figure 3.1.3a). Today, Carpman and Grant (2002) state many designers and architects consider wayfinding to be low priority (as cited in Center for Inclusive Design and Environmental Access, 2010, p. 1). They describe it as an unattractive addition to architecture design that can be solved using signage. Furthermore, architects and designers do not specialize in wayfinding, though they are responsible in creating innovative ID solutions involving wayfinding (Center for Inclusive Design and Environmental Access, 2010, p. 5). Wayfinding is not only an architectural issue. It is also a graphic issue, which requires collaborating with graphic designers as part of the design process. Overall, various methods of wayfinding should be provided in order to accommodate diverse users. Kevin Lynch is a father figure who influences wayfinding within a global scale of city structures. In 
The Image of the City, he introduces five important elements used to help navigate through a city, which can similarly be applied to a building for diverse users. The visual elements are landmarks which are used as a type of reference point, edges are linear boundaries, districts with common identifying characteristics, nodes are important spots worth investigating, and paths are the connecting routes to the other elements (Lynch, 1960, p. 46-78). These methods of creating a mental map of a city can similarly be used when perceiving buildings using both visual and nonvisual techniques. Within the built environment, there are many wayfinding methods that can be used including visual cues such as landmarks, signage to provide directions, directories showing maps, and colour and light to reinforce pathways (Nussbaumer, 2012, p. 49). In order for people to find their destination, some people read, some hear, some use light or colour for orientation, some touch, and others prefer using a combination of these wayfinding techniques. Therefore, various wayfinding methods should be used as communication systems within architecture design in order to create inclusive buildings that accommodates everyone.
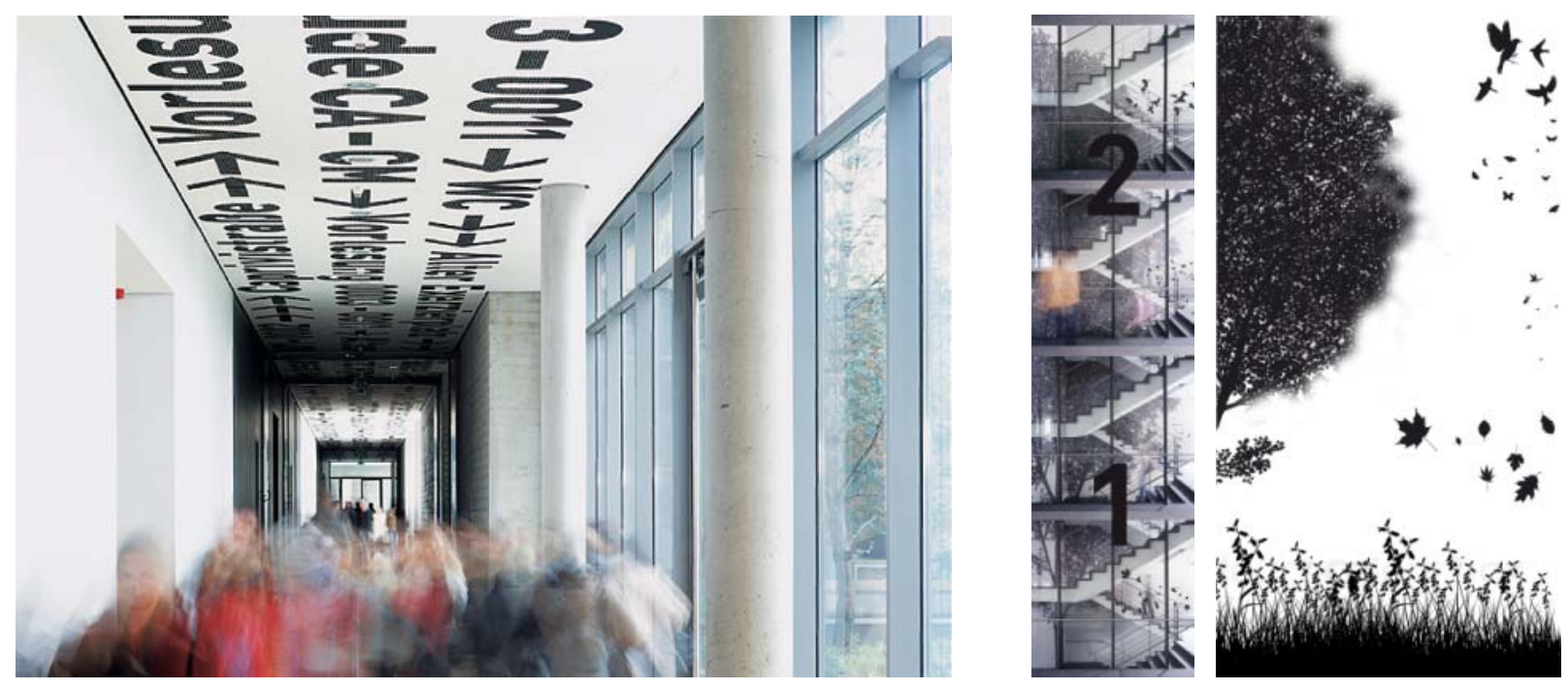

Figure 3.1.3b - Functional signage showing direction of movement (left) vs. narrative signage system showing flow of movement up a building corresponds to different elevations of natural elements as wayfinding (two right images) 
Buildings with strong architectural elements using various wayfinding techniques complemented with thoughtful signage system contribute significantly towards occupant satisfaction and usability. Signage acts as a medium between architecture (the sender) and users (the receiver) forming the basis for orientation within spatial situations (Schittich, 2013, p. 42). It uses both visual and non-visual communication in space benefiting a diverse group of people. According to Beate Kling (2013), he states signage is integral as "a person who loses their sense of orientation can suffer the loss of one of their most fundamental capabilities, their independence, possibly their self-esteem, and their sense of identity.... the unity of thought, feeling and action" (prologue). Signage is integrated within architectural design assisting in orientation. They do not only function as guidance for others in a pragmatic way, but they may also allow users to experience orientation in a narrative way, creating identity within the building (Schittich, 2013, p. 41\&44). For instance, Osnabrück University of Applied Sciences guides users to their destination points by a "sky" of letters and numbers on the ceiling (Figure 3.1.3b left). It only serves a purpose in orientation. Conversely, Kreissparkasse Tübingen integrates scenes of nature on the walls in the main stairwell (Schittich, 2013, p. 44-45). Each floor represents a different species in relation to the height of these in real time (Figure 3.1.3b two right images). In doing so, each floor is given an identity and narrates the signage system to enhance people's experiences. 


\subsection{RESPONSIVE AND ADAPTABLE ARCHITECTURE THROUGH MULTI-}

\section{SENSORY EXPERIENCE}

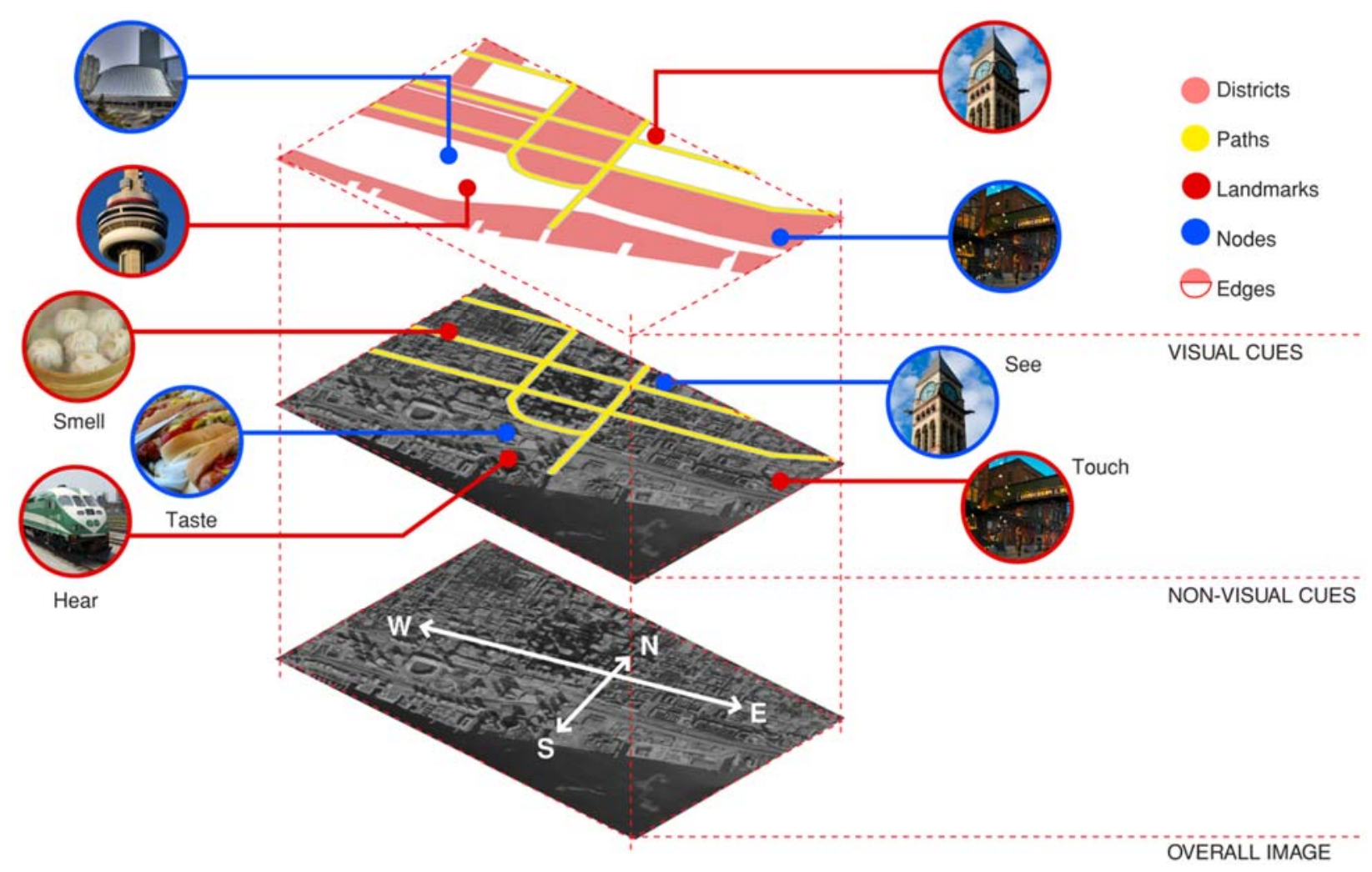

Figure 3.2.a - Multiple senses are fragments creating an overall image of the environment

Our experience of accessibility is not only through vision, which is predominantly discussed in the previous section. According to Lefton and Brannon (2002), 70\% of our sensory information comes from vision (as cited in Steinfeld, 2012, p. 109). However, when sight is not available for those with vision loss or when sight is not enough, people depend on other senses for additional information through sound, touch, smell, and taste (Figure 3.2a). Hearing, for instance, plays an important role detecting information 360 degrees outside the field of view, even though people focus on one direction (Steinfeld, 2012, p. 119). Mainstream society never uses a single sense for perception. We can close our eyes, but we cannot close our ears. 
Therefore, people always use more than one modality of sense, creating a multi-sensory experience. This further creates sensory stimulation for growth and learning. Kevin Lynch (1960) states these various senses reinforce one another to enhance each other's abilities (p. 83). Thus, our understanding of the world is constructed using nearly all our senses, creating fragments which form an overall image of the environment. In this section, a discussion on sensory experience, lighting, acoustics, colour, and materials are important to consider within an inclusively designed building in order for people with diverse abilities to orient themselves easily. 


\subsubsection{INTEGRATE NON-VISUAL INFORMATION FOR WAYFINDING}

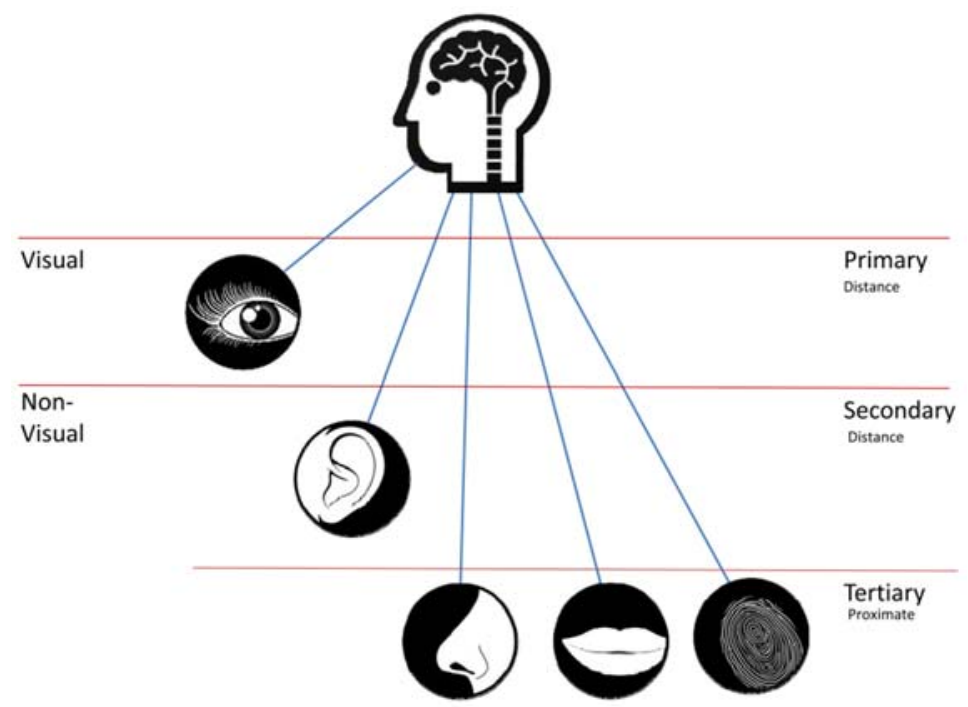

Figure 3.2.1a - Multiple senses connect to the brain to receive and interpret information about the environment

We have five different senses in total. The hierarchy of these senses consist of eyes to see for perceiving distance and is the only visual sense (Figure 3.2.1a), followed by non-visual senses including ears to hear to detect distance, nose to smell, mouth to taste, and hands to touch (Holl, Pallasmaa, \& Gómez, 2006; Arthur \& Passini, 200, p. 34-35). These last three senses experience objects within close proximity. Our abilities to sense the surrounding are all connected to the mind. In The Eyes of the Skin: Architecture and the Senses, Pallasmaa (2005) focuses on how our senses is an ongoing dialogue interacting and enhancing each other (p. 12). Vision alone somewhat disconnects us from the environment. Though, when integrating multiple senses into the design of buildings and the built environment, it helps people engage and understand their surrounding better. He argues that skin (haptic) is the oldest sense which truly connects the body to the surrounding (Pallasma, 2005, p. 12).Visual perception integrated with non-visual imageries allow the body to remember who you are and how one is located in the world. 


\section{DESCRIPTORS}

\begin{tabular}{|c|c|c|c|c|c|c|}
\hline Visual & Dark/Bright & Saturated/Neutral & Perspectival/Flat & Intimate/Nast & Solid/Void & Detailed/Minimal \\
\hline Aural & High/Low Pitch & Quiet/Loud & Clear/ Reverberant & Vocal/Non Vocal & Natural/Artifical & Attack/Decay \\
\hline Haptic & Static/Mobile & Rough/Smooth & Light/Heavy & Porous/Solid & Hard/Soft & Warm/Cold \\
\hline Kinetic & Strong/Light & Free/Restricted & Indirect/ Direct & Level/Shifting & Sustained/Quick & Temporal/Constant \\
\hline Thermal & Hot/Cold & Dry/Humid & Natural/Artifical & Enviremental/Source & Radient/Conductive & Constant/Responstive \\
\hline Olfaction & Weak/Intense & Stagnet/Fresh & Appealing/ Putrid & Nautral/Industrial & Spicy/Sweet & Invigurating/ Soothing \\
\hline
\end{tabular}

Figure 3.2.1b - Senses provide information and enhance our experiences within architecture design

There are two forms of wayfinding: visual and non-visual. Visual wayfinding is described earlier using signage and other techniques such as landmarks. Non-visual wayfinding involves an integrated process using various senses creating a physical environment through a mind's eye. Firstly, people use their senses to search for cues, which are visual and non-visual clues as information of our surrounding (Steinfeld, 2012, p. 276) (Figure 3.2.1b). Access to information is necessary for the general population to provide knowledge and control of the environment. The most common form is visual cueing, though people with vision loss depend on sensory cues such as sound, tactile, or smell. Within a complex setting, wayfinding becomes difficult when there is excessive information because there is an over-stimulation of the mind (Arthur \& Passini, 2002, p. 188). Therefore, perception occurs. According to Goldstein (2010), perception involves receiving and interpreting information from our senses (as cited in Steinfeld, 2012, p. 108). It is both a mental and sensory process. It sorts necessary from unnecessary information for taking further actions. Our perception creates a mental map of the overall environment, representing a setting constructed by our cues through various senses (Arthur \& Passini, 2002, p. 23). This benefits everyone, but is particularly useful for people with vision loss, when they want to find their way independently and effectively within an unfamiliar setting. 


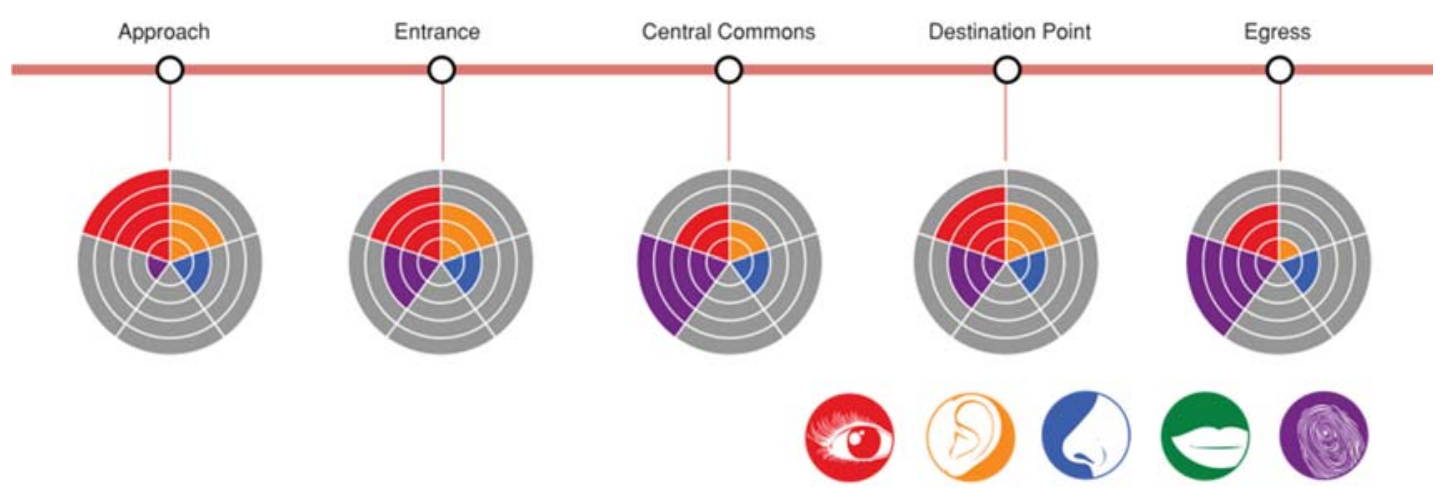

Figure 3.2.1c - Various non-visual wayfinding techniques to assist in orientation for diverse users

Within inclusively designed buildings, integrating multiple senses in search of cues (Figure 3.2.1c) to form a mental map through perception ultimately creates situational awareness, which is guided by previous experiences (Steinfeld, 2012, p. 109). According to Cohen, Weisman (1991), Regnier, and Norman (2002), situational awareness maintains the concept of familiarity to preserve independence and ease of usability of familiar products and environments (as cited in Steinfeld, 2012, p. 149). This benefits everyone including the aging population and people with dementia. Furthermore, situational awareness allows us to make decisions for spatial orientation, ensuring safety and usability for wayfinding. For example, when an individual with vision loss senses the leg of a chair through touch and sound with his cane, his perceptual system helps him realize that there is an obstructive object ahead. Therefore, supporting awareness accommodates a wider group of people, including those with sensory and cognitive impairments, by integrating multiple senses for wayfinding. Through previous experience, they provide information of our surrounding to avoid accidents by relying on non-visual senses when vision is lost. Four functions of sound, light, colour, and textures are discussed, which have an effect on the quality and usability of inclusive buildings. 


\subsubsection{SOUNDSCAPE SENSORY}

Within the built environment, acoustics assist with wayfinding created by the quality of sound, reverberation, and design of spaces (Standards Development Committee, 2010, p. 90). Holl, Pallasmaa, and Gómez (2006) argue, "we stoke the edges of the space with our ears" (p. 31). People with visual impairments depend on responsive acoustic cues provided by our environment to ensure safety. Soundscape of the acoustical environment allows people to hear using a hearing aid, orient themselves, and increase situational awareness in order to understand their surroundings.

Within interior settings, acoustics define areas spatially, have different sound qualities depending on the size and function of the space, and create a mental map of the visual world to determine which path of travel to take. Schafer (1997) argues that it is importance to provide soundscapes, such as sound signals (alarms), keynotes (distinct background sounds), and sound marks (waterfalls), to help users navigate through the environment (as cited in Steinfeld, 2012, p. 279). All of these contribute to the overall experience and enjoyment of users. Furthermore, Laszlo (1999) claims design considerations of ceiling height, wall surfaces, and upholstery are necessary to control sound reverberation (as cited in p. 280). Various acoustic treatments can be implemented in circulation routes and rooms to reduce the impact of noise. Inappropriate selection of materials can distort or enhance auditory information cues (Standards Development Committee, 2010, p. 91). In addition, every public corridor should be constructed to facilitate wayfinding by using acoustic treatments to differentiate main corridors from secondary corridors. Furthermore, good acoustical conditions for the perception of human speech are important to support communications among people and in meeting rooms. These need to be isolated from background noise or creating echoes that can impede speech perception (Nussbaumer, 2012, p. 70). As a result, acoustics play an important role within a universally 
accessible environment, especially for people with visual impairments, to define spaces that can only be perceived through sound. This accommodates a wider population of people creating better experiences, act as wayfinding devices, and increase usability of the building in order to avoid excessive background noise. 


\subsubsection{ILLUMINATION WITHIN AN INCLUSIVE ENVIRONMENT}

Lighting is essential within an inclusive environment benefiting a diverse group of users. It is especially important for people with sensory impairments who rely on other information available to them for navigating the world with dignity. By designing for people with visual impairments ensures that basic needs of all users are met as well. Lighting also enhances colour, contrast, and highlights particular features within an interior space (Bright \& Cook, 2010, p. 20). Overall, effective lighting referring to the amount, direction, and quality of light, which shapes spaces, creates atmosphere, and is aesthetically appealing (Steinfeld, 2012, p. 282). It provides visual cues creating visual comfort, health, safety, direction of movement, usability, and independent use of space. This further plays an important role during cases of emergency. Thus, all of these have an impact in creating inclusive environments using two major light sources including artificial and natural lighting.

Artificial lighting becomes difficult when the placement of lights alter one's perception of the environment. It negatively affects people's ability to navigate through space, becoming an accessibility and safety concern. Seniors and those with vision and cognitive disabilities further experience disorientation in an environment with uneven distribution of light (p. 285). One of the discomforts include glare. People with vision loss become more sensitive to glare as they age (p. 286). Direct and indirect glare from light sources should be avoided to prevent accidents from occurring. This can be achieved by minimizing glare through careful locations of light fixtures and appropriate selection of matte floor finishes (p. 286). Thus, discomfort and glare should be avoided within inclusive buildings, which negatively influence their perception of the environment. 

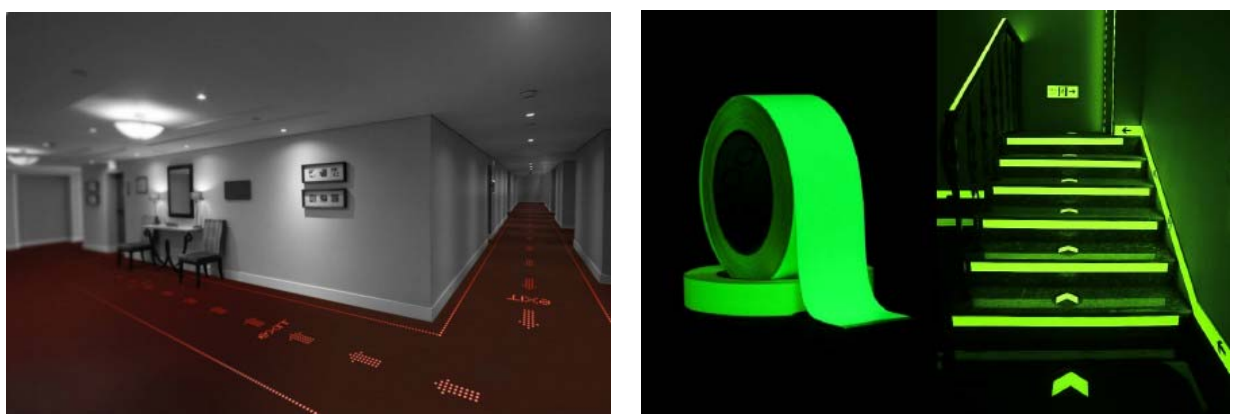

Figure 3.2.3a - Emergency lighting for safety using LED (left) and photo-luminescent tape (right)

In addition, artificial lighting promotes safety by illuminating general areas and specific features at night in exterior and interior environments. This is one of the principles of ID in order to meet diverse needs. High risks are involved when no lighting exists. Within a building, general lighting integrated with task lighting in certain areas prevent injuries and allow people to perform tasks (p. 287). This is even more important during cases of emergency when electricity is interrupted. Emergency lights or back-up lights guide people to safety by illuminating the escape route within major circulation routes (Figure 3.2.3a). Once inside the emergency exit, handrails and stair nosings are illuminated using either LED or photo-luminescent tape to mark the remaining egress route to safety (Bright \& Cook, 2010, p. 75). At night in open and public spaces, exterior lighting is essential to enhance safety and usability by illuminating main paths of travel through space and to perceive signs in the dark. This increases confidence for everyone by creating a more secure environment.
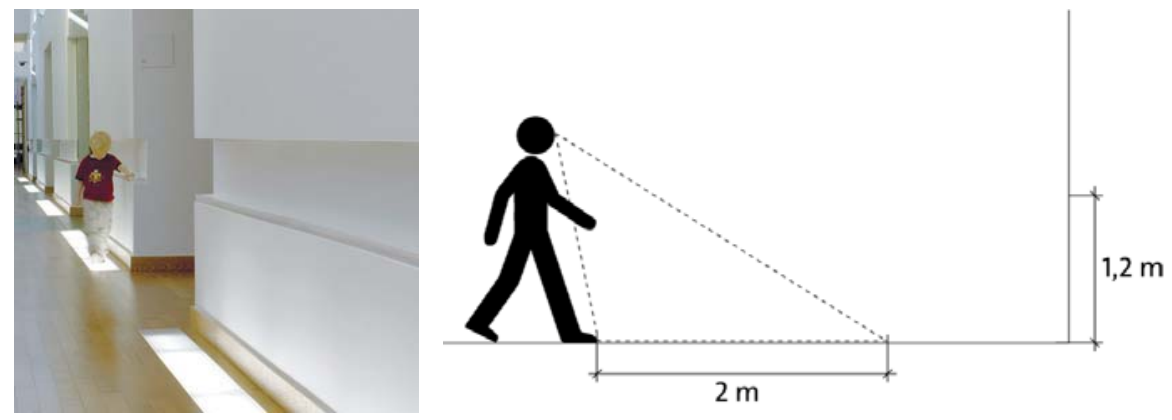

Figure 3.2.3b - Anchor Centre for Blind Children uses lighting to guide children 
Lighting also plays a role in providing movement through space. This is particularly useful for people with different levels of visual impairment who depend on other senses for navigation. Anchor Center for Blind Children located in Denver, Colorado (Figure 3.2.3b) creates indents in the wall which act has a handrail and provides illuminated strips on the floor to guide children as they can perceive brightness (Sokol, 2014). According to Bright and Egger (2008), most people look down on the floor as an information source for spatial awareness (p. 182-183). This builds their independence in an inclusive environment, benefitting a diverse group of users when traversing architecture.

Daylighting is the second source of illumination and is a natural light source. The challenge for most buildings is how to harvest, harness, and use natural light effectively without causing any negative effects (Bright \& Egger, 2008, p. 50). For instance, direct sunlight inside a building creates bright light, which produces glare and hard edged shadows. This is a safety concern because it alters people's perceptions of the interior environment, making it difficult for people to use independently. This is especially true for people with cataracts, which causes light to be scattered in their eye (Bright \& Egger, 2008, p. 49). On the other hand, people need daylight because studies have shown that the production of body chemicals, including melatonin for instance, affect emotional states which depend on light exposure (Steinfeld, 2012, p. 285). Thus, by providing accessible daylight within a building can help neutralize these fluctuations ( $\mathrm{p}$. 285). This benefits users' health and well-being when daylight enters the building interacting with the human body. Thus, daylighting must be carefully considered in order for people to use the building effectively. 

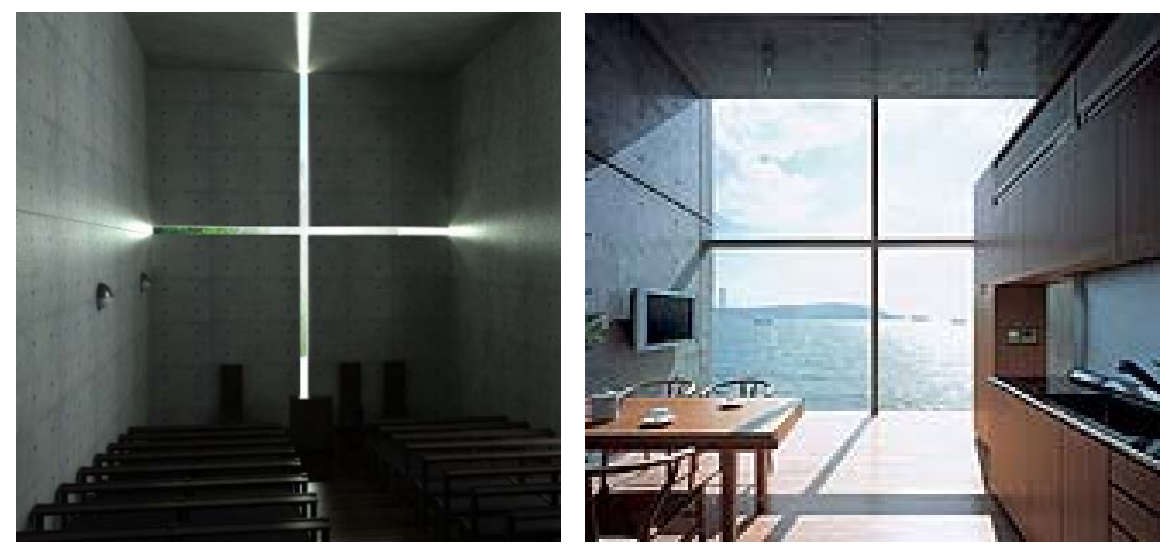

Figure 3.2.3c - Tadao Ando's Church of Light (left) creates different experiences compared to his $4 \times 4$ House (right)

Illumination entering the building through high ceilings, light shelves, courtyards, light wells, large windows, and indirect light from north facing skylights to maximize light diffusion are possible design solutions to bring light deep into the building (p. 285). In addition, natural light is used for orientation as wayfinding. Those who cannot see respond to the presence and absence of light through touch (Bright \& Egger, 2008, p. 70). For instance, people with visual impairment are able to sense light levels (Sokol, 2014). By using skylights within architecture design guides people through a building to maintain independence and enhance usability in high traffic areas. Finally, daylighting has the ability to change shape and experiences within an interior space. This alters people's perception when there are two identical rooms with different approaches to integrating daylight. To illustrate this idea, Tadao Ando's Church of Light offers a sense of being enclosed with only natural light entering from the cross window (Figure 3.2.3c). The lighting creates a very symbolic and spiritual interior space. Furthermore, lack of window openings create a visual disconnection to the outside world causing a negative psychological effect for people (Bright \& Egger, 2008, p. 49). Conversely, his 4x4 House contains a very open space with natural light filtering-in and maximizing views to the exterior (Figure 3.2.3c). These two opposite approaches show the importance of natural daylight creating different qualities of 
light and atmospheres for different aesthetic appeals. This is important for diverse people to understand the impact of light to the human body to enhance usability and maintain safety within an inclusively designed building. Therefore, light plays an important role within the design of buildings. Light does not only act as a visual cue, it also acts as a sensory cue through touch. Diverse users can benefit from effective use of natural and artificial light providing comfort, health and safety, usability, navigation, and sense of dignity. 


\subsubsection{PERCEPTION OF COLOUR}

Colour plays an important role in our everyday life. It affects our mood, speaks a language, and is beautiful to our eyes creating variety in our colourful world. Every colour has a meaning and a function. However, how can we experience and understand colour equally and fairly, including people with different levels of colour blindness? They cannot differentiate colours from one another when placed side-by-side (Steinfeld, 2012). Thus, colour within an inclusively designed building and environment must be designed effectively in order to benefit everyone. By accommodating for people with vision loss, we can meet the needs of the general population as well.

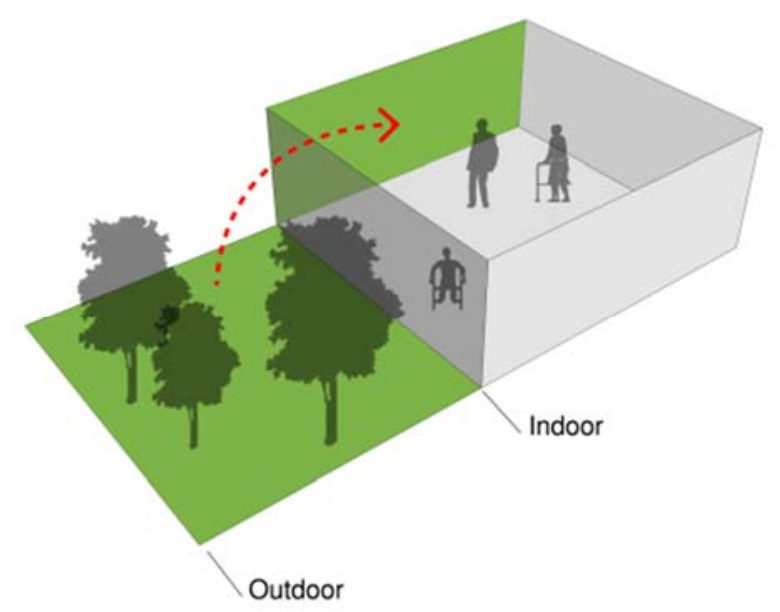

Figure 3.2.4a - Enhancing behavior through colour psychology

Colour psychology affects our mood and behavior interacting with the human eye and brain. It consists of hue (colour), saturation (lightness and darkness of a colour), and value (grayness of a colour) (Steinfeld, 2012, p. 290). All of these contribute to creating an emotional response which people experience unconsciously. This is one of the functions of colour. Many designers either intentionally or unintentionally select a colour to achieve a specific atmosphere which benefits occupants. For instance, green replicating the outdoors has an effect on the 
healing process for patients within healthcare (Bright \& Egger, 2008, p. 109) (Figure 3.2.4a). Not only is this functional but this is also visually pleasing. This is further enhanced with the addition of lighting. Colour is influenced by light. They are never considered in isolation from one another (Bright \& Cook, 2010, p. 22). Lighting further enhances colour creating an ambience for people to experience. Thus, the selection of colour used within interior environments has an impact on people's behavior and within ID, this is important to determine who it is designed for and how it is used.

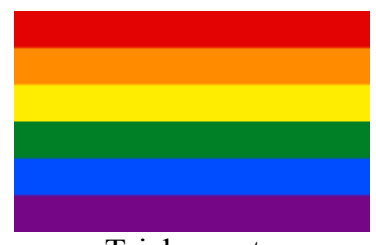

Trichromats

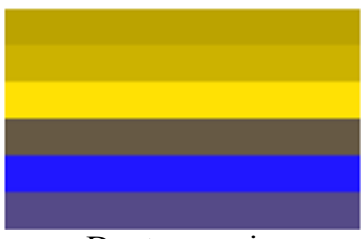

Deuteranopia

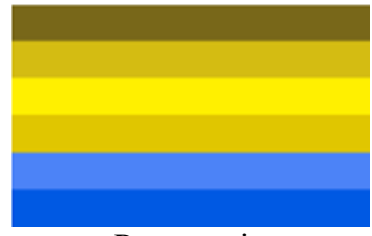

Protanopia

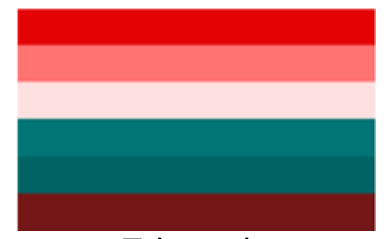

Tritanopia

Figure 3.2.4b - Different levels of colour blindness and the importance of using primary colours for contrast

Colour also acts as information creating legibility to clarify the perception of space (Steinfeld, 2012, p. 289). For instance, a legible interior distinguishes specific features from larger surfaces through colour contrast, making them easy to identify regardless of people with cognitive or vision disabilities. For instance, features such as doors, handrails, and controls, which are clearly distinguishable from the wall make them easier to find, use, and experience space safely through the use of colour. Implementing primary colours will assist most people, especially those with different levels of colour blindness. They represent true colours with no traces of any other colour and are high in contrast (Bright \& Cook, 2010, p. 115) (Figure 3.2.4b). In addition, there must be at least $70 \%$ difference in colour contrast in order to effectively be used by everyone (Steinfeld, 2012). Legibility is also important for wayfinding and signage systems. Colour coding speeds visual search by associating it to an object we see in the physical world to avoid cognitive dissonance (10 Reasons to Use Color, 2014). However, signage systems 
cannot only rely on colour creating confusion and disorientation for people who are colour blind. Since colour is only a visual perception, it must be supplemented with another form of information to serve a broad population such as sound or touch. Colour is also used for emphasis to enhance a meaning (10 Reasons to Use Colour, 2014). Our eyes are attracted to high contrasting colours. We naturally search for a meaning when objects stand out. According to Health Facilities Management, children are attracted to bold colours to stimulate their minds for growth and learning (Creating a Sense of Adventure, 2009). Thus, colour provides an understanding of the environment which is further integrated with non-visual information to accommodate a diverse group of users within inclusively designed buildings. 


\subsubsection{SPECIFY MATERIALS AND FINISHES}

Interior materials and finishes have an effect on the quality of life for users, contributing to health, safety, psychological, and well-being. There are four key elements to consider for interior finishes including floor covering, wall finishes, ceiling finishes, and textiles/upholstery. Each of these elements will be discussed.

Flooring within inclusive environments should be selected based on their positive characteristics and avoid negative impacts. Some issues with floor covering include falling. It is considered one of the most common types of accidents in building interiors, mainly affecting people with physical disabilities and older adults (Steinfeld, 2012, p. 299). Other issues with flooring are slipping and tripping. Slipping refers to surfaces exposed to moisture and tripping refers to abrupt changes in floor surface heights between rooms. A small difference in height can cause accidents to occur. Furthermore, deep-pile carpeting should be avoided. It is considered a barrier for seniors and PWD because it causes too much friction, making it hard to wheel on (p. 299). Some floor coverings also cause hazards for people with poor vision creating illusions caused by bold patterns, such as horizontal lines appearing as stairs cause accidents even though the floor is flat (p. 299). Thus, floor covering should be slip, trip, and fall-resistant, and avoid heavy carpeting to benefit everyone. Other advantages of selecting appropriate floor covering include providing appropriate lighting levels for visibility without causing glare for people with poor vision, and some flooring have a positive impact on acoustical quality of the space (p. 299).

Walls can either be painted or finished with wallcovering, which are highly durable. Wallcovering ranges in patterns and colour humanizing interior environments. They transform institutional interiors to create more familiar settings. Vinyl wallcovering is often used with a fabric backing. They provide stability, are sound absorbing, and easy to clean (Brawley, 1997, p. 244). Areas with high traffic patterns require high performance standards (p. 244). 
Ceiling finishes provide acoustic quality within interior spaces. Most commercial spaces have hard surfaces and contain large open spaces, causing sound to bounce from one surface to another (p. 247). An acoustical ceiling absorbs sound reverberation and is considered the best way to control noise (p. 248). When selecting ceiling finishes, it is important to consider fire safety codes, prevent growth of mold and bacteria, and does not absorb moisture (p. 248). Ceilings should always be white for higher reflectance qualities.

Upholsteries come in many different colours, patterns, and textures. It is important to select appropriate fabrics by considering low maintenance, up-to-date fabrics, flammability requirements, breathability, moisture barrier, abrasive level, and infection control (p. 229). One of the most innovative fabrics in healthcare settings is Crypton (p. 230). It is water and stain resistant, antibacterial, strong, and breathable. Elizabeth states it is not a coating but each fiber is permanently encased in every fiber of the material (p. 230).

Overall, there are many ranges of floor covering, wall finishes, ceiling finishes, and textiles/upholstery to choose from. However, they are selected based on aesthetics while meeting functional needs of people with diverse ages and abilities in order to create inclusive environments. 


\subsection{SECURE ARCHITECTURE FOR SOCIAL INTERACTION}

Everyone benefits from social participation in an inclusive setting visually, non-visually, and socially. They create more dynamic spaces within the built environment, enhance thoughts/emotions and behavior, improve mental health, build friendships, and celebrate diversity, which is further promoted through ID (Gehl, 1987, p. 15). Social interaction stimulates the mind, which is evidently important for children's growth and learning (Creating a Sense of Adventure, 2009). For this section, we will discuss how to create interactive spaces for the general population by introducing a hierarchy of social participation. They are maintaining visual connection, integrating circulation spaces as interactive places, and social places define human behavior for social engagement. These in turn create safe and accessible environments that can be used by all. 


\subsubsection{MAINTAIN VISUAL CONNECTION}

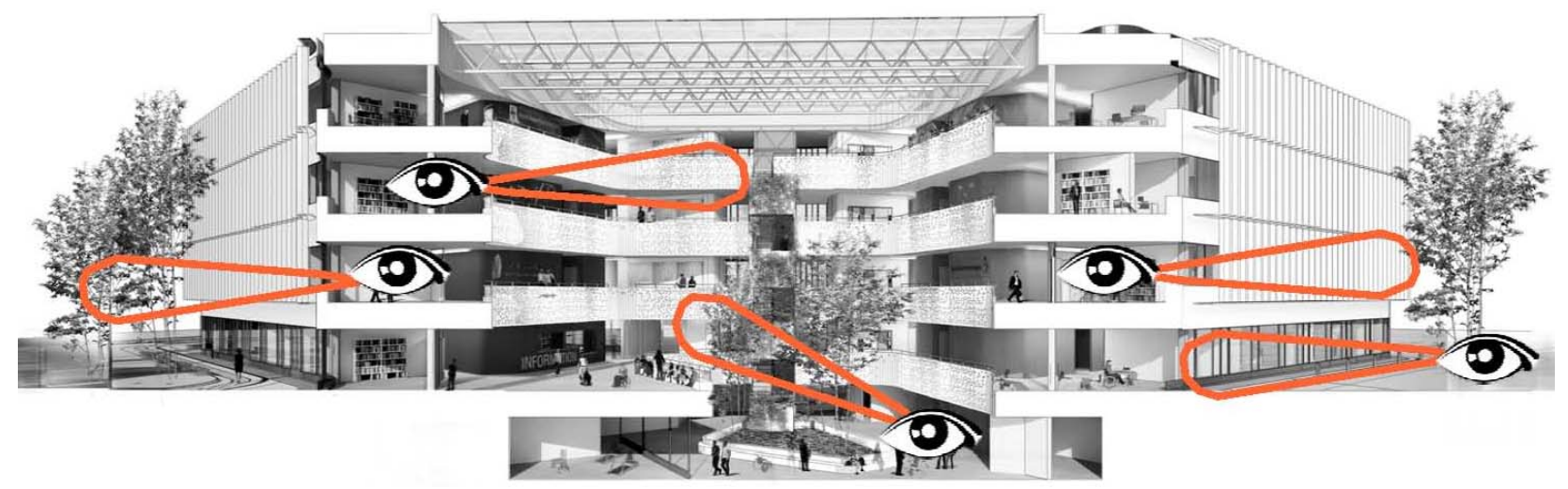

Figure 3.3.1a - House of Disabled People's Organization

Providing information about the environment allows people to become aware of the surrounding to enhance safety and usability. Within an inclusively designed building in terms of social participation, maximizing sightlines by creating visual connection supports this idea on two levels: personally and architecturally. First of all, Jane Jacobs, an activist who is the author of an influential book The Death and Life of Great American Cities (1961) introduces an important concept she calls "eyes on the street". She states that within a city, we make our communities safer together when residents, acting as surveillance, see and hear people occupying the streets from indoors (Figure 3.3.1a). This protects them on the streets as well as residents themselves. In addition, she argues that people are generally attracted to movement (Jacobs, 1961; Gehl, 1987, p. 23). Movement, in this case, may refer to both water features stimulating other senses or street performances drawing crowds. When people occupy the streets, they become more interesting, active, and eventually safer to use. They represent key areas of movement where people can see and be seen, becoming part of the action. Both these concepts demonstrate normal human behavior on a personal level when there is high visibility between the viewer and participant. This overall idea within a macro-scale of a city can be applied to an 
architectural scale. Similarly within an inclusively designed building, maintaining visual connection makes people feel secure when they are provided with information by increasing awareness of their environment and guiding them to their destination point. People with a hearing impairment for instance, need to be able to read lips or use sign language by having direct line of sight (Steinfeld, 2012, p. 165). Archea (1984) further states that social spaces are related to visual access, providing exposure to information (as cited in p. 170). Thus, interior social spaces become more usable when people have clear sightlines through the use of transparency. 


\subsubsection{INTEGRATE CIRCULATION SPACES AS SOCIAL PLACES}

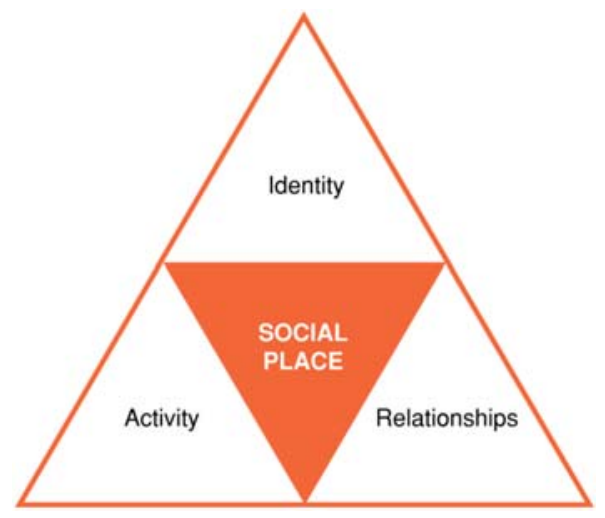

Figure 3.3.2a - Definition of social place

Social activity is a form of contact occurring spontaneously in many spaces and places (Gehl, 1987, p. 15). However, spaces and places differ within the built environment. Space is an undefined area with a sense of placenessless, whereas place has a meaning and is a more tangible (Schroeder, 2012). Within an inclusive setting, public places provide opportunities for human interaction, which benefit everyone as no individual user group can survive without constant informal contact with other members of society (Alexander, Ishikawa, Silverstein, 1977, p. 618). This, along with ID, signify the acceptance of differences by helping and learning from each other. There are three fundamental aspects to creating a social place (Figure 3.3.2a). They are identity which have a defined space and image, activity referring to use and function where people interact, and relationship in terms of proximity and walkability (The Place Diagram, 2012). These social places can be separate or can be integrated as part of an existing space within a building.
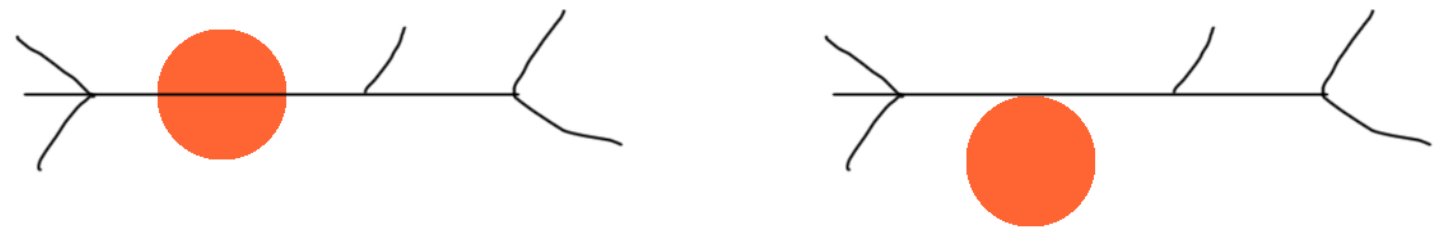

Figure 3.3.2b - Social spaces cut through the middle vs. tangent 
In the case of creating accessible environments that can be used by all, integrating social places with circulation spaces are more ideal to maintaining social interaction. This further enhances the earlier concept of maximizing sightlines for creating awareness and providing information of their surroundings. According to Alexander, Ishikawa, and Silverstein (1977), two different qualities of social gathering spaces exist (Figure 3.3.2b): when a circulation path cuts through the middle of a social place creating a highly exposed area for interaction (p. 619). This is typically found in atrium spaces and are used as temporary areas for socializing. On the other hand, tangent involves a social place that is adjacent and open to the main circulation route (Figure 3.3.2b). This pattern of human behavior involves people constantly passing through it.

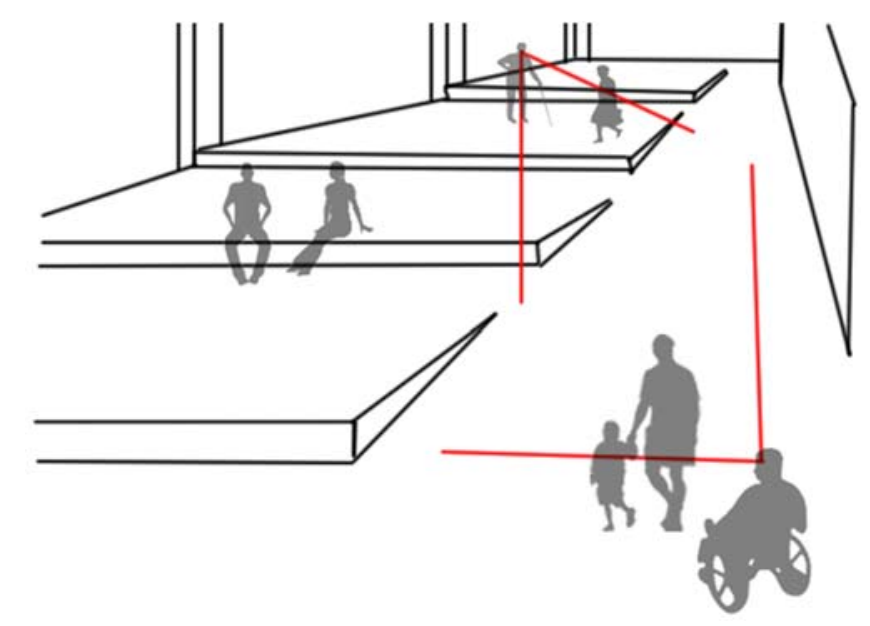

Figure 3.3.2c - Circulation space as social space

However, they have the choice of continuing their path or are attracted to human activities and stay behind. This allows people to settle down longer when it is a semi-public space and create an identity within a complex building, which can assist with orientation (Figure 3.3.2c). Thus, these social places represent all three elements which benefit the general population maintaining safety, enhance usability, and encourage places for interaction. 


\subsubsection{SOCIAL PLACES DEFINE HUMAN BEHAVIOR FOR SOCIAL ENGAGEMENT}

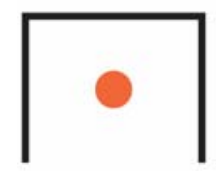

a) Enclosure

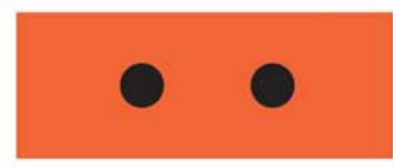

b) Well-defined space

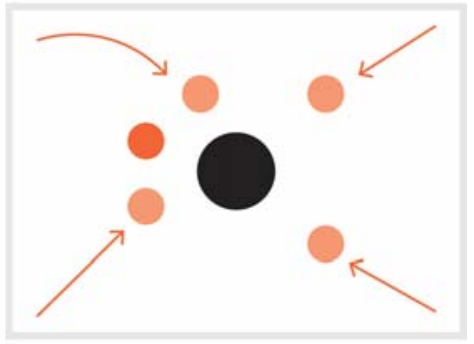

c) Place of interest

Figure 3.3.3a - Three different spaces affecting human behavior for social engagement

Designers dictate how people use public spaces for social engagement. Though, they are often abandoned for social reasons or events causing people to change the intent of the space. Overall, these spaces affect human behavior with choices and independence for taking action. As mentioned earlier, people are attracted to light, seeing other people, and moving objects. Their behaviors respond to environment visually and non-visually. According to Christopher Alexander in A Pattern Language (1977), various social places are introduced representing different qualities of spaces and how people use them (Figure 3.3.3a). Firstly, an enclosed space creates an intimate space either for individual use or interaction amongst a small group of people. A greater sense of privacy is achieved in this scenario. On the other hand, a well-defined space through the placement of furnishing or using an area rug to physically mark a territory creates a place for social engagement. It provides a more public and open gesture for interaction. Finally, places of interest attracts people to gather. These spaces can either contain stationary objects, such as a statue, or an active object, such as sounds and movement of a water feature, to affect people to move towards a point. Thus, people behave based on the design of social places to encourage different types of social engagement. 


\subsection{CASE STUDIES}

Three diverse case studies are presented exploring the three design strategies introduced in the theoretical framework. However, each case study represents a different theme. They are creating accessible architecture as communication, responsive and adaptable architecture through multi-sensory experience, and secure architecture for social interaction. The first case study explores re-designing an existing building to become a fully accessible home, the second investigates an education facility which is used to enhance multiple senses, and finally the last example is a true representation of the proposed design for this thesis to show similar connections. Although these examples are very diverse, they all relate to the thesis topic of creating inclusive environments used by all. 


\subsection{THE WAREHOUSE}

Location: $\quad 44$ Patton Avenue, Princeton, New Jersey

Type: $\quad$ Residential

Size: $\quad 6,000$ gross square feet (Graves, 199, p. 228)

Date: $\quad$ Designed in 1974, Completed in 1992 (Graves, 199, p. 228)

Designer: $\quad$ Michael Graves \& Associates
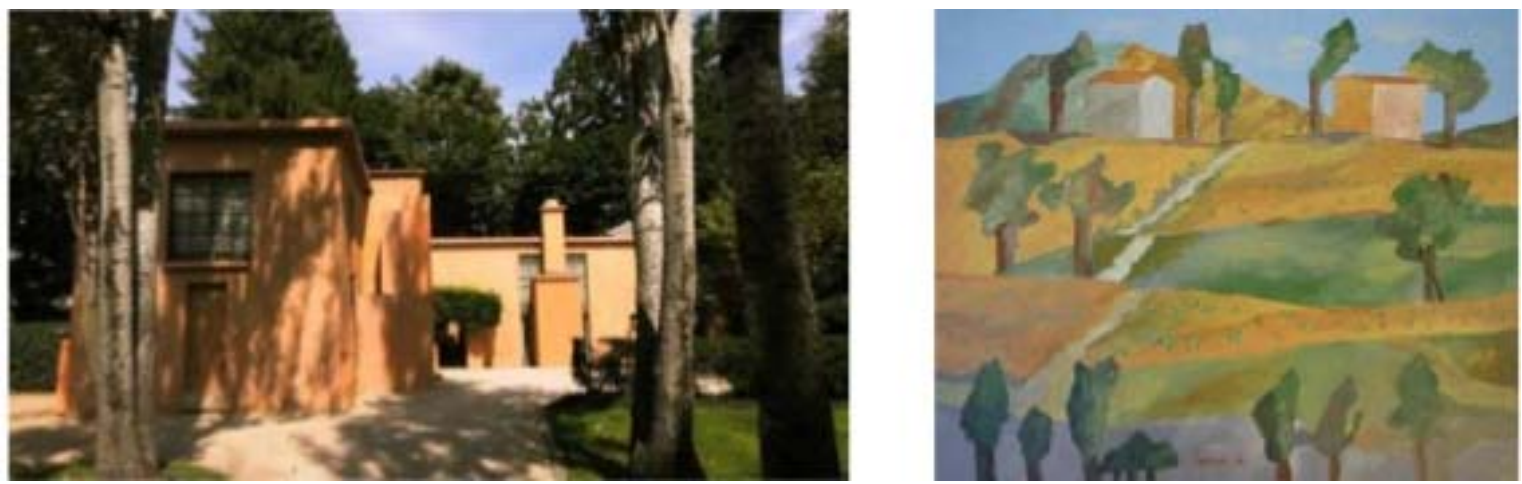

Figure 4.1a - Front view as one approaches the site and the building reminds Graves of Italian farmhouses

The Warehouse represents the first design strategy introduced as part of this thesis, which is creating accessible architecture as communication. Michael Graves is a renowned product designer, architect, and advocate for ID. As a designer, he understands the needs of PWD since he is in a wheelchair himself. He designed his own home integrating accessible features. A disused warehouse was converted into a beautiful home. The original warehouse was constructed in a Tuscan vernacular style (The Warehouse, n.d.). He fell in love with the building at first sight because it reminded him of Italian farmhouses (Figure 4.1a). His intention for the home was adaptive-reuse to become a beautiful sanctuary surrounding himself with all of his own architectural designs, objects, and furniture. He continues to use his home today as a laboratory to experiment with new accessible ideas (The Warehouse, n.d). 

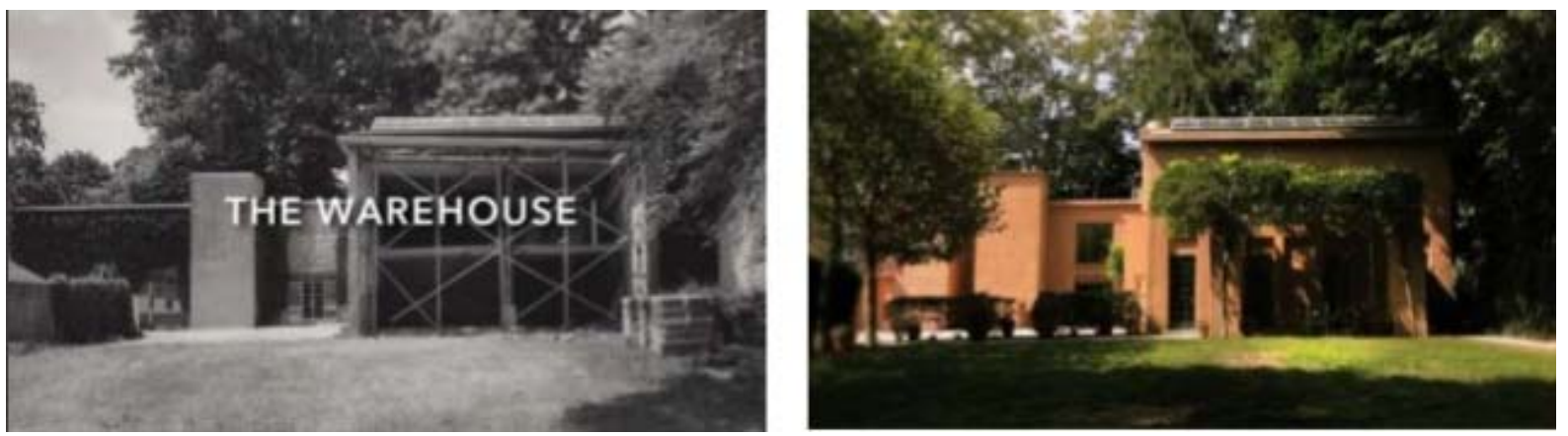

Figure 4.1b - Architectural expression of an industrial warehouse vs. a residential home

Design Features: The Warehouse symbolizes communication within architecture by using the concept of 'form follows function'. Originally the industrial building contains elements of monumentality, high ceilings, enclosed space, and many storage cells (Figure 4.1b). He reuses the exterior structure and all of the interiors are gutted-out. He carefully takes the L-shaped building and integrates holistic design, dividing spaces based on the sun to maximize daylight for the library, dining and living rooms, kitchen, and bedrooms (Graves, 199, p. 228). For instance, since he wants light in the morning, the kitchen faces east (At Home with Architect Michael Graves, n.d). Additional windows and doors are punched out to provide views and connections to the outdoors. Overall, he creates a practical place to live in by maintaining the stucco facade while integrating residential furniture and objects with careful ornamentation. A library with a wisteria-covered pergola opens up to a garden terrace provides a unifying connection between indoor-outdoor spaces for the Warehouse. 

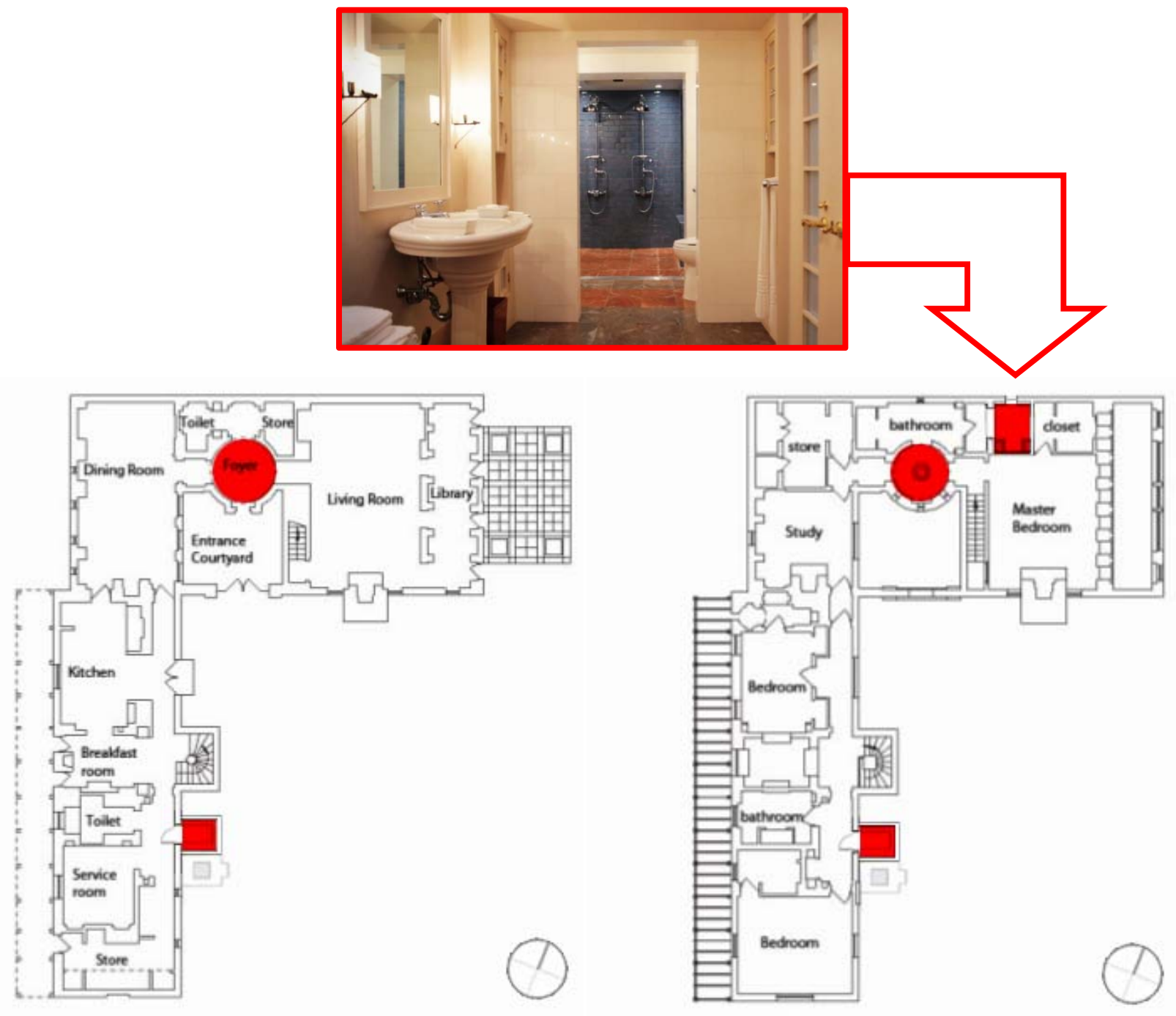

Figure 4.1c - Renovations with additions to an existing building to make it fully accessible

Accessibility is experienced while traversing the Warehouse. Firstly, when he became paralyzed in 2003, he renovated the building in such a way that it does not draw attention that it belongs to a PWD. He added an elevator adjacent to the spiral stairs, removed the balustrade in the foyer for a wider turning radius, and redesigned the ensuite to accommodate his wheelchair (Figure 4.1c) (Nussbaumer, 2012, p. 258). A typical curb for a shower does not work for everyone, though it protects water from overflowing. Instead, he added a roll-in shower with a horizontal drain on the floor to prevent water from getting to the other side (p. 258). 

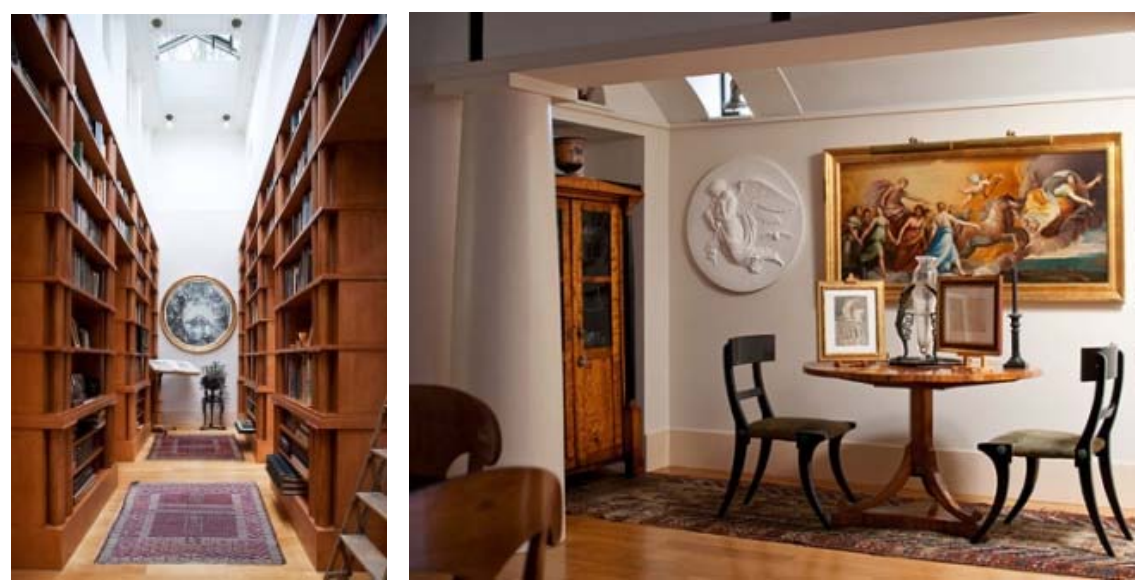

Figure 4.1d - Brightly lit interiors and interesting qualities of spaces

Secondly, there are many interesting qualities of spaces when people traverse the building, accommodating diverse needs who depend on light, form, and volume, in order to create spatial awareness. When people first approach the site, a row of trees create a natural canopy acting as a gateway to the Warehouse (Figure 4.1a). The driveway and the entrance courtyard are all flushed, making it easy to approach. Once inside the library, there is a sense of vertically with a skylight on the roof illuminating the rows of books (Figure 4.1d). Furthermore in the dining room, people experience the intimacy of the space when small clerestory windows capture slices of light to enhance the arched ceiling (Best Of Home Interior, n.d.).
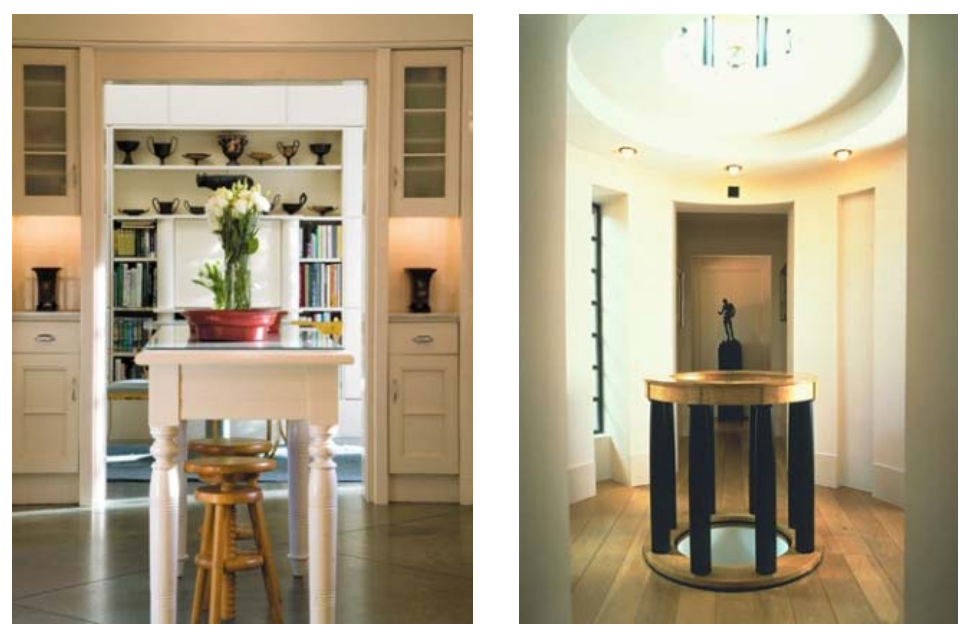

Figure 4.1e - Enfilade and landmarks for wayfinding 
The building also integrates communication system through wayfinding. Once inside the building, the rooms are easy to understand with doorways creating passageways to different spaces. The spaces flow when people walk through the building in a linear pattern. In addition, Graves integrates landmarks, such as paintings and sculptures, in his home to make them easier to remember when traversing the building (Figure 4.1e). 


\subsection{HAZELWOOD SCHOOL FOR THE MULTIPLE SENSORY IMPAIRED}

Location: $\quad 50$ Dunbreck Court, Glasglow, Scotland

Type: $\quad$ Educational

Size: $\quad 29,000$ square feet

Date: $\quad$ Completed in 2007 (Sokol, n.d.)

Designer: Alan Dunlop Architect Limited
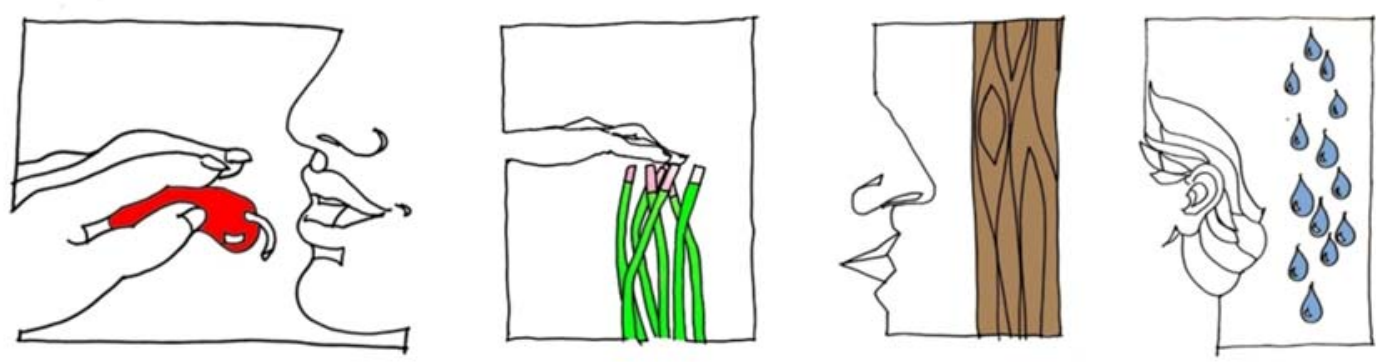

Figure 4.2a - Hazelwood School uses sensory cues to promote independence and sense of dignity

Hazelwood School explores the second design strategy of responsive and adaptable architecture through multi-sensory experiences. It is an elementary school responding to children with diverse disabilities, particularly those who are blind and deaf (Hazelwood School, 2009). They depend on other senses to understand their surroundings, enhancing independence and maintaining dignity (Figure 4.2a). The school itself is a learning tool intended to be usable and easy to navigate by anyone. Within the site adjacent to the school is a residential unit containing three bedrooms (Figure 4.2c). It is known as the "life skills house" to teach children basic life skills while providing accommodation (Hazelwood School, 2009). 


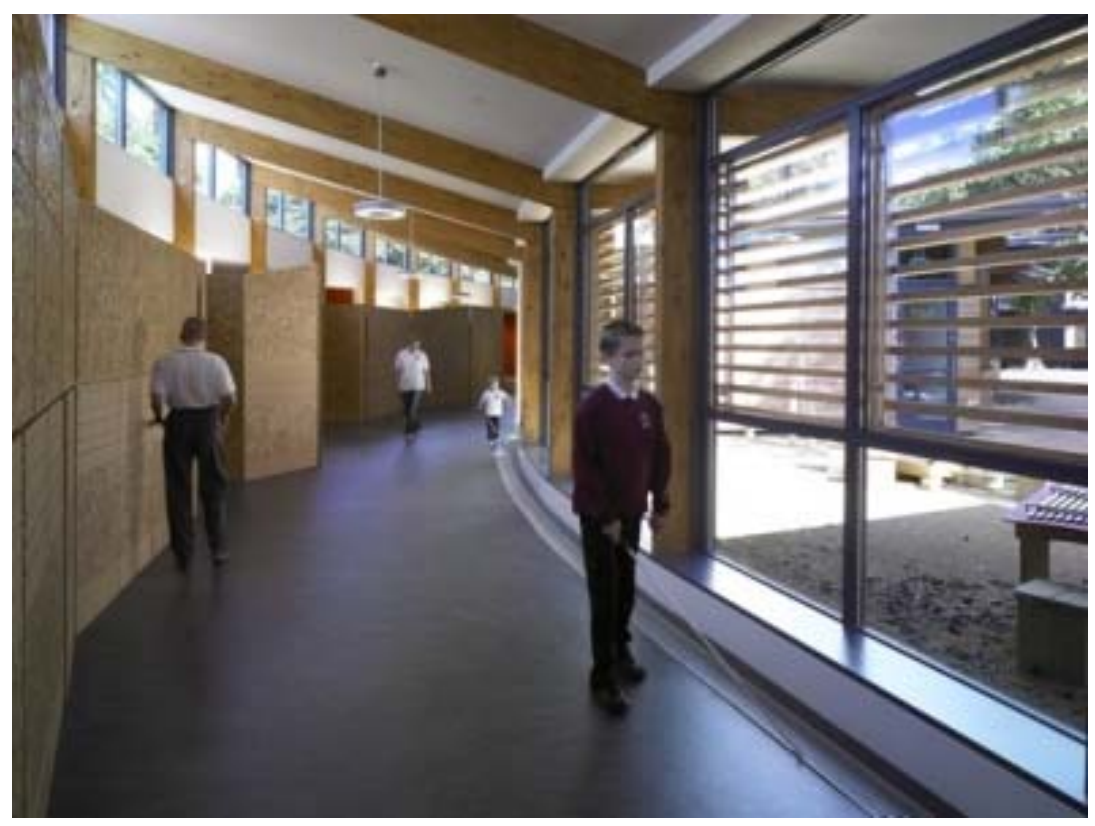

Figure 4.2b - Orientation within the building through various senses

Design Features: The building relates to the site and various architectural elements respond to the users. When vision is not available to everyone, people rely on other senses to create awareness of their surroundings. The environment provides sensory cues to assist with orientation. These cues include sound, light, colour, and interior finishes. The building is in an sshape, which wraps around existing trees while connecting with the natural landscape. The form further creates intimate spaces internally and externally for children to use (Hazelwood School, 2009). Internally, children understand their location within the building by seeing and smelling trees when relating their body to the environment (Figure 4.2b). Externally, the teaching gardens enhance growth and learning by stimulating their minds. 


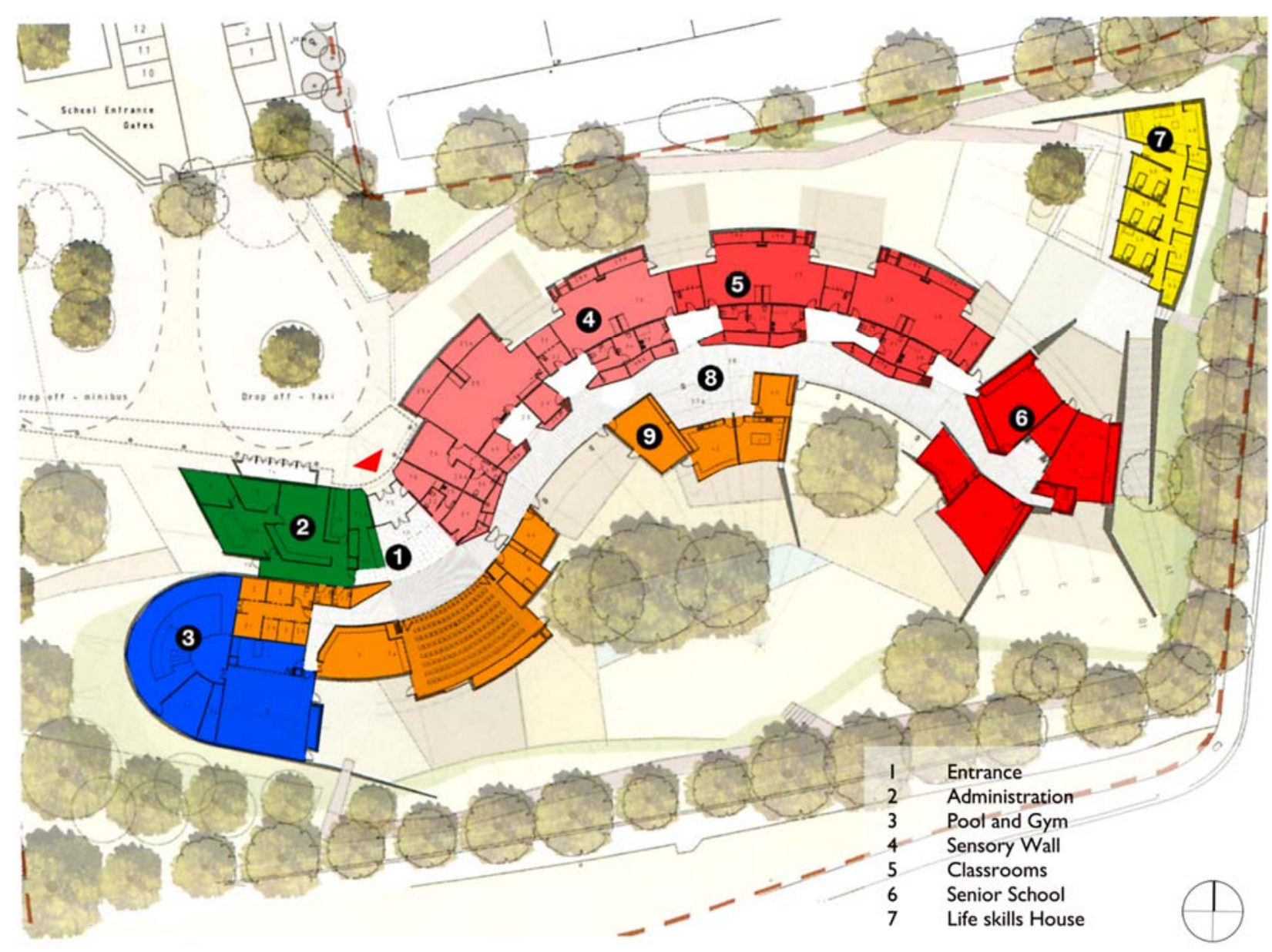

Figure 4.2c - Floor plan of Hazelwood School

Since this school is mainly occupied by children with poor vision, sound becomes an important element to consider. Majority of the classrooms are north facing towards the park providing quiet learning spaces away from major streets (Figure 4.2c). There are some classrooms facing east $\&$ south. To reduce heavy traffic noise, they contain high slate walls acting as sound barriers (Hazelwood School for the Multiple Sensory Impaired, 2009). 


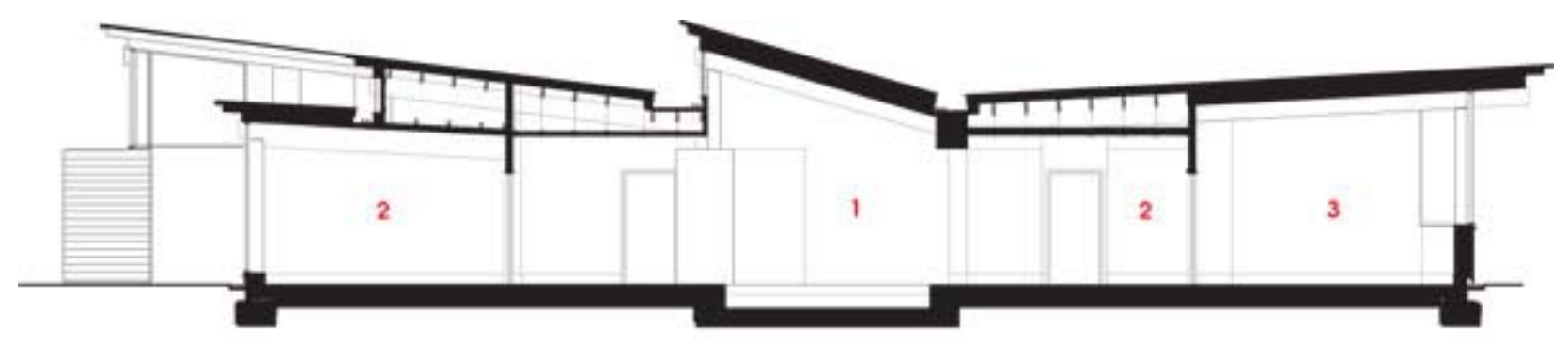

Figure 4.2d - Building section through 1) the street 2) \& 3) classrooms

Both artificial and natural lighting are used at Hazelwood School. Daylight filters into the building with north facing clerestory windows, which penetrate deep into the classrooms and the main circulation route called the 'street' (Figure 4.2d). Clerestory windows are used because full height windows are distracting for children with partial vision (Sokol, n.d.). Some windows are protected with louvers to prevent solar heat gain (Sokol, n.d.). Overall, all these windows do no create glare and provide even distribution of light (Hazelwood School for the Multiple Sensory Impaired, 2009). Since natural light provides immense illumination within the building, this reduces the use of artificial lighting. However, they are still provided using energy efficient suspended fluorescent light strips.
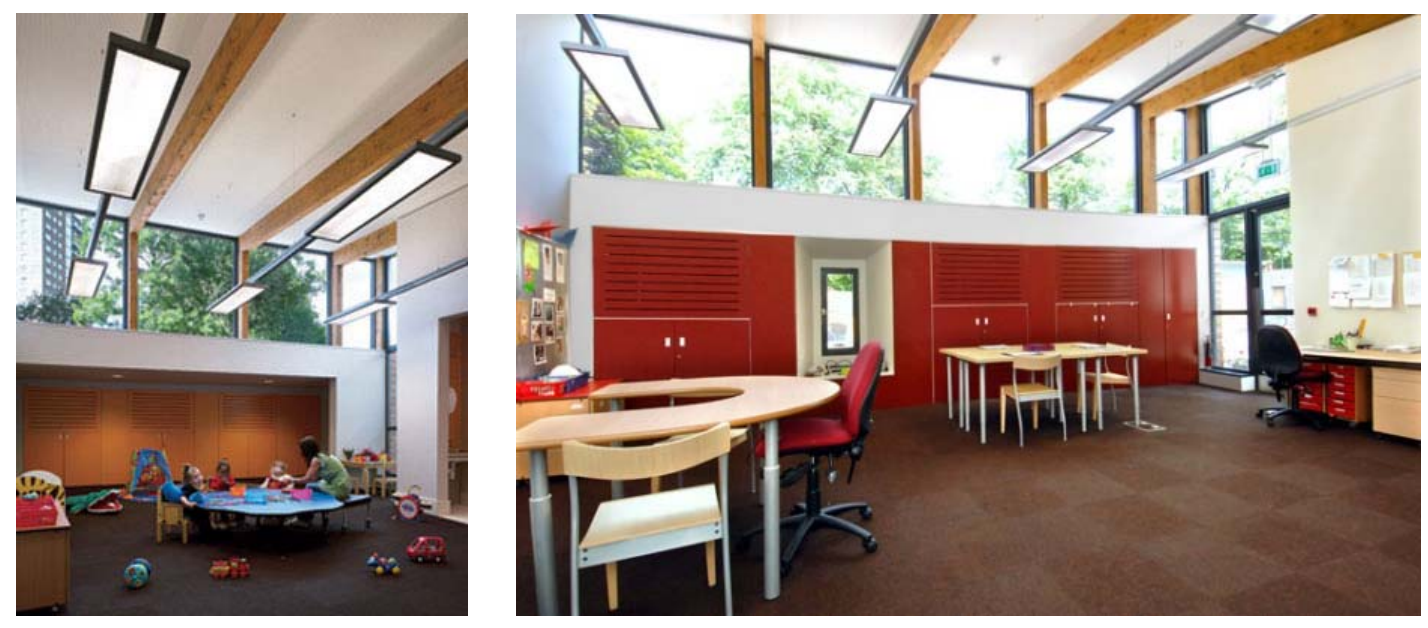

Figure 4.2e - Nursery classrooms use yellow and primary use red storage boxes for colour coding 
Colour is not predominantly used in the building compared to materiality. Within the building, subtle colours provide information as visual indicators in transitional spaces and storage boxes (Hazelwood School, 2009). However, colour coding is used in the classrooms to assist in navigation. Nursery rooms have yellow storage boxes in a matte finish to prevent glare, primary uses red (Figure 4.2e), and secondary classrooms are in maroon (Hazelwood ASN School, n.d, p. 8).

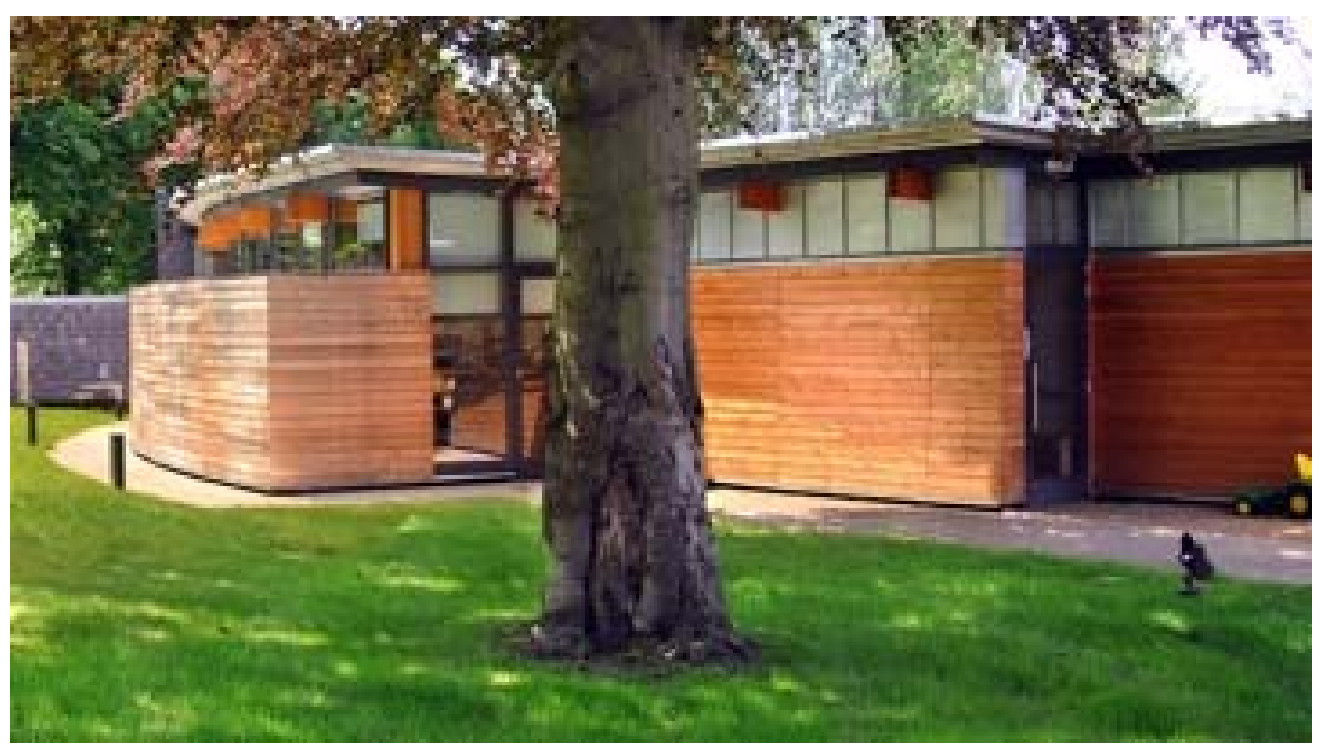

Figure 4.2f - Material selection for external building uses timber and slate

The designers mainly selected natural finishes for wayfinding to complement the park landscape and reflect the roofing material of adjacent houses nearby (Hazelwood ASN School, n.d.). Starting from the exterior, the walls are clad with timber weatherboarding, which is warm in colour, smells nice, and is beautiful to touch creating a non-institutional feeling (Sokol, n.d.). It contrasts in colour with a hard surface of slate (Figure 4.2f) and benefits the building by absorbing solar energy and lowering interior temperature for classrooms (Hazelwood ASN School, n.d.). Once inside the building, the materials are highly textured as people depend on touch for orientation. The floors are made of a matte grey surface which are high in contrast from 
the walls and do not create glare. In the street or the main circulation route, a sensory wall replaces handrails using a folded cork plane on the north wall reducing traffic noise (Figure 4.2b), provides a warm tactile quality, and directs flow of movement (Sokol, n.d). The south wall is fully glazed, which faces the park and the busy road beyond (Hazelwood ASN School, n.d.). This represents typical conditions of how people experience buildings in their everyday life outside the school. Furthermore, the ceiling is simply finished with white drywall to reflect light with European whitewood glulam timber frame to complement with the outdoors (Hazelwood ASN School, n.d.). The window frames are made of Finnish redwood providing cues for locating windows to open them independently when needed (Hazelwood ASN School, n.d.). 


\subsection{FONTYS SPORTS COLLEGE}

Location: Eindhoven, Netherlands

Type: $\quad$ Sports Complex/Educational

Size: $\quad 16,500$ square meters

Date: $\quad$ Designed in 2009-2010, completed in 2012

Designer: Mecanoo Architects

Fontys Sports College represents the final design strategy of secure architecture for social interaction. The complex is multi-functional integrating sports and education all under one roof. It includes five sporting halls, indoor rock climbing, restaurant, library, educational facilities, and a parking garage (Fontys School of Sport Studies, n.d). Since completion, this building has become the new meeting place within campus.
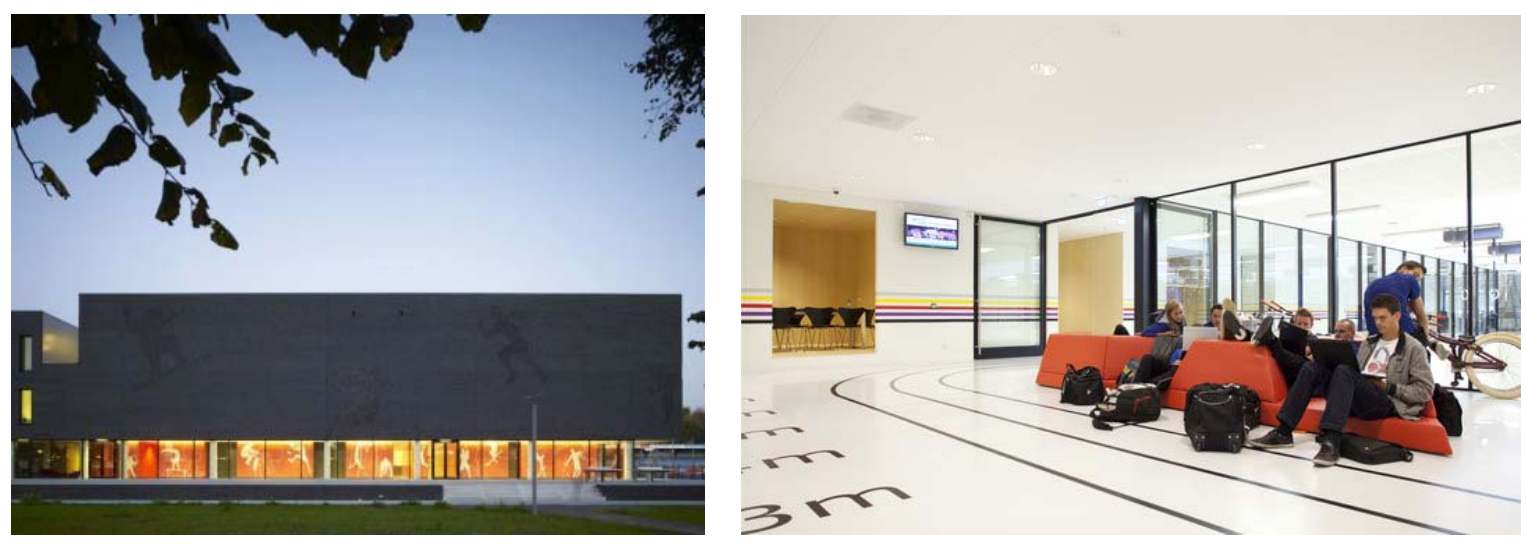

Figure 4.3a - Open ground floor and visual connections between various spaces to the sports hall

Design Features: For this building, it is important to maintain visual connection between indoor-outdoor spaces as transparency provides information for people creating awareness. Currently, all the sports programs are located on the ground floor for easy access for visitors (Fontys School of Sport Studies, n.d). These sports and educational programs are technically separated functionally. They are closed off during sporting events and for security reasons during 
off-school hours (Fontys School of Sport Studies, n.d). However, all sports programs are completely open to immediate spaces with glass for viewing the action (Figure 4.3a). This provides opportunities for cross-disciplinary interaction between sports and education (Fontys School of Sport Studies, n.d). The visual connection encourages interaction between the sports halls, corridors, study areas, restaurant, and the entrance halls (Fontys Sports College, n.d.). According to Van Der Wal, the project architect, the intention is to construct a social building with the ground floor that is completely transparent (Figure 4.3a) creating dynamic spaces and enhancing security for the park in the evening (Fontys Sports College / Mecanoo, 2012). Essentially, visitors and students can see sports everywhere, regardless of where one is located within the building. Finally, the indoor rock climbing gym is the highest point within the complex (Fontys Sports College, n.d.). It has a large glass window where people from outside can see the climbers from afar (Fontys Sports College Eindhoven Scores with Bolidt, n.d.).
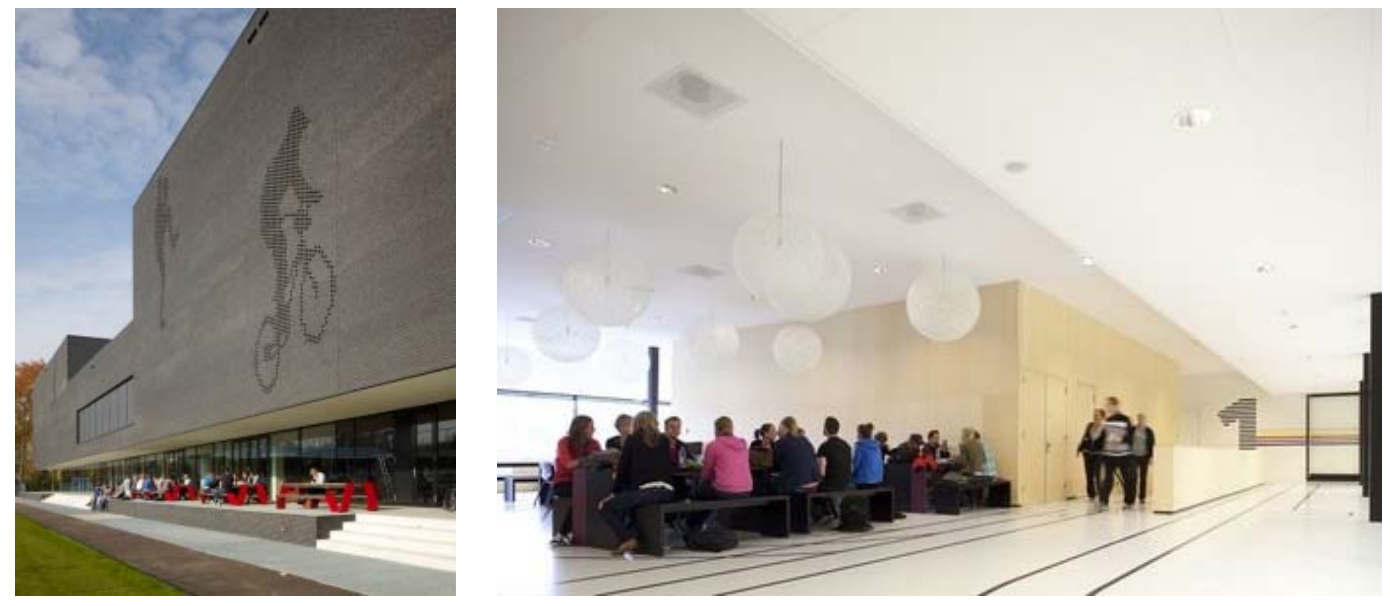

Figure 4.3b - Interactive spaces in the exterior and interior along circulation routes

Furthermore within Fontys Sports College, circulation spaces are integrated as social places which look into adjacent spaces of the sports halls. Circulation no longer acts as functional spaces. It also encourages social interaction creating dynamic and engaging spaces. 
For instance, the building form is compact in design. However, the architect has left room around the building to expand its spaces. On the ground floor before people enter the building, a space has been provided which act as a stage for the building, inviting athletes and social encounters to occur outdoors (Fontys School of Sport Studies, n.d) (Figure 4.3b). This, along with the purpose of the building for playing sports, encourage building friendships and creating social interactions within a building (Fontys Sports College / Mecanoo, 2012). 


\subsection{DESIGN PROPOSAL}

Residential homes provide places to see and because of their private condition, they offer less places to be seen. In order to be exposed in public, the built environment must be enabling. For this thesis project regarding ID, it is ideal to design a community centre which explores three design interventions discussed earlier. A community centre is selected because it represents a community for social gathering, social support, and holds other important public functions. Furthermore, the director of ID Research Centre states,

all [community centres] can anticipate welcoming "the world's largest minority." Unlike other minority groupings you might find yourself in, persons with disabilities are far more diverse than the majority. ...the steps you take to welcome and include visitors with disabilities make the experience better for everyone (Treviranus, 2012).

For these reasons, a community centre is important to explore for this thesis representing diverse people within a community. Designing a fully inclusive building promotes equal access and usability by various groups of people, regardless of age and abilities. This benefits diverse needs of the population including children, family, PWD, and seniors by creating accessible equipments, programs, and policies for all. 


\subsection{SITE}

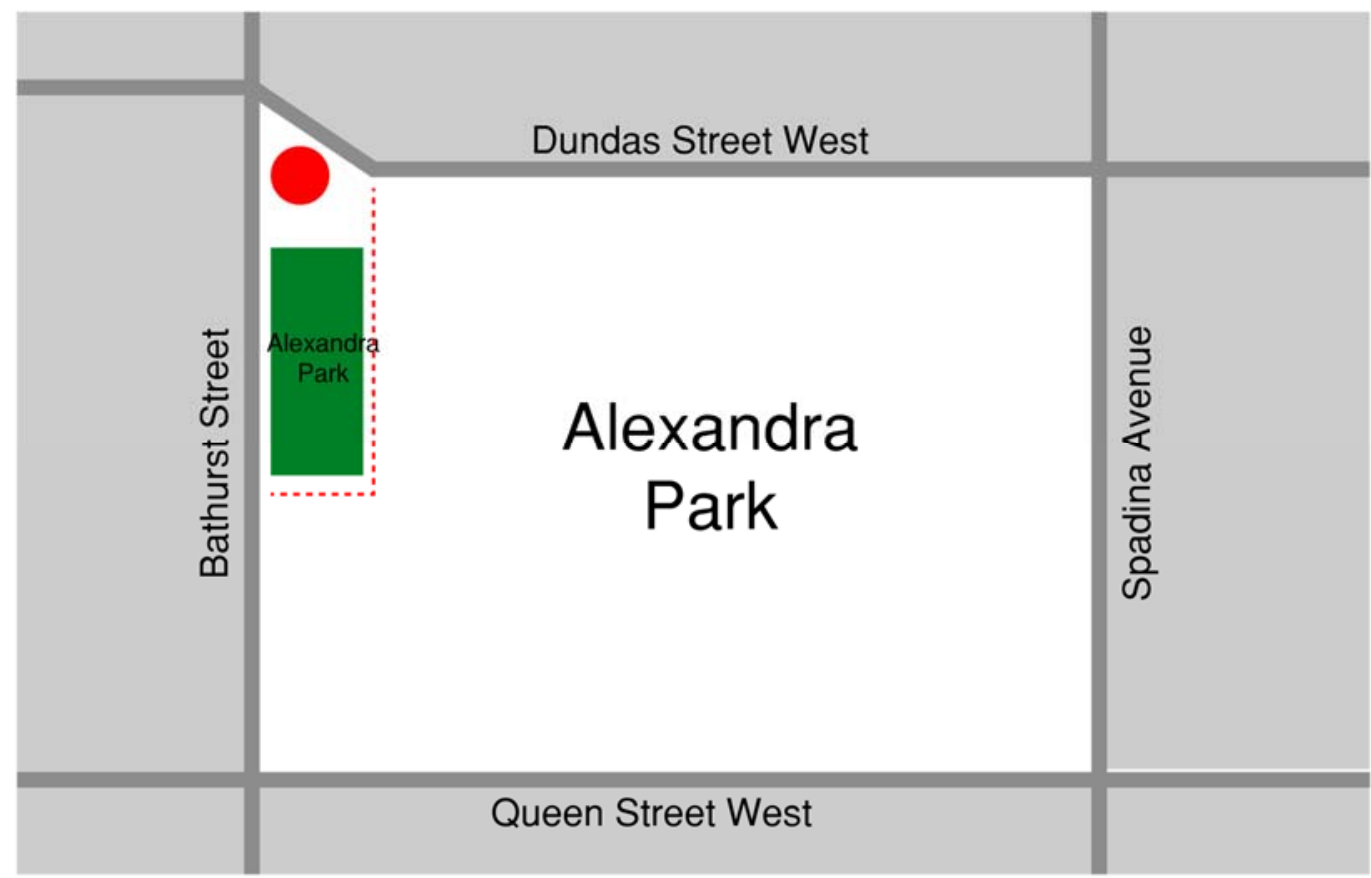

Figure 5.1a - Community centre in Alexandra Park neighbourhood (marked in red)

The site for this community centre will be discussed from a macro, meso, to micro scale.

The focus for this thesis project is Canada because our nation is considered behind in terms of creating a fully inclusive environment compared to New York, United Kingdom, and Japan (Steinfeld, 2012, p. 73). This refers to legislative acts, architecture design, and implementing features into the physical environment. Within Canada, Toronto is selected as it is considered one of the most culturally diverse cities in the world and a walkable city with access to public transportation, supporting people's health and wellness. Within the city, Alexandra Park neighbourhood is chosen. It is a large city block bounded by Dundas Street West on the north, Spadina Avenue on the east, Queen Street West on the south, and Bathurst Street on the west (Figure 5.1a). 


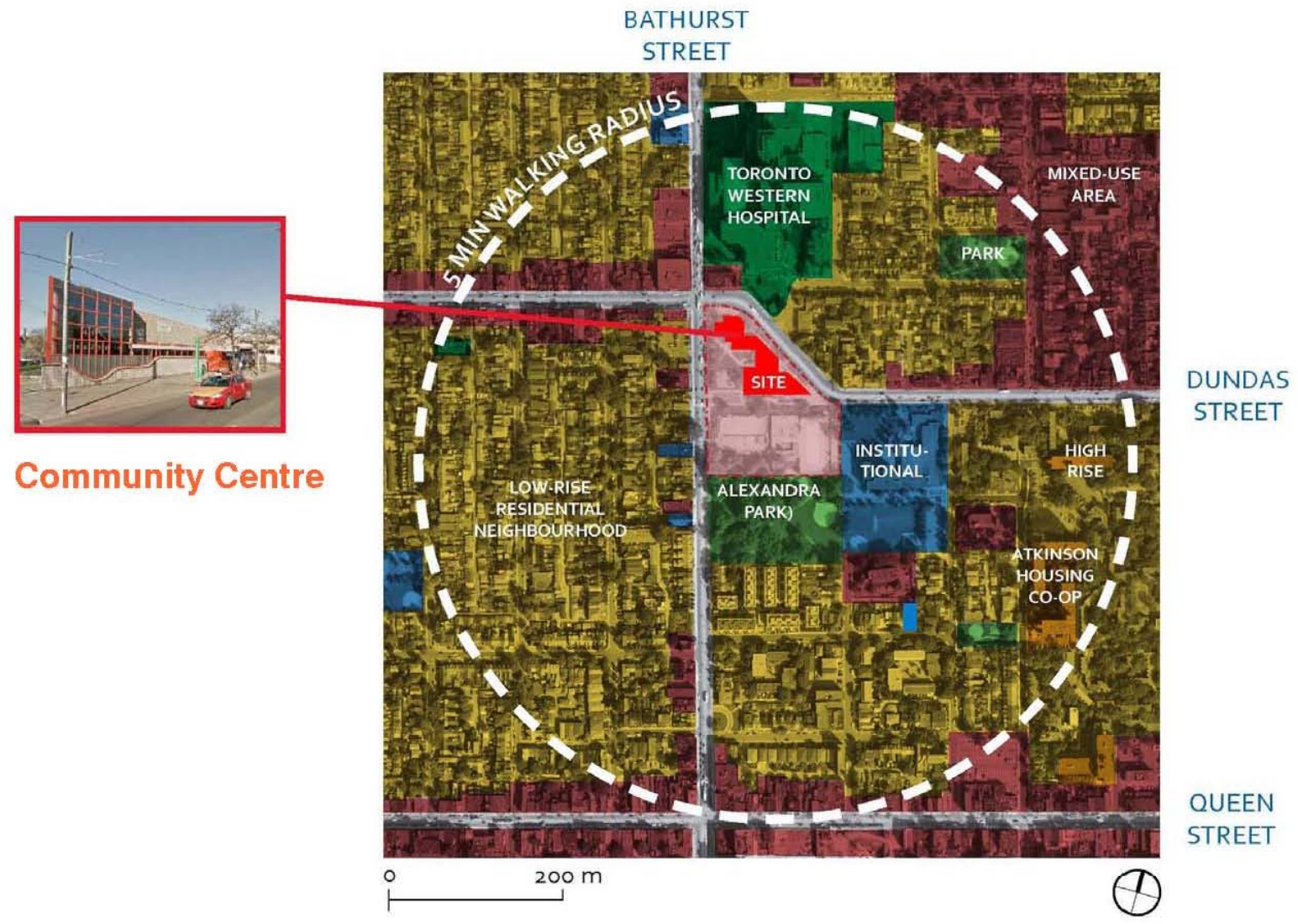

Figure 5.1b - Site selection and neighbourhood

This neighbourhood is currently going through many changes in order to meet the diverse needs of the community including a shift in demographics, the community is aging, condominiums are rising, and the existing Atkinson Co-op Housing is being revitalized (Scadding Court Community Centre, 2014). The neighbourhood contains many benefits such as low residential units with some retail at grade to enhance social interaction, within close proximity to Kensington Market and Chinatown, adjacent to the Toronto Western Hospital, and Alexandra Park (Annual Report, 2010, p. 2) (Figure 5.1b). According to the 2006 Canadian Census, the area mainly consists of low income families with visible minorities including Chinese, African-Canadian, South Asian, and immigrants (Society Profile \#2, 2007; Society Profile \#4, 2007). It is important to understand the demographics of this city block because 
many people are dependent on environmental resources. Thus, many amenities and services must meet diverse needs, such as offering swim times for Muslim women only (Annual Report, 2010, p. 5).

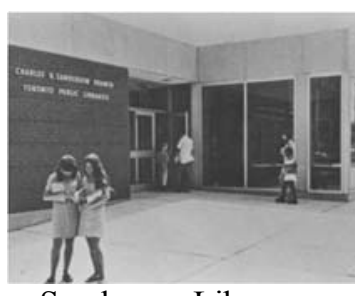

Sanderson Library

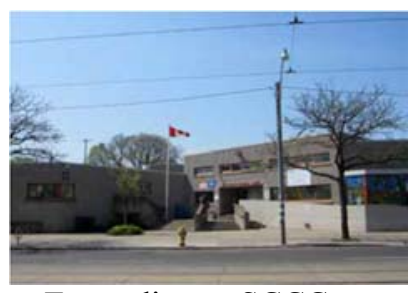

Expanding to SCCC

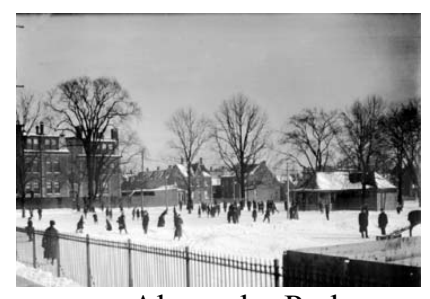

Alexandra Park

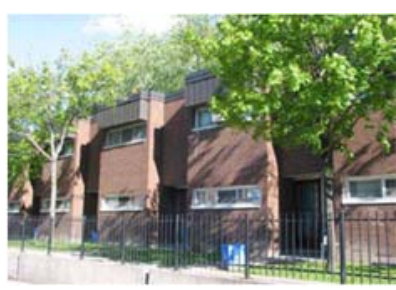

Low residential units

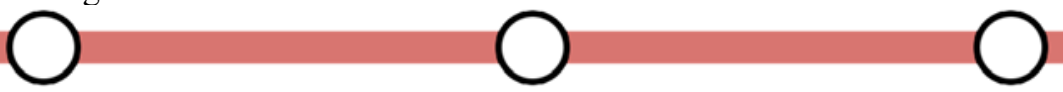

Figure 5.1c - Urban renewal plan for Alexandra Park along Bathurst Street

Most importantly within Alexandra Park is Scadding Court Community Centre (SCCC), which is a destination point for people to engage and interact. A brief introduction about the history and the current use of the building will be discussed to provide an overall understanding (Figure 5.1c). Previously, Casimir Gzowski, a Polish Engineer, purchased a large estate, including today's current site containing the community centre and library, and built a home at the park in 1841 (Cities for People, 2010). Around the late 1960s, the neighbourhood underwent urban renewal (Dundas Street West Final Design Report, 2011, p. 97). As part of the plan, a green space called Alexandra Park was built, along with low rise houses, and a low concrete building to divide the park from the street (p. 97). In 1968, Sanderson Library was built (Myrvold, 1993, p. 14). In 1978, SCCC was built as an expansion to the existing library creating an integrated community facility (p. 14; Our History, n.d.). In 1992, it was temporarily closed to improve barrier-free access within the building (History, 2014). 


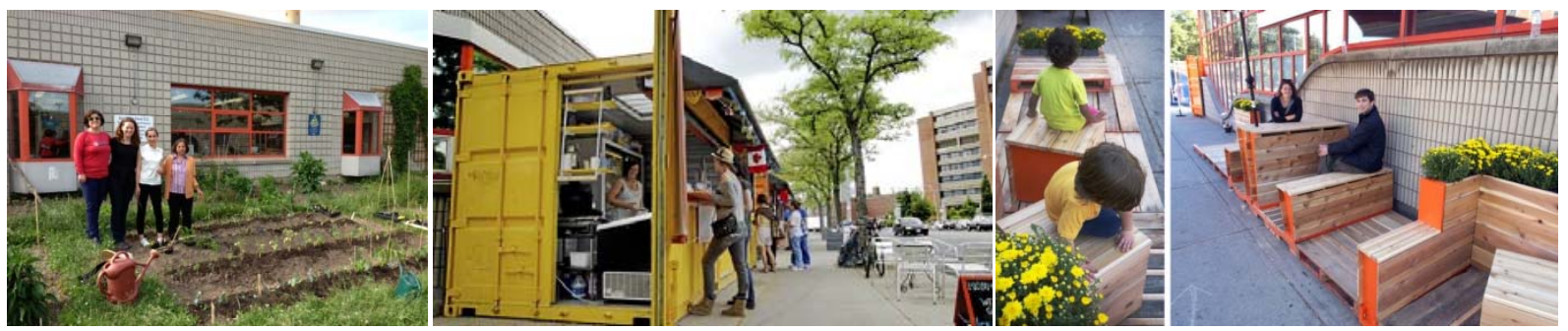

Figure 5.1d - Current condition of urban farming, Market 707, and public patios for seating

Scadding Court Community Centre is located at 707 Dundas Street West and is $5,110 \mathrm{~m} 2$ (55,000 ft2) (Our History, n.d.). The building contains a gymnasium, an indoor pool, change rooms, weight room, community spaces as classrooms and meeting rooms, daycare, offices, and café (Annual Report, 2010, p. 2). It offers a variety of recreational and social services to a wide range of users including barrier-free swim for PWD, children's Saturday club, and is home to Alexandra Park Neighbourhood Learning Centre offering adult literacy programs (Annual Report, 2010, p. 2 \& 4). SCCC is adjacent to Alexandra Park containing an outdoor pool, a wading pool, and an artificial ice rink in the winter, which becomes a skate park in the summer. As of 1997, many people in the community are involved in urban agriculture at SCCC, promoting community development, food security, and social inclusion (Figure 5.1d) (Annual Report, 2010, p. 3). Recently in 2011, Levitt Goodman Architects designed Market 707 to create an outdoor market using shipping containers to encourage more street activities and allow entrepreneurs to start up a businesses at a low cost (LGA, 2014). A design competition was launched to create public patio spaces to enhance the outdoor market (Market 707's New Public Patio, n.d.). Today, there has been many discussions to redevelop and revitalize the site to improve the uses and future potentials of the neighbourhood. Overall, this neighbourhood looks like it is in a bad condition containing eclectic uses, which explains why it needs to be revitalized. Though to everyone, this place is a true representation of a community. 


\subsection{KEY ISSUES}

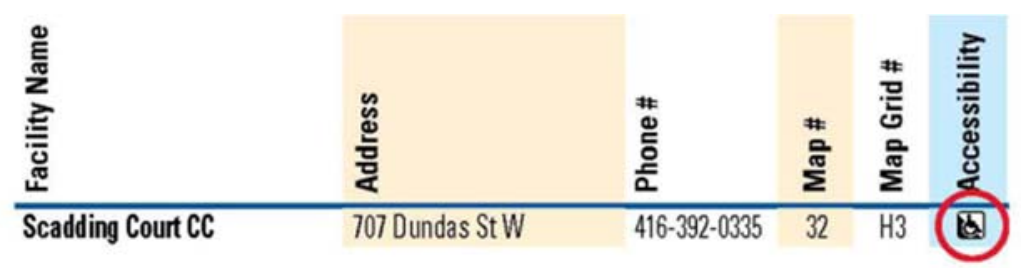

Figure 5.2a - Scadding Court Community Centre is considered a partially accessible building

As of Fall 2013/Winter 2014, there are a total of one inaccessible, 33 partially, and 14 fully accessible community centres within Toronto and East York District (Fun Guide, n.d., p. 10; see Appendix B). According to the list, Scadding Court Community Centre is considered a partially accessible building, even though some accessibility design improvements are done (Figure 5.2a). For this thesis, the goal is to re-design a portion of the building to become fully inclusive. However, before undertaking the design of the community centre, it is important to outline current major key issues with the building.
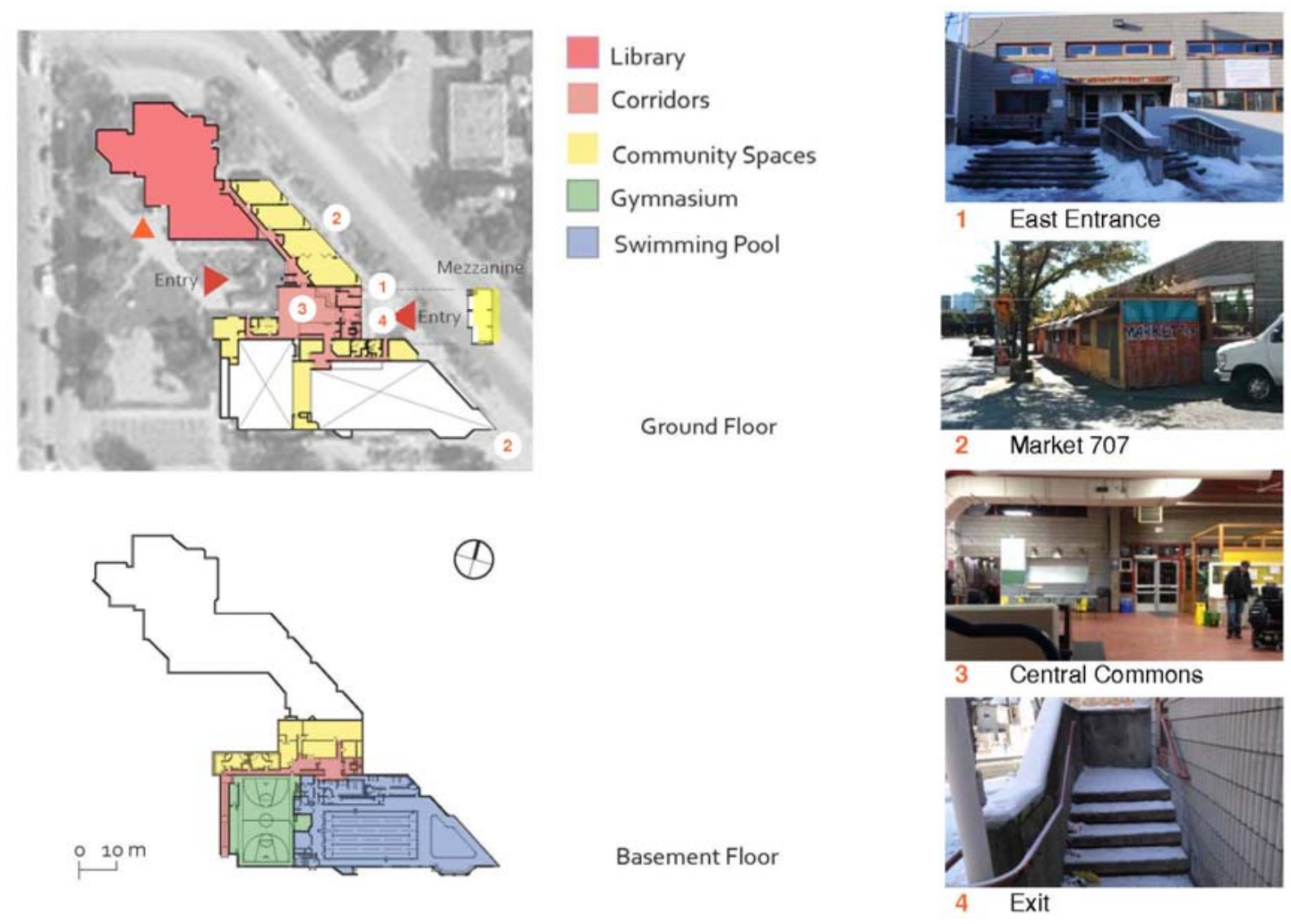

Figure 5.2b - Key issues with SCCC 
They are:

1) It is understandable that SCCC is only meeting minimum accessibility standards. However, as mentioned earlier, what is accessible is not always inclusive. Creating a ramp adjacent to a major set of stairs at the front entrance is equitable but not equal. This is an in inclusive issue, affecting people's rights and dignity (Figure 5.2b).

2) Market 707 is designed to encourage social engagement at street level only. There is a total disconnection between the container market and the community centre. They are positioned right up against the building blocking views from the windows. The community centre currently only attracts residents and not external visitors because of the context of Market 707 (Figure $5.2 b)$.

In addition, the building is designed by Casey and Dunker Architects in 1978 (History, 2014). At that time, the architects' vision is to create an enclosed community centre to resolve issues of crime, violence, and drug use in the area. This is what the shipping containers are doing to SCCC as well. Enclosing the building furthermore is not practical and explains why many people today still criticize about the difficulty of finding particular rooms within the building (Cities for People, 2010) (Figure 5.2b).

3) The central commons or atrium space is unpleasant in all ways. Once inside this space, there is no sense of orientation whatsoever in terms of which direction leads people to the library and swimming pool. The extended views also do not lead people to important destination points. All materials and colours are very similar, making them difficult to distinguish. The flooring 
creates glare, which is not appropriate for seniors and people with visual impairments (Figure $5.2 b)$.

4) Within a multi-storey building, exit stairs create barriers for PWD because not everyone can walk down the stairs to safety. In the case of SCCC, which is one storey high, the means of egress contains stairs as well creating barriers. It is meeting AD standards but is not fully inclusive (Figure 5.2b).

5) Currently, the main entrance to SCCC are unidentifiable as the building is complex in design. It is accessible on the east and west ends of the site. However, Sanderson Library has a separate entrance and is easy to reach from the community centre (Figure $5.2 \mathrm{~b}$ orange arrows).

6) All major functions within the community centre, including library, community rooms, swimming pool, and gym are on different floor elevations. Within one floor, there is a $450 \mathrm{~mm}$ difference in height with stairs and ramp to access different parts of the building. This change in elevation is related to the existing topography of the site with a higher elevation on the north and a lower elevation on the south. The travel distance between these major functions are far, making them inconvenient to reach (Figure 5.2c).

There are other issues with the building, however these address major concerns within the scope of the design. 


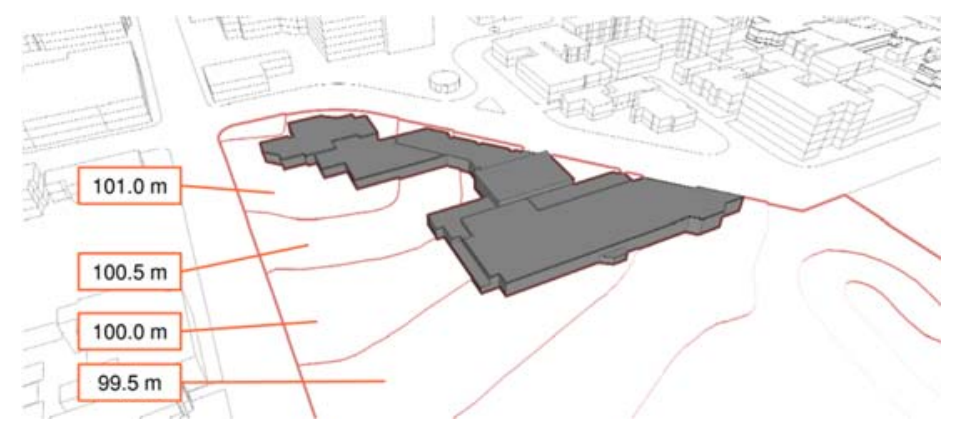

1. Existing Topography

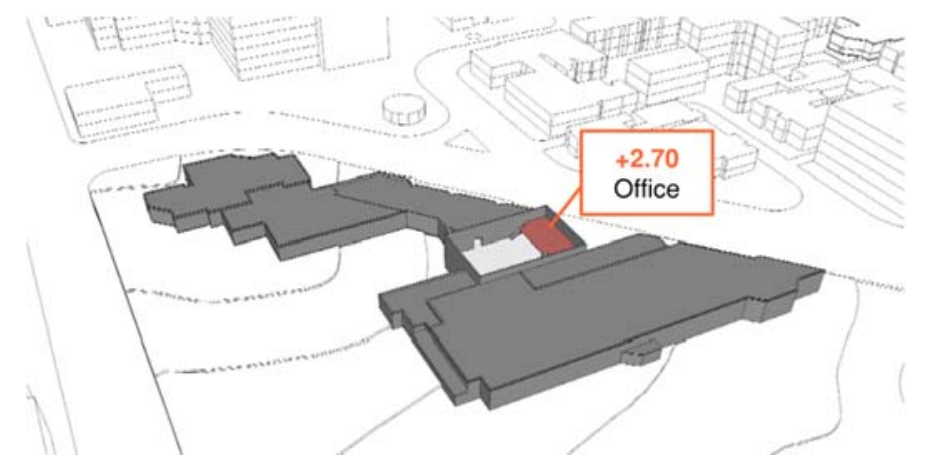

2a. Mezzanine A.F.F.

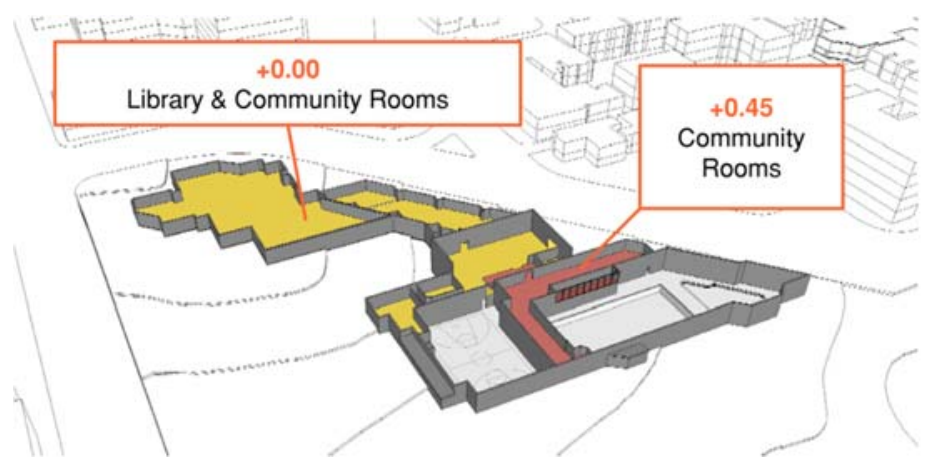

2b. Ground Floor A.F.F.

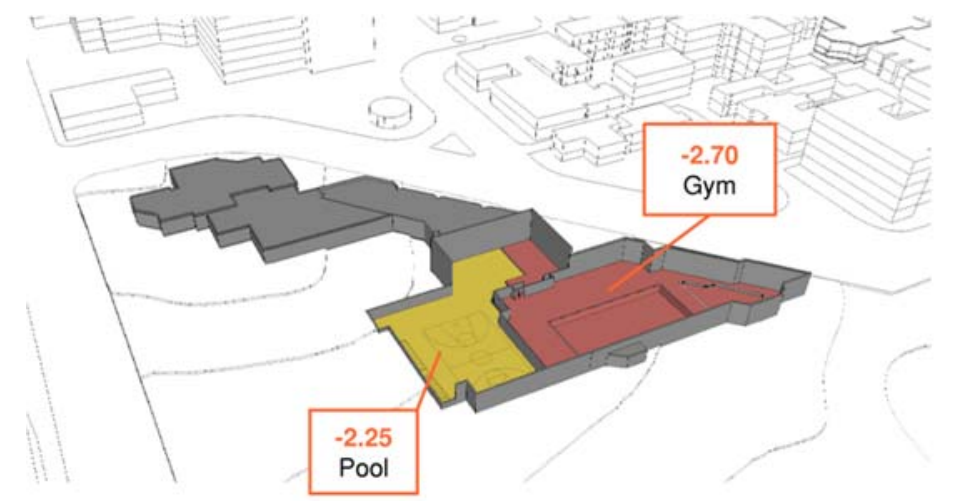

2c. Basement A.F.F.

Figure 5.2c - Existing site conditions to consider 


\subsection{SCOPE OF THE DESIGN}

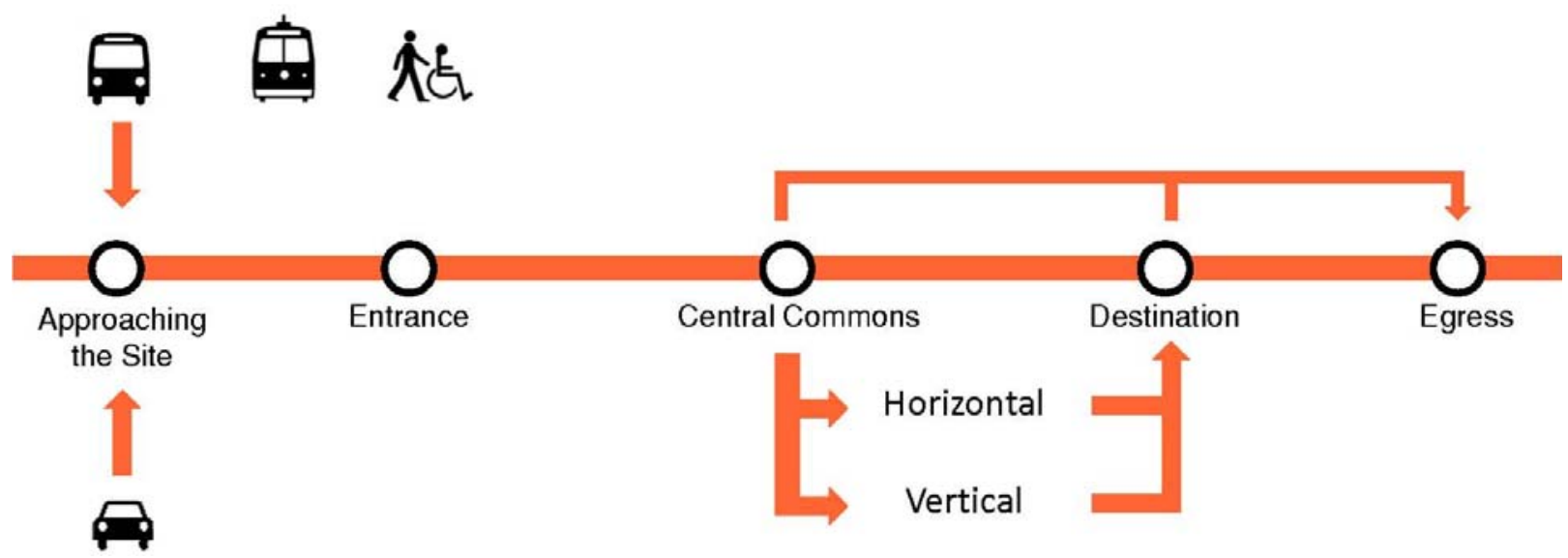

Figure 5.3a - Scope of work from approach, entrance, central commons, destination point, to egress

For this thesis, the scope of the design focuses on how people approach the site, either by taking public transportation or walking from the north-west intersection of Dundas and Bathurst, or by car from the parking lot on the sound. Once people have approached the site, they need to legibly find the entrance to the building, enter the central commons space directing people and transitioning to their destinations points horizontally or vertically, and finally to the means of egress for cases of emergency (Figure 5.3a). The intent is not to design the entire building because once people can easily approach and enter the building independently, the rest just follows if it is designed inclusively. 


\subsection{DESIGN CONCEPT}

Redeveloping the community centre involves many people within the design process creating an accessible building used by all. In doing so, it is essential to address existing and emerging needs in order to design for the future. Based on the diverse culture and history of Alexandra Park, there is a need to break down barriers while preserving the identity of the neighbourhood. The building's identity will also be preserved since everyone uses various programs and services there. The plan is to re-design public spaces within SCCC by supporting existing recreational and educational programs enhancing community life through inclusive social interaction, and creating a venue for neighboring communities for engagement.

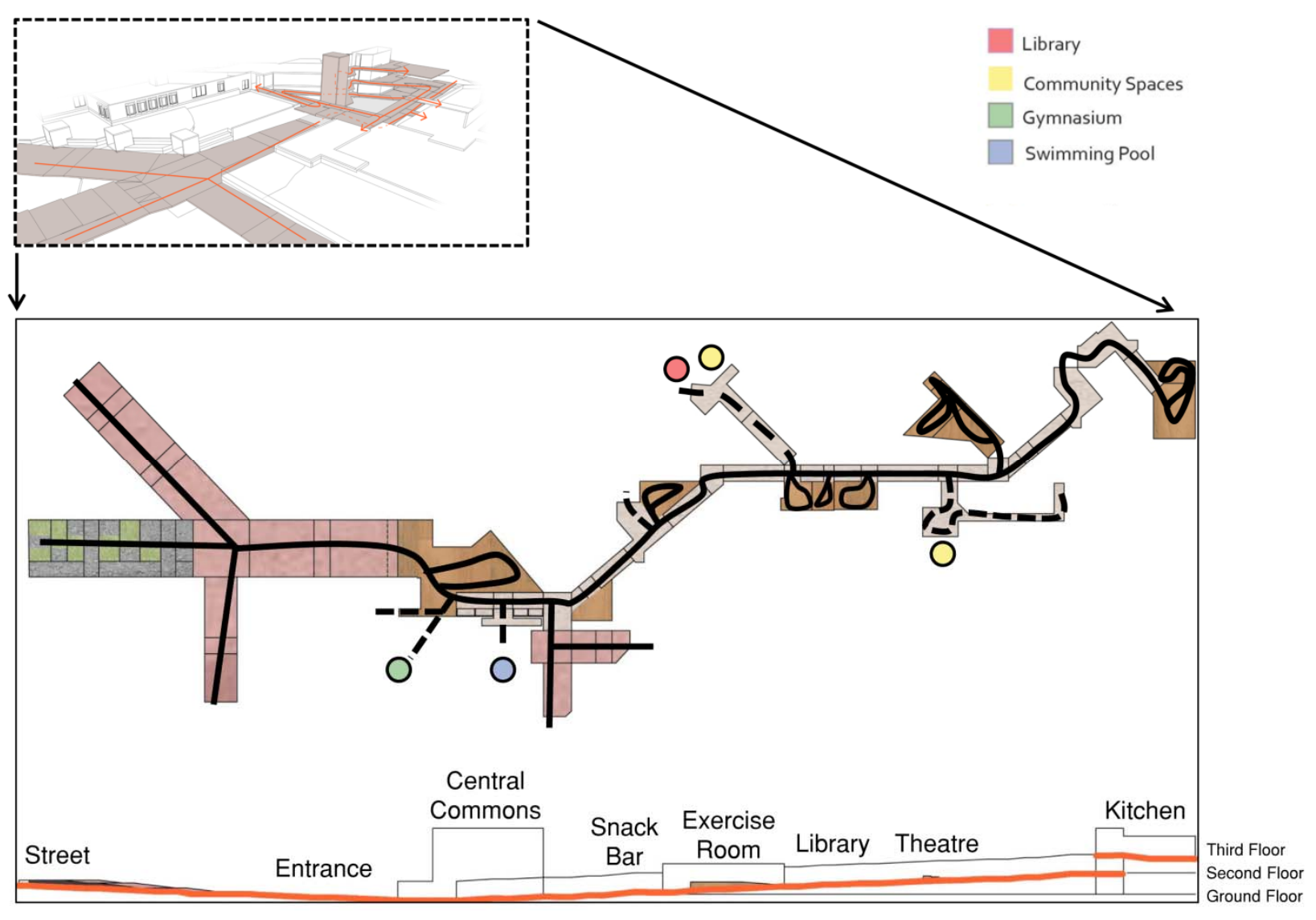

Figure 5.4a - Design concept involves a spiral ramp that extends outwards 
Scadding Court Community Centre will be fully inclusive. The contemporary design intervention will improve the heart of the neighbourhood by renovating the public plaza, front entrance, central commons, and means of egress to enhance visitors' experiences. The separate entrance to Sanderson Library will be removed and accessible from the community centre, making central commons a more dominant space for all users. Accessibility will be experienced by designing spaces along a ramp, which is used as both circulation and functional purposes. It connects people horizontally and vertically to enhance different spatial experiences when the building unfolds (Figure 5.4a). It is at 1:20 or 5\% running slope, which is a comfortable slope (Standards Development Committee, 2010, p. 41). By designing spaces arranged along a ramp enables everyone. Internally, there is a spiraling ramp with break-out spaces connecting various existing programs within the building. This language extends outwards to the site or public plaza. The extension fans or radiates outwards, creating a welcoming gesture for both residents and visitors alike. The public plaza acts as an informal gathering space, which eventually leads people to the main entrance of the building.
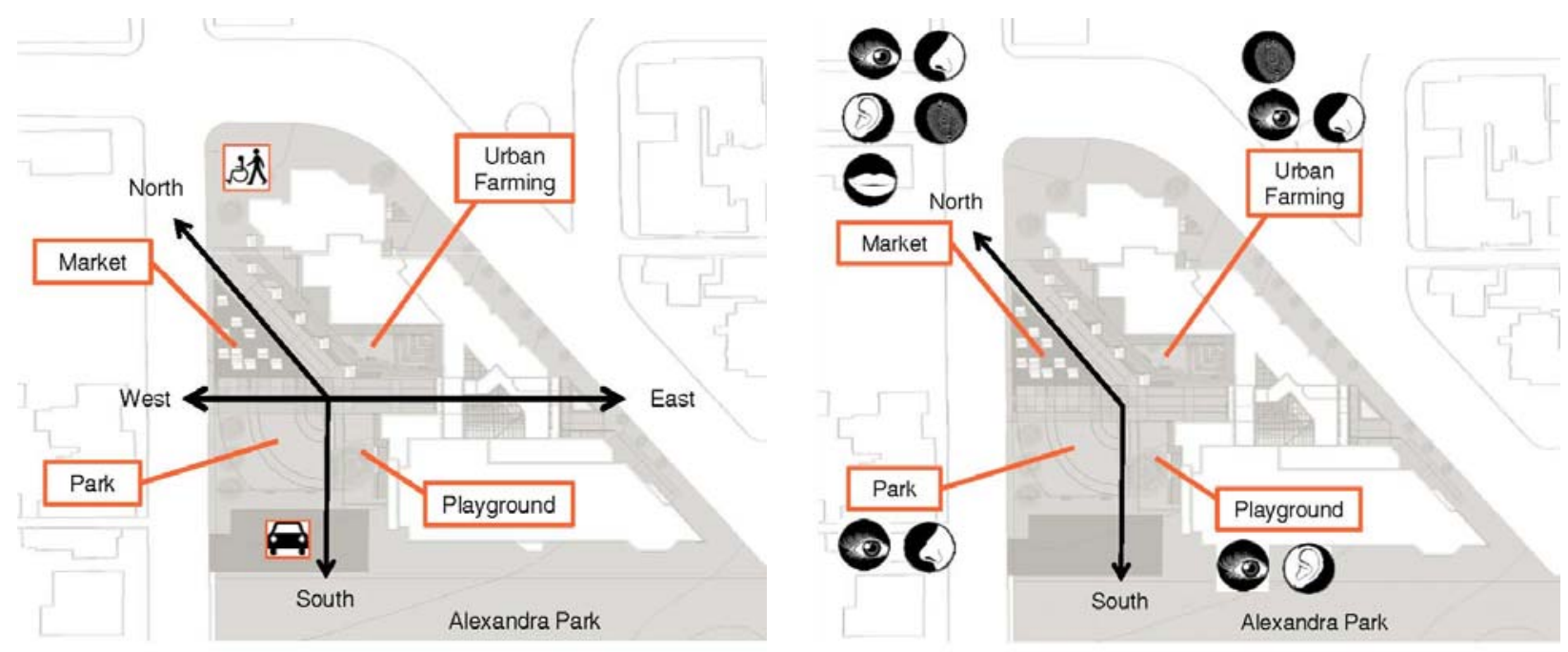

Figure 5.4b - Cartesian orientation to access the public plaza 
The public plaza re-uses shipping containers from Market 707 , which is originally disconnected from the building. By placing the market along the path of travel towards SCCC creates social engagement between various people. The path of travel is organized in four major cardinal points of the compass by relating to the existing context of the site (Figure 5.4b). This technique improves memory and is used as orientation for various groups of people (Universal Design New York, 2001, p. 47). It assists people to independently enter and leave the site, in order to reach public transportation at the intersection on the northwest or parking lot on the south. Along these major circulation paths are four quadrants with various functions to maximize views within the public plaza. They include a market square on the northwest, which is within close proximity to the street for easy access and acts as a gateway, urban farming on the northeast corner adjacent to the market, which acts as a semi-private space, playground on the southeast adjacent to daycare centre, and a recreational park on the southwest. All of these functions create opportunities for social engagement with proper amenities for seating and interacting, uses various senses to stimulate their minds for wayfinding, and depending on which route people take, the overall experience is different. People arriving to the site from the intersection experience more congestion and noise, whereas on the south of the community centre is Alexandra Park, which is more green and quiet.

Along the west Cartesian direction is a secondary path leading people to the street to extend the linear movement from central commons. This path introduces a different flooring material to represent an informal path of travel and acts as amphitheatre seating to observe the stage, which is all the interactions happening within the public plaza and people's movements converging to the main entrance of the building. There is an open space located before the main entrance for street performances and a water feature creating a multi-sensory experience. In order to draw people from the public plaza to the main entrance, the sound and movement of the water 
feature directs people to converge towards the centre, and the repeated water element inside the central commons space guides people to walk towards the entrance. Overall, the new public plaza is safer and more attractive for everyone to use.
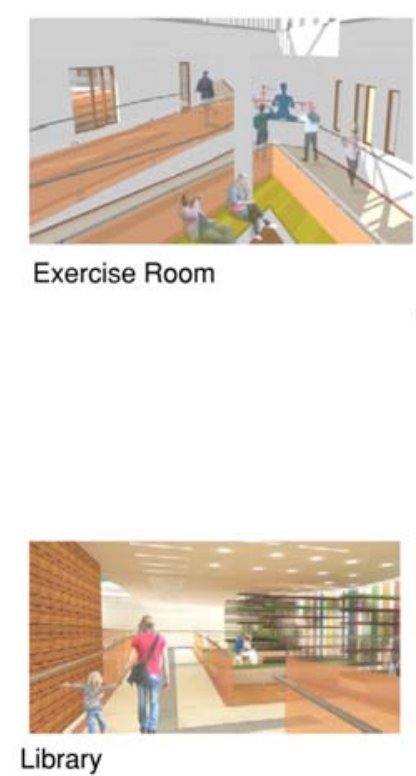

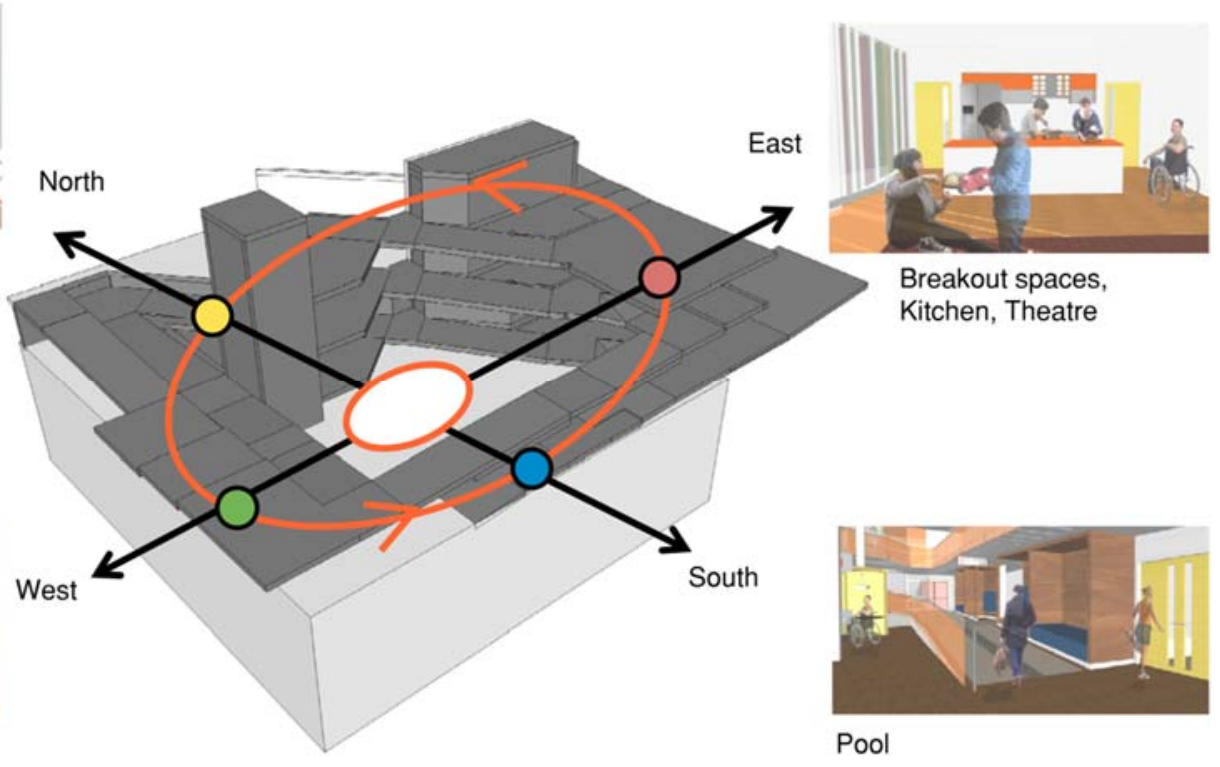

Figure 5.4c - Interior concept creating break-out spaces while connecting different programs and services

As people traverse inside the building, the spiraling circulation creates a triangular shaped movement to reach different destination points. These destination points are essentially break-out spaces for various functions within the building (Figure 5.4c). They are each given its own identity creating landmarks. This helps people to orient themselves when they are always in relation to the central commons space (Steinfeld, 2012, p. 208). The centrally-located open space contains an information desk and an informal gathering space, which is a focal point within SCCC. Furthermore, there are outdoor elements which are brought indoors creating a sense of connection to enhance spatial experiences.

Since SCCC is an existing building that is important for the neighbourhood, it is essential to preserve it while adding contemporary designs to a designated landmark. In doing so, it 
celebrates the historical and cultural significance of the community. Majority of the existing building with the white concrete facade will be preserved and locations of internal functions will be maintained. In addition, a new modern glass central commons space will break the enclosed expression of the existing building by creating a more open and welcoming entrance for everyone. This makes it easier for people to find particular rooms within the building by exposing internal circulation, creating situational awareness of the surrounding. The central commons space creates a highpoint within SCCC, making the building easier to identify from afar and represents an important landmark within a low-rise neighbourhood.

Finally, the means of egress can safely be used by everyone during cases of emergency through sound, light, and touch, regardless of age and abilities. Emergency exit signs and fire alarm direct people to safety during evacuation. Once people traverse the exit stairs, areas of refuge are provided for people with physical disabilities. Photo-luminescent tape are used along handrails and stair nosings, directing people to safety by touch and sight. 


\subsection{STRATEGIES IMPLEMENTING THREE DESIGN INTERVENTIONS}

The design concept integrates three interventions in order to create an inclusive environment that can be accessible and used by all. As mentioned earlier, they are accessible architecture as communication, responsive and adaptable architecture through multi-sensory experiences, and secure architecture for social interaction. Each of these elements will be explained in relation to the proposed design for SCCC within the public plaza, renovated central commons, and means of egress.

\subsubsection{ACCESSIBLE ARCHITECTURE AS COMMUNICATION}

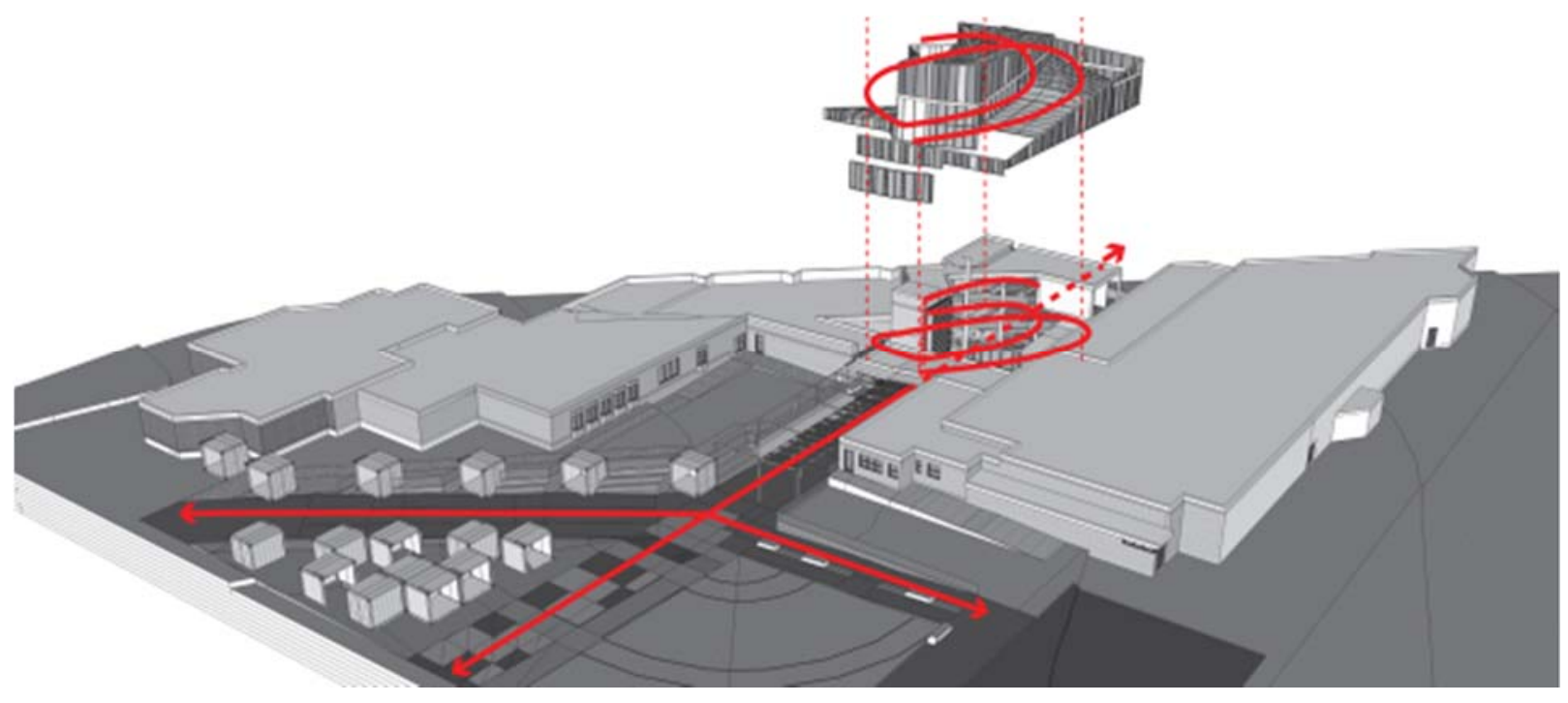

Figure 5.5.1a - Form follows function for SCCC

The function of a community centre is represented through various forms. It provides safety and usability for diverse users by enhancing their situational awareness. Firstly, within an enclosed white concrete facade building, the transparent glass opens up the building within the central commons (Figure 5.5.1a). This creates a more welcoming experience for people using various services and programs within the building. This is expressed through extruded boxes framing internal activities of people sitting down, interacting, and traversing the ramp connecting 
from one space to the next. In addition, the colourful glass on the facade represents diversity where cultural differences come together. They create a spiraling movement reaching up towards the sky, demonstrating people's objective to traverse vertically, which echoes the internal movement within the building, and splits downward towards the edges of the public plaza in different directions.
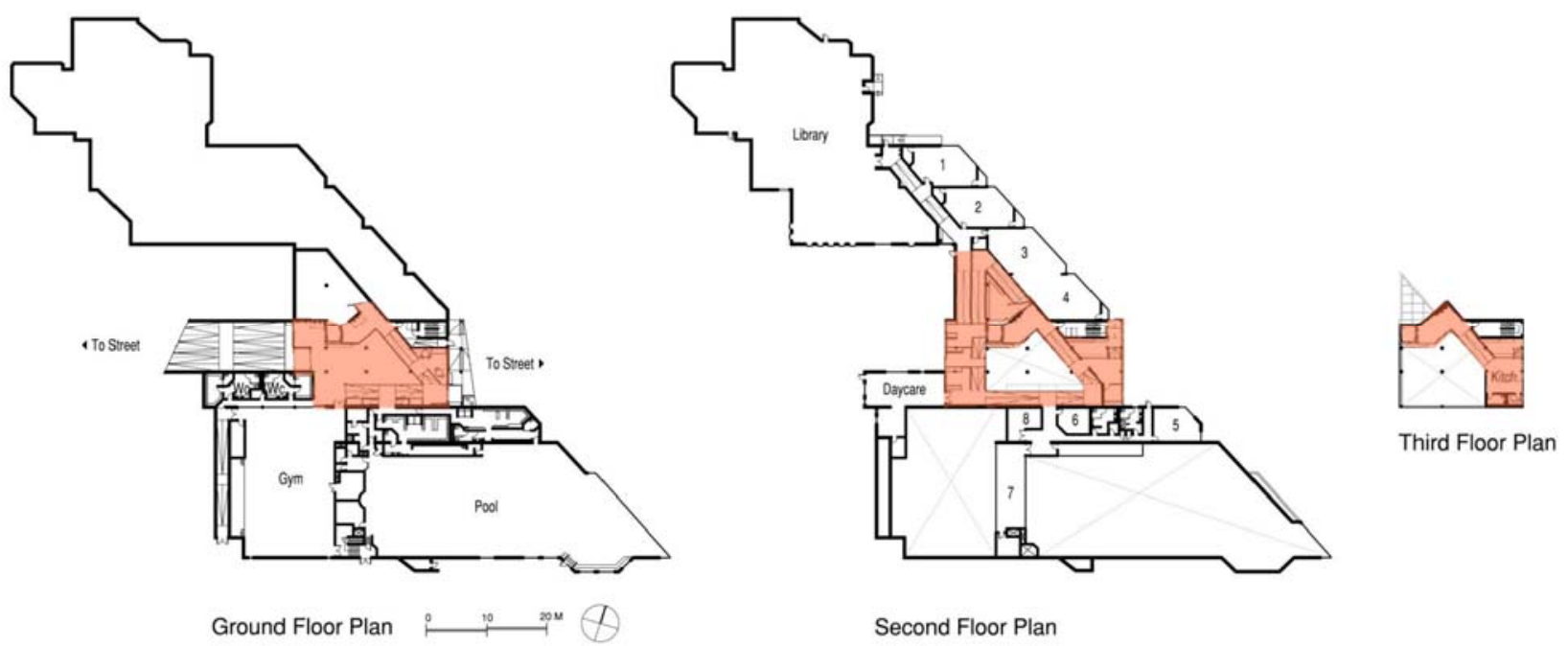

Figure 5.5.1b - Communicating accessibility through visual experience

People's route is like a journey that involves spatial experiences of accessibility the moment they approach the site. A continuous ramp connects and moves people from the public plaza to the entrance, central commons, destination points, and down towards means of egress (Figure 5.5.1b). The main circulation path is used as a focal point within the design concept celebrating an inclusive environment that can be used by all. When traversing the site, people experience an energetic and dynamic open space full of people and activities. Many features within the public plaza stimulates their mind, creating interest and engagement with their surroundings. As they continue traversing the building, they are guided into a room filled with natural daylight and openness. The ceilings are high and their eyes wander from their height up 
to the ceiling. Through spatial awareness, they realize these spaces are all connected through an internal ramp, which takes people from one floor to the next. They search for cues and see a stacked ramp surrounding the open space. They feel a sense of confidence since everyone can independently move horizontally and vertically within the building. The interior is warm and inviting using natural materials. As they walk up the ramp, the fluorescent light tubes on the ceiling further guide people to the upper floors and the ceilings are low, creating a sense of intimacy and comfort.

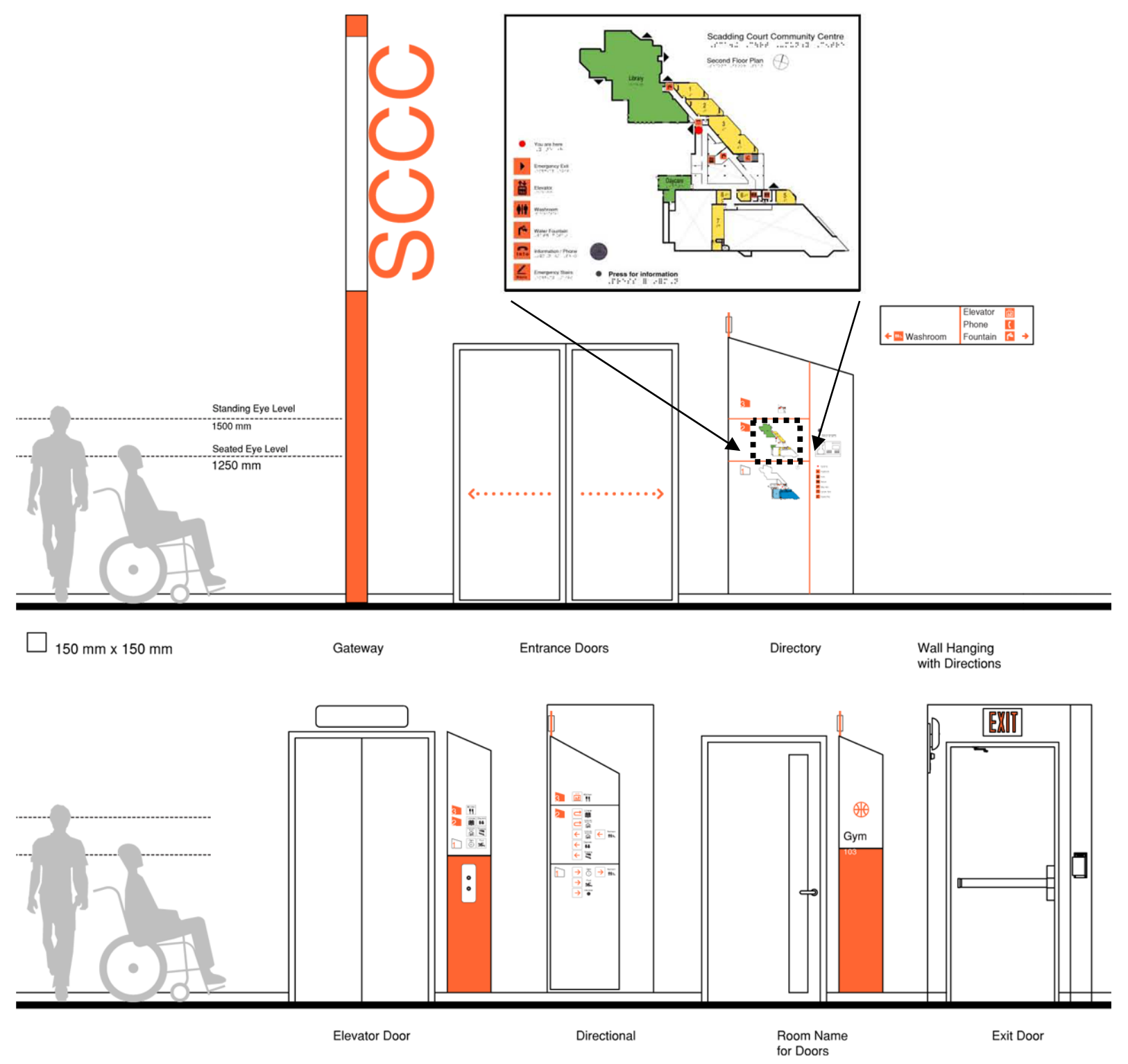

Figure 5.5.1c - Signage system within SCCC 
While traversing the building, various wayfinding techniques are provided in order to benefit everyone with different abilities. Visual cues within the public plaza using landmarks, such as sound and movement from the water fountain provide a sense of orientation for people. The flooring material further directs them to their designated location. Within the central commons, a main feature containing the living wall integrated with a water feature creates a point of reference when experiencing the building. The interior space is further supported by a signage system with directories showing a map of the building, directional signs on walls and ceilings, and room names on doors (Figure 5.5.1c). Colour coding reinforces pathways to their destination points by coordinating colour with the function of the space, such as blue for the swimming pool. Directories do not only provide visual communication, they also accommodate people with hearing loss integrating information with Braille tactile signs and audio for people with vision loss. Thus, this allows diverse people to find their way around the building independently as some people read, hear, use light, colour, and/or touch for orientation. 


\subsubsection{RESPONSIVE AND ADAPTABLE ARCHITECTURE THROUGH MULTI- SENSORY EXPERIENCE}

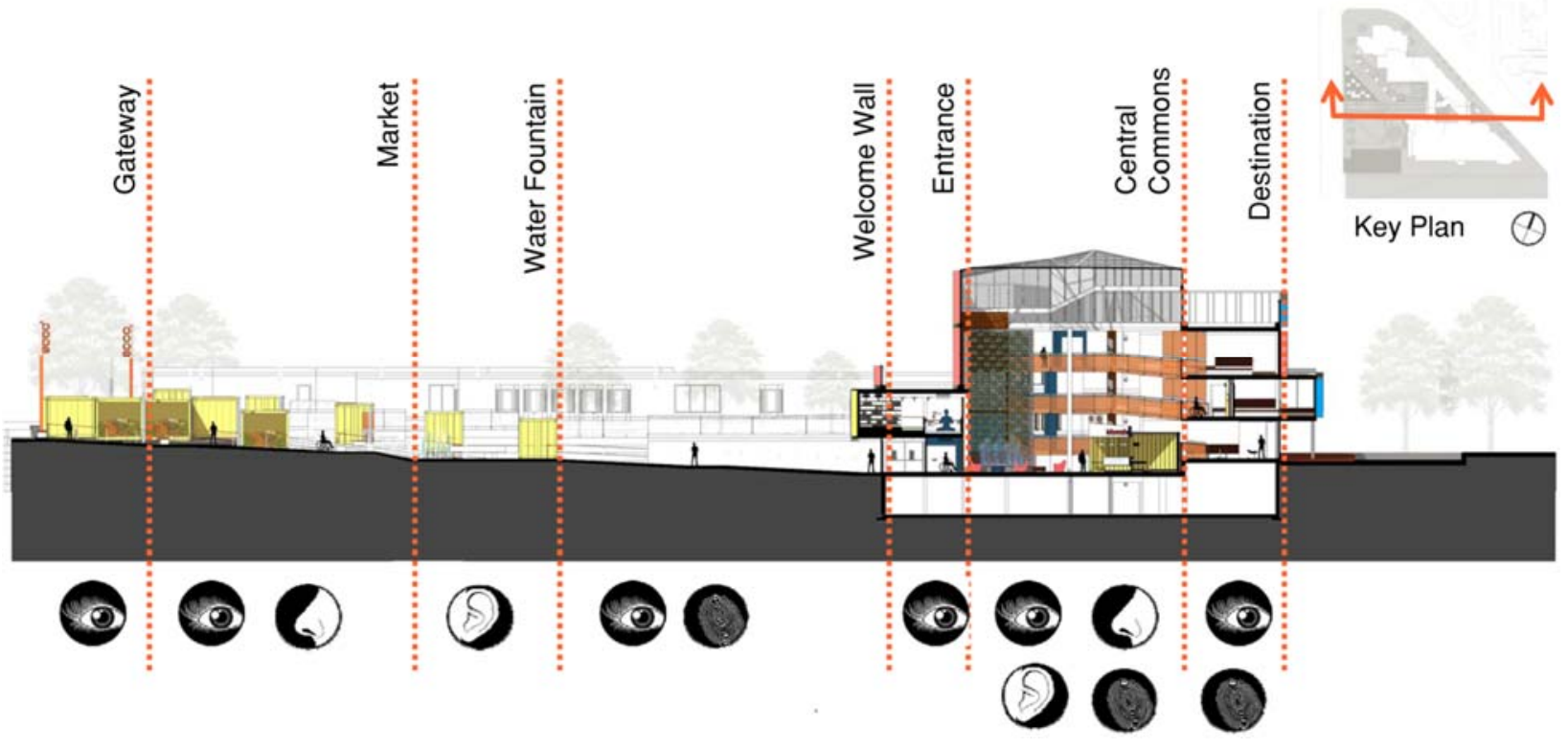

Figure 5.5.2a - Multi-sensory experience to access public plaza

Scadding Court Community Centre is not only perceived through vision. People with differing abilities depend on other senses to receive information about their surroundings creating situational awareness. Depending on the direction of arrival to the site, the multi-sensory experience is different creating identities within the public plaza to help people orient themselves easily (Steinfeld, 2012, p. 43). People approaching by foot from the northwest intersection of Dundas and Bathurst are guided by the interactions and diverse smell of food from Market 707 on one side and the smell of various plants and vegetables from urban farming on the other side. They are further directed towards a water fountain in the centre creating movement and sound to animate the public plaza (Figure 5.5.2a). On the other hand, people approaching from the parking lot on the south to the site encounter a luscious green environment with sounds of children playing in the playground on one end and people doing yoga on the recreational field. The path leading to the entrance are guided by tactile flooring and hand railing. The flooring is wide 
enough to suggest a sense of welcoming in a bold red colour to draw their attention. When people entering on the north and south meet at the water fountain to the main entrance, they are guided by a welcome wall that is interactive through touch, changing the colour of the facade based on the heat of their hands (Figure 5.5.2e). (This promotes social interaction amongst different people.) As they enter the central commons space, a different flooring pattern is used with tactile flooring to guide them. The sound of water from the fountain creates a focal point within the space along with the smell of fresh plants. If they want to speak to someone about the building, they can locate the bold information desk, which is made from a shipping container to correspond with the vendors used at Market 707. Otherwise, they can direct themselves through the building by following the bold guardrail which creates a ribbon throughout the entire building. Once again, tactile flooring is provided to guide people with vision loss, railing for balance to accommodate seniors and people with physical disabilities, and contrast on walls assist diverse people. As they walk along the main circulation route, they encounter various break-out spaces which attract them to either enter or continue walking along their path of travel through sounds of people interacting, smell of food in the snack bar, smell of books to sit down and read, smell of food in the kitchen, and sounds of a movie playing in the theatre.

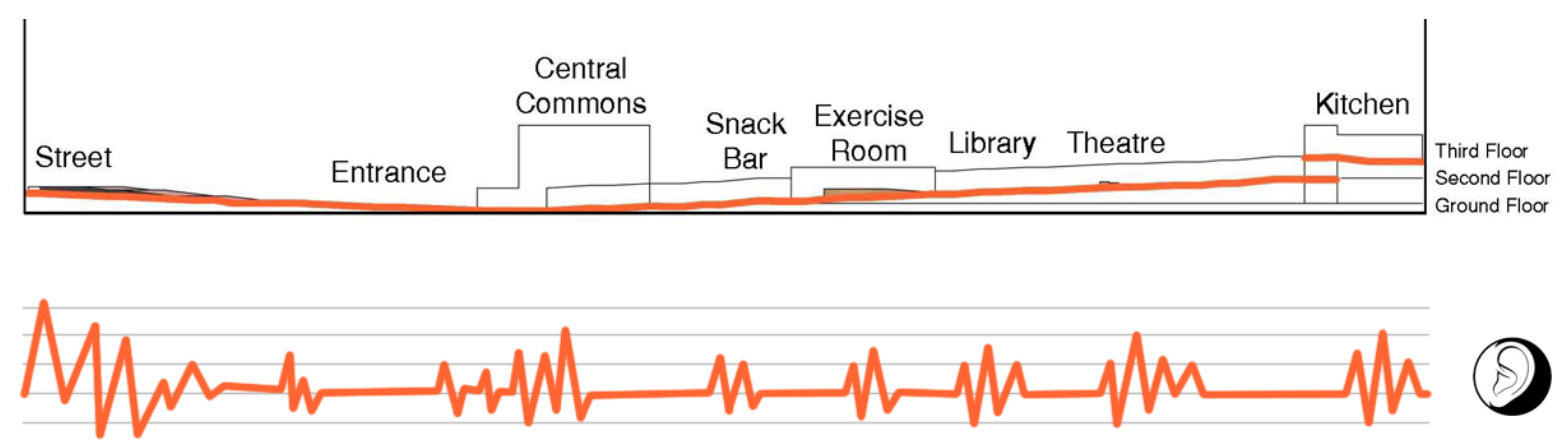

Figure 5.5.2b - Experiencing sound within SCCC 
While approaching and entering the site, people with vision loss sense sound for information of their surroundings. Within the public plaza, people hear sounds of conversations happening between various people and detect a safe outdoor environment for people to gather (Figure 5.5.2b). They are further guided by a musical water fountain. As they enter the central commons space, people hear sounds of a calm waterfall. Although this is a large open space, sound is not unpleasant to perceive creating confusion and agitation. This is achieved by using sound-absorbing materials to create a quiet environment, while allowing conversations to occur without creating echoes. However, people with vision loss do perceive entering a large open space when their cane touches the floor and the sound resonates towards the walls and ceiling. As they walk along the ramp towards different destination points, they hear sounds of smaller rooms with people carrying conversations in more intimate spaces.
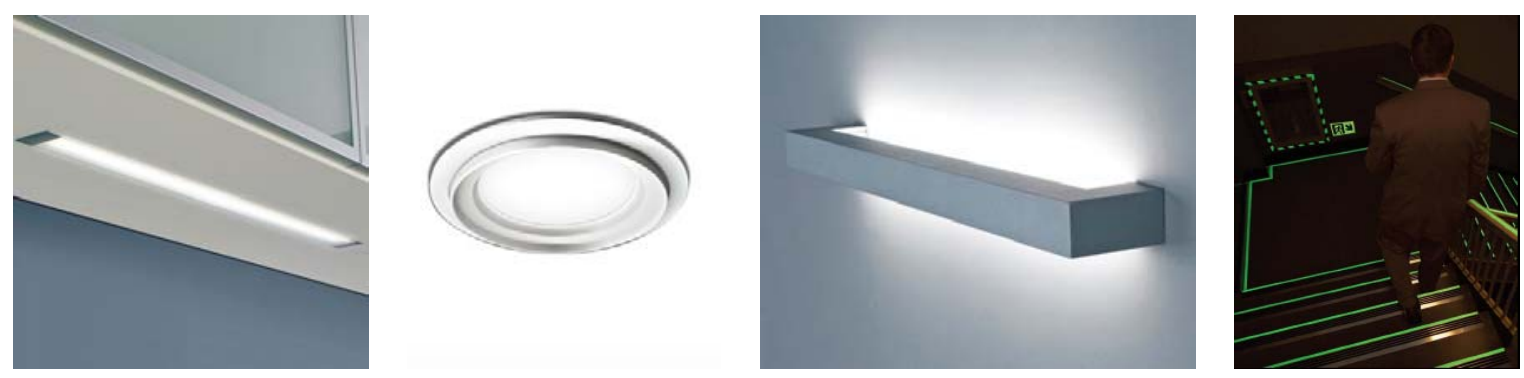

Figure 5.5.2c - Interior lighting with recessed light strips (main circulation), and recessed LED (destination points). For means of egress, linear wall mounted light fixtures and photo-luminescent tape are used

Illumination within an inclusive environment uses both artificial and natural light providing health, safety and usability for everyone. There are many different types of artificial lighting used. However for general lighting, recessed fluorescent light strips are selected because they are more common in commercial interiors, easier to control, generate less heat making them more energy efficient and provide an even distribution of light (Steinfeld, 2012, p. 283-4) (Figure 5.5.2c). They provide comfort and do not produce glare when matte flooring is used. 
They run along the main circulation path providing illumination and orientation, similar to runway lighting for airplanes. Within destination points, recessed LEDs are used to let people know they are entering a different space along their path of travel. They are also energy efficient and are dimmable, providing flexibility to adapt to different uses of the space (Steinfeld, 2012, p. 284). In the means of egress, linear wall mounted fluorescent lights are used to illuminate the space for safety and when there is power outage, the photo-luminescent tape provides direction of movement to ensure safety for everyone.

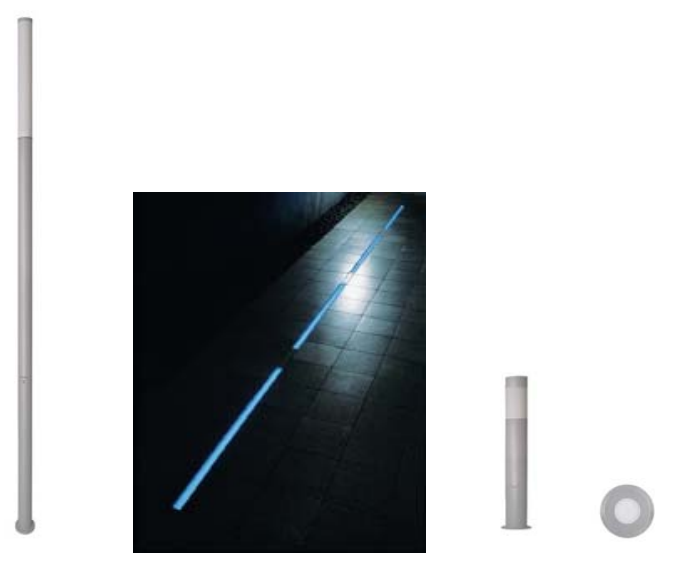

Figure 5.5.2d - Various external lighting used in the public plaza enhancing safety and usability

At night, various external lights are provided to illuminate traffic routes to enhance safety and usability (Figure 5.5.2d). Four meters high modern LED light posts provide general lighting within the public plaza. For major circulation, LED floor light strips are used to create edges distinguishing hard from soft surfaces. A different lighting system is used for secondary circulation using bollard lights, providing additional information of the surrounding for everyone, especially for people with poor vision. LED are used for architectural lighting on the building facade and floor underwater lights, which change colour for the musical water fountain for people to enjoy. 


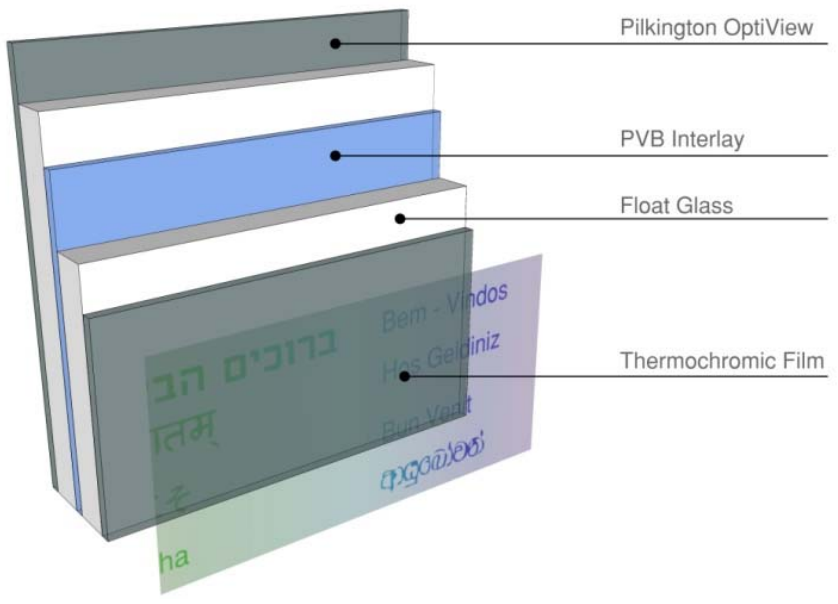

Figure 5.5.2e - SCCC uses Pilkington anti-reflective glass system with thermochromic film for welcome wall only

Natural light is used within central commons for many reasons benefiting everyone providing comfort, navigation, improve quality of space, health, and safety. Firstly, the central commons space is a large open space creating the illusion of being outdoors. However, daylight must be controlled to prevent glare and discomfort for everyone, especially for people with poor vision and seniors to ensure safety. Pilkington anti-reflective glass is used at SCCC with the addition of thermochromic film for the welcome wall only (Pilkington OptiView, n.d.) (Figure 5.5.2e). This prevents direct light from entering the building, avoiding strong light and hard edge shadows. The welcome wall creates a sense of interaction between people and is used to greet visitors when they enter the building. Welcome is written on the facade in many different languages. Thermochromic film is further selected to represent a community centre, which supports diversity and inclusion. Secondly, within the community centre, natural light is used for navigation. Daylighting within a building suggests a more public and open space for gathering. People always have a sense of location when relating their body to the location of the sun since they are naturally attracted to light (Steinfeld, 2012). Whereas a space which only depends on artificial lighting is less pleasing compared to natural daylight and is mainly used for circulation 
purposes. Thirdly, natural light provides a good source of vitamin D, which is good for our health and wellness (Steinfeld, 2012, p. 287). This is extremely important for occupants who stay indoors majority of their time and in northern climates.

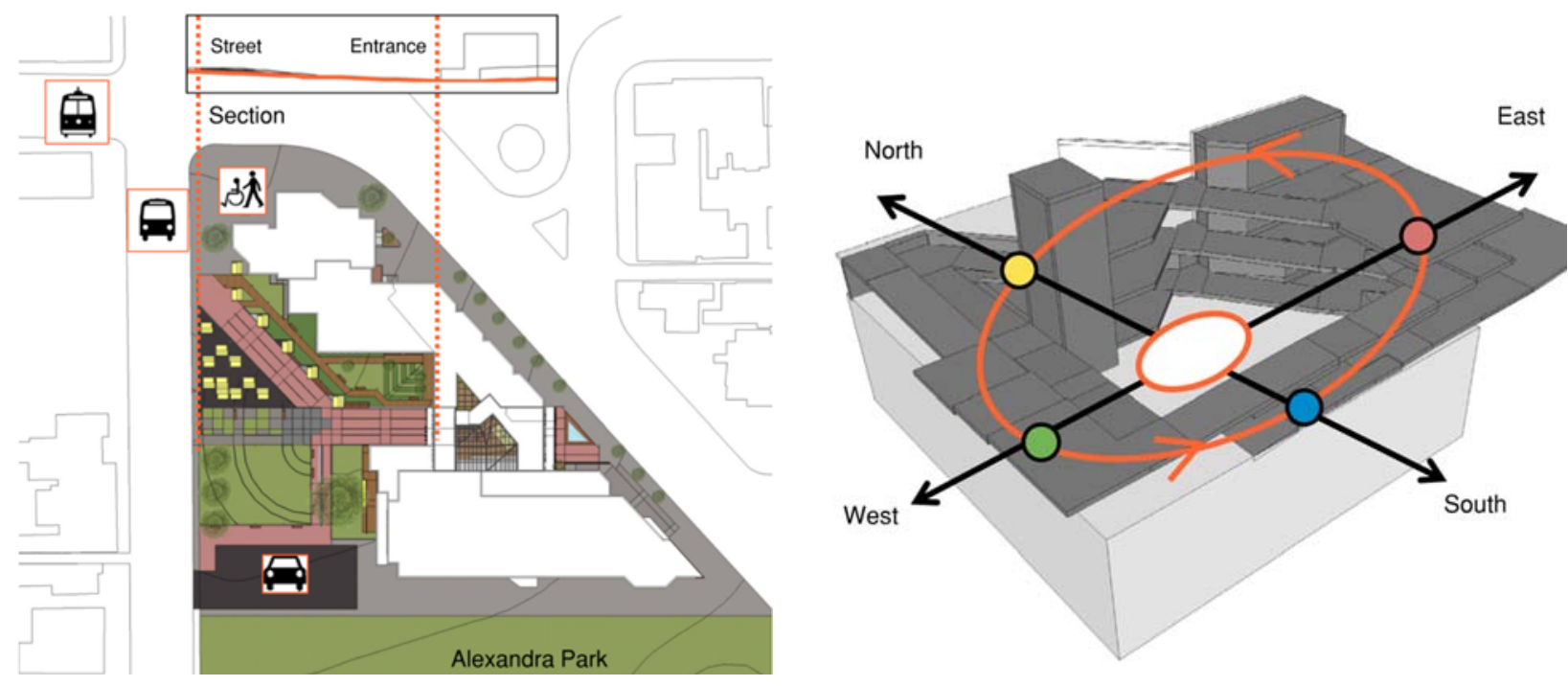

Figure 5.5.2f - Colour contrast and colour co-ordination provide visual information in exterior (left) and interior (right) environments

Colour is used in many different ways within SCCC. It provides colour contrast to assist everyone, especially for people with poor vision and older adults, represents a community centre, and provides information about their surroundings (Figure 5.5.2f). For instance, the floor uses the same material but in two different colours to distinguish walkable surface from edges. Edges provide safety and usability for all users, preventing them from walking towards a wall and soft surfaces. Colour is also used to represent a community centre meaning diversity. This is applied on the building facade as well as inside the central commons space suing colours green, red, blue, and yellow. They are used because they contain true colours and are high in contrast (Bright \& Cook, 2010). This accommodates everyone, especially people with vision loss. They are further used within destination points to provide a sense of orientation for people. They are 
colour co-ordinated to the function of the space, such as green for the library since it is located adjacent to the public plaza. These colours are further used on directories and directional signs when experiencing the building. Thus, primary colours are selected to accommodate diverse users within SCCC in order to provide information for them about their surroundings.

Many interior and exterior materials are specifically selected because their characteristics provide many advantages within an inclusive environment. Not only are they aesthetically pleasing, they also function as well. They provide information for diverse users, regardless of age and abilities. 
The following is a list of interior and exterior materials/finishes with an image and a brief description explaining why each particular material is selected.

Interior Materials and Finishes

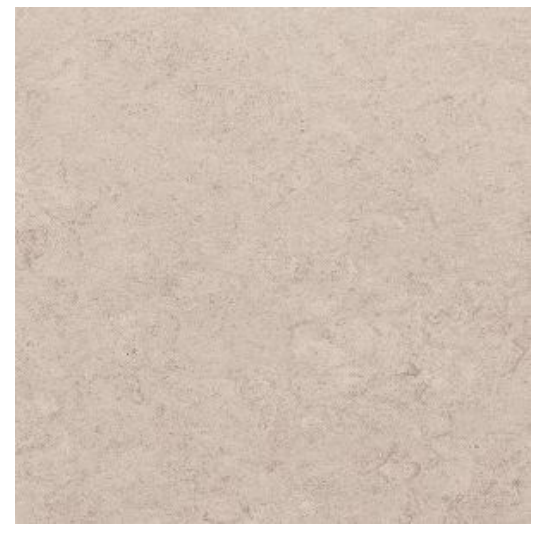

The ramp flooring is made of linoleum, a natural material which is slip-resistant (Marmorette with NATURCote, n.d.). Mushroom colour is used throughout with cherry colour as edges for contrast and to unify with the destination points flooring. They are easy to clean, durable, contain the same

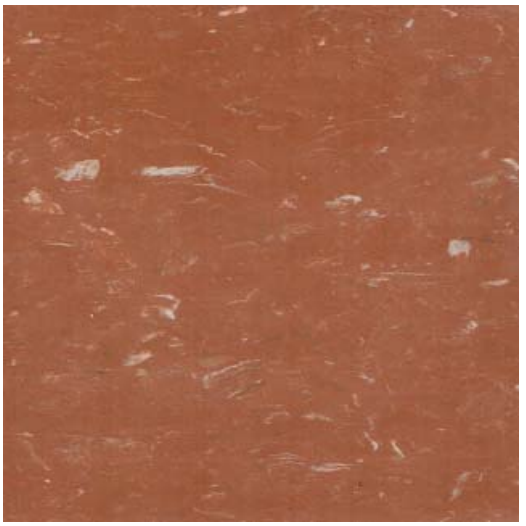
colour throughout its layer creating consistency, is a soft material which is appropriate for absorbing sound, and contains a smooth matte finish preventing glare, injuries from falls, and discomfort. This is especially important for people with vision loss and seniors to avoid confusion.

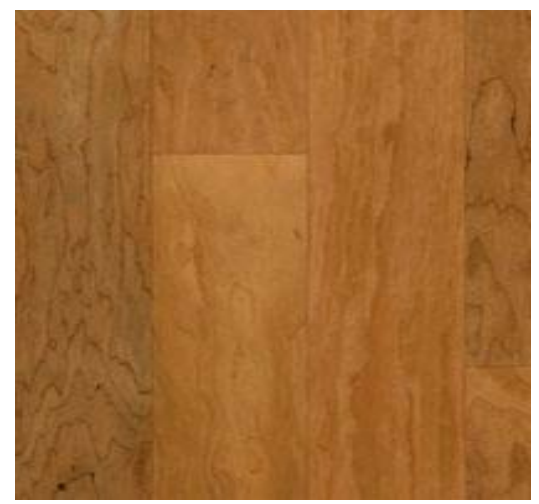

Commercial hardwood flooring is used in destination points. The colour is similar to the edges of the main circulation route but is different in texture and material. It is very warm in texture, is easy to maintain, and performs well in high traffic interiors (Performance Plus, n.d.). It also does not 
have a shiny surface, creating reflection and illusion causing visual distraction (Steinfeld, 2012, p. 301).

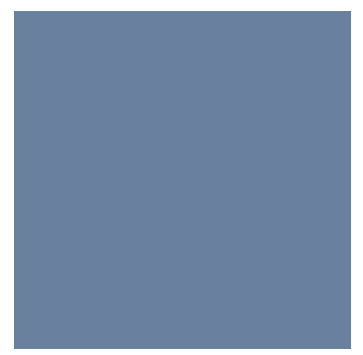

The main circulation is made of two wall types. The first is semi-gloss painted walls, making them easy to maintain and is in a light colour to reflect bright interiors in the space. It is mainly in Pearl White

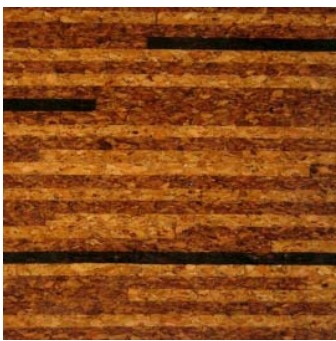
colour from Benjamin Moore and Nantucket Blue to define the water fountain. The second is cork providing contrast in colour, texture, colour, smell, and acoustic quality. This is used as accent walls and walls requiring attention with directories and directional signs. Both these finishes do not have any effect on glare for people.

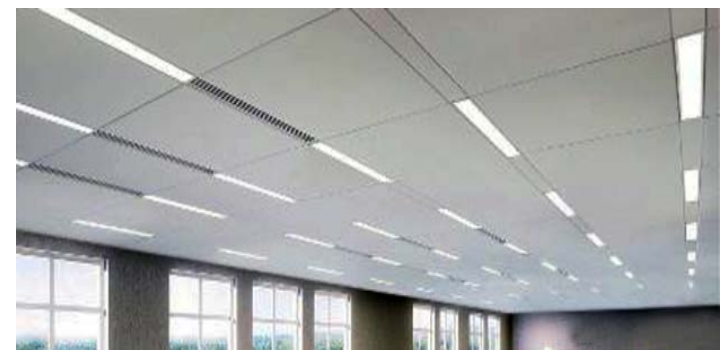

Acoustic ceiling tiles are used within the main circulation route while destination points use drywall, creating different spaces within a unifying central commons space. The panels absorb sound avoiding echo for people who depend on hearing (Marmorette with NATURCote, n.d.). 

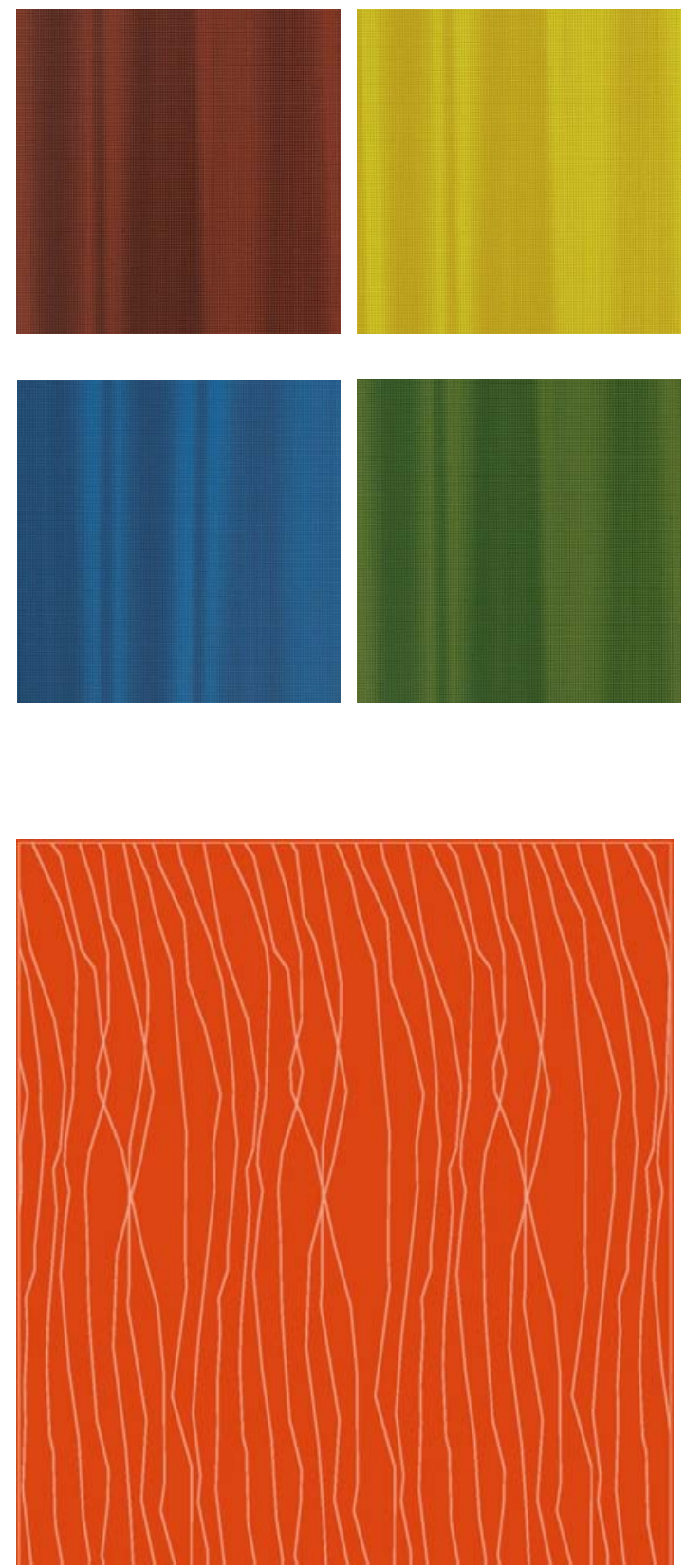

Upholstery uses Maharam, which is a common commercial product that is $100 \%$ vinyl. It is stain resistant and durable enough to withstand high abrasion. Different destination points use a different colour for easy navigation accommodating diverse people and co-ordinate with the function of the space.

The guardrail is from 3 form which is made from recycled acrylic. It is translucent with a sandblasted finish providing safety for everyone. A closed guardrail prevents depth perception for PWD and seniors causing falls and distractions (Steinfeld, 2012). The bold orange colour provides contrast in a subtle interior, drawing people's attention when circulating vertically within the building. This is an important feature people use and access within the central commons space. 
The main circulation route uses this red stone pavers. It is flat, stable, and durable that can be used by everyone. They are ideal for walkways and have colour contrast against other flooring finishes along with a grey natural straight curb.

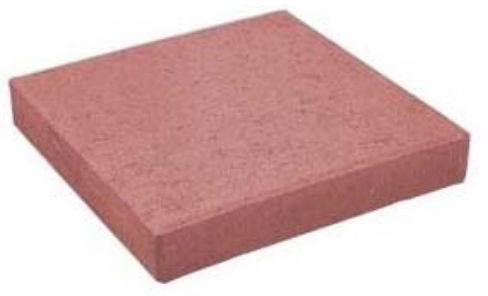

The reddish tone repeats into the interior to create a sense of harmony. The natural straight curb contains simple geometry and clean edges.

The secondary or informal circulation route is in a charcoal cobble stone colour. It is very durable to walk on. (Both main and secondary circulations use radiant floor heating to create safe walkways for everyone to walk on during the winter). It is bordered with the natural straight curb to unify with all the flooring materials in

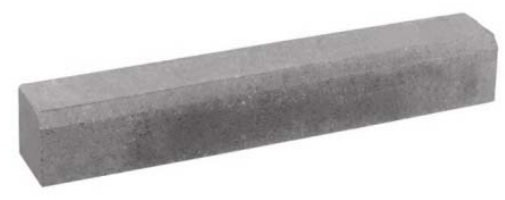


Seating are made of teak wood, which is a durable material for outdoor furnishings. It resists against decay, repels water, does not shrink, and ages well (Choosing Durable Wood for a Garden Bench and Outdoor Furniture, n.d.). There are handcarved lettering on the benches to engage with people.
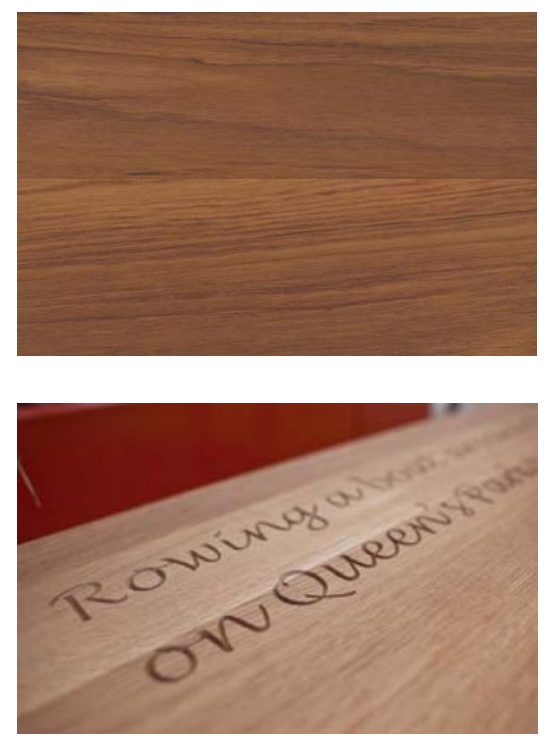

Ipe wood is selected for the urban farming flooring. It is a more natural material which corresponds with the function of the space. The surface is durable, splinterfree, smooth, and matte, making it an appropriate material for everyone to use. It also resists against decay and mold (Ipe Wood, n.d.).

The concrete walls are in the same material as the existing building facade to create a sense of unity. Some of these walls are lit under the wooden seats for illumination at night.
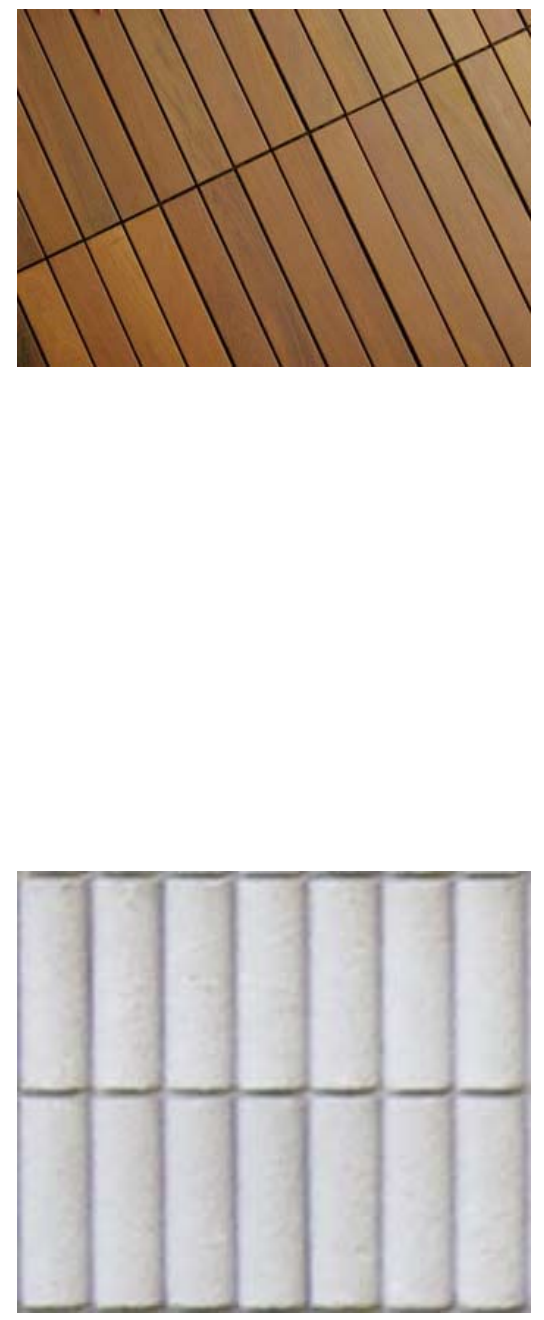


\subsubsection{SECURE ARCHITECTURE FOR SOCIAL INTERACTION}

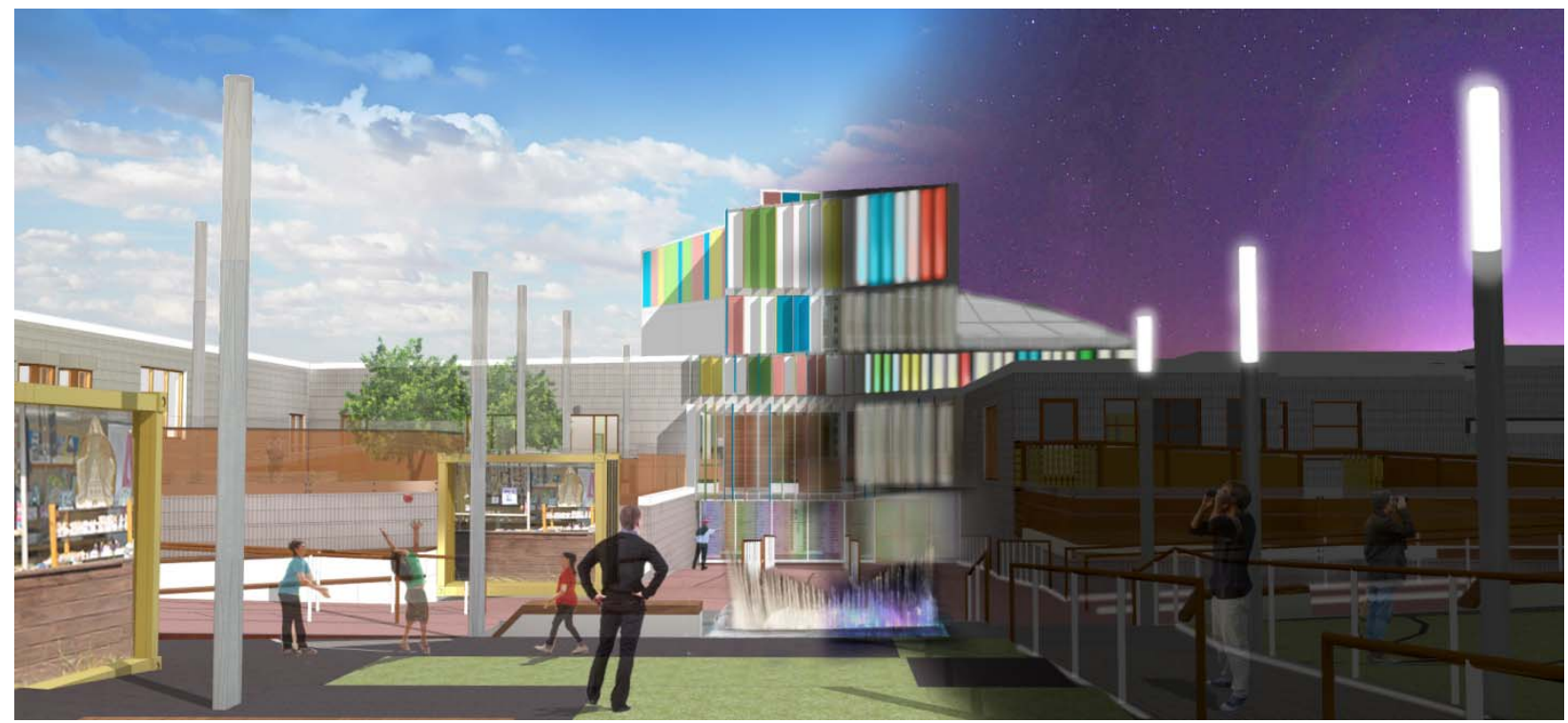

Figure 5.5.3a - Rendering demonstrating secure environment for taking action and reaching destination points

When information is provided for people, they create situational awareness and respond to the surrounding. An environment is more secure and usable when there are clear sightlines. Within the public plaza, maintaining visual connection provides information about the safety of the space and establishes their decision-making. When people are occupying public spaces, it attracts other people to be engaged, creating an interactive space. In this case, the public plaza contains many functions within the space. All of these functions are highly visible, regardless of where the person is standing within the site (Figure 5.5.3a). Based on the user's objective when approaching the site, one is provided with choices of whether to experience what is happening in the public plaza, because there are a lot of activities happening which attracts their attention, or to walk past everything in order to access one of the services inside the building. This scenario can only be achieved when people are provided with information of the surrounding through clear sightlines and observing people occupying the streets. Another scenario is the transparency 
between outdoor and indoor spaces. Similarly, when people from outside observe people within the building, they become determined to enter the building in order to reach their destination point. Thus, Jane Jacobs' infamous "eyes on the street" concept is applied to SCCC providing information for users to establish usability and safety of the space (Jacobs, 1961).

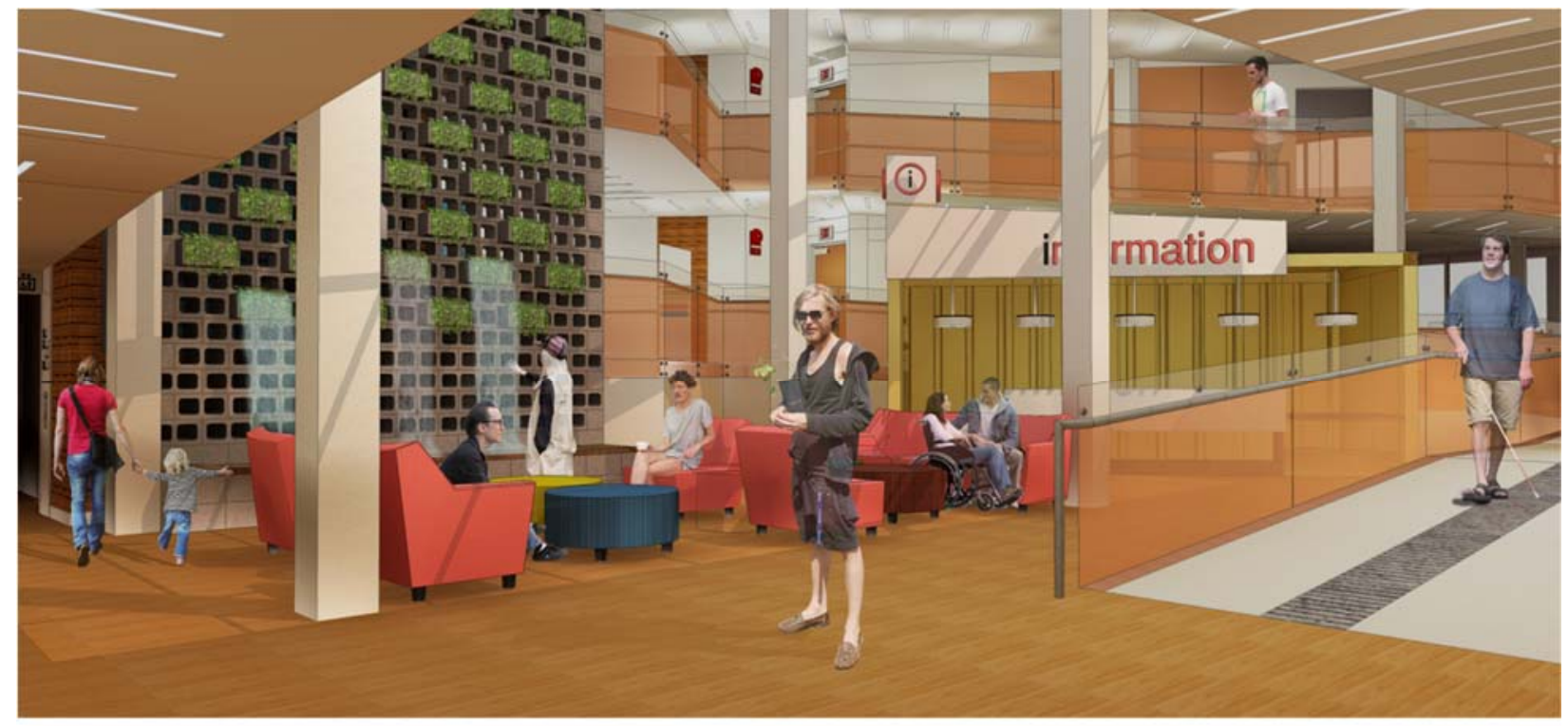

Figure 5.5.3b - Interior view of the central commons space

Furthermore, when circulation spaces are used as social places, they enhance the overall quality and contribute to people's quality of life. Within central commons, circulation spaces serve a functional purpose. In this case, the social space is in the middle, creating a highly exposed area for interaction (Figure 5.5.3b). This is the first open space people approach as they enter the building either from the main west entrance or the secondary east entrance. The central commons acts as a transitional and welcoming space with informal and easy to move furnishings to accommodate various social gathering functions, offer an interactive living wall/water feature creating a multi-sensory experience, provide an information desk to assist with wayfinding and encourage social exchange, and direct people to destination points from the central node. 


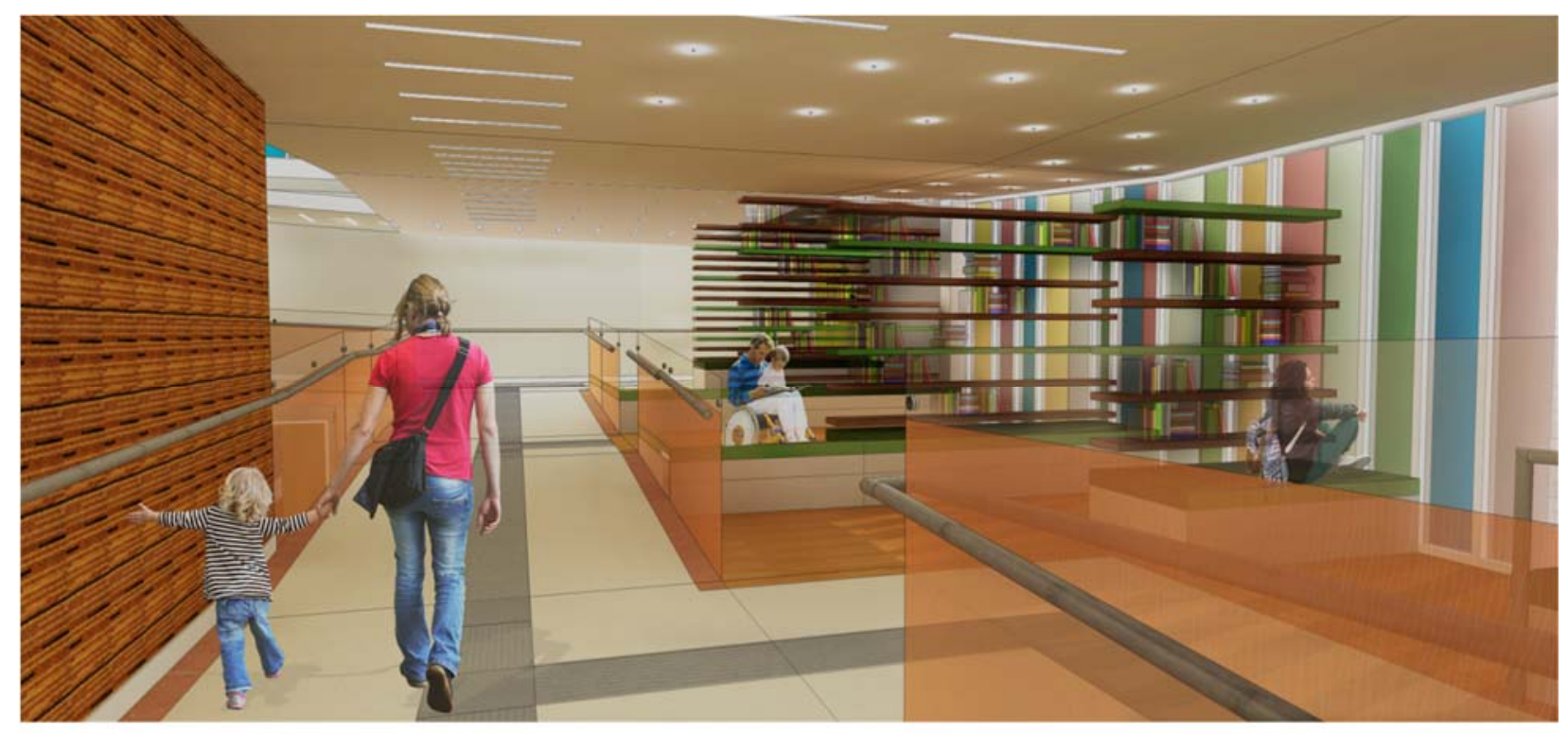

Figure 5.5.3c - Interior view of the library (intermediate space)

From central commons space, people circulate along the main path of travel. Occasionally, these circulation spaces are integrated with social places creating an identity, providing activities, and building relationships amongst others, benefiting people's health and wellness. Human behavior detects places of interest by seeing other people engaging. People have the choice of either continuing their path of travel or stopping by at the library (Figure 5.5.3c). These circulation spaces allow for social interaction, which is beneficial for diverse people within an inclusive environment. They further act as wayfinding through use of colour by directing people to the actual library and provide a sense of orientation when relating their current location to central commons space. 


\section{CONCLUSION}

This thesis topic is simply not an architectural issue. It also encompasses political, economic, social, and technological aspects. This concept is still relatively new in Canada. Any changes made to our built environment are considered small-scale and moving incrementally slow. Though, it accommodates diverse needs, including children, families, PWD, and older adults. It also offers innovation within design, increases productivity, marketability, and provides usability and access to buildings. Overall, ID enhances people's sense of dignity, self-esteem, independence, and quality of life.

This thesis project investigates the concept of ID within the built environment by taking a community centre in Toronto to test various design interventions. However, there is much to uncover on the topic of ID. Thus, it is recommended that we raise sensitivity about ID at an early age and stage. By understanding this concept, people can learn from each other by considering and respecting differences. In addition, we must remember that people do not only experience the environment visually. We also depend on non-visual senses to perceive the world. This represents the interactions between the user and the environment creating equity and equality. Though, there are also interactions between various users which enhances their well-being. This is social interaction amongst people within the environment. In doing so, it is a holistic approach to experiencing an inclusive environment. Furthermore, it is recommended that both the client and architect have the same belief towards creating an inclusive environment. Otherwise, they only need to meet minimum standards and it does not push both parties to think beyond them. Architects have an important influence on the way communities are shaped and how people interact with them. Thus, the roles of an architect is important to create and sustain an inclusive environment. 
Finally, ID is about today and our future. The next phase of research will focus on design within the physical environment including private dwellings, private spaces, and how building performance and maintenance effect inclusivity. Beyond the physical environment, research on assistive technology, communication and information, and employment needs to be studied further. We must also analyze and respond to Canada's changing demographics. We must continue to collaborate and understand the barriers affecting diverse users in order to improve inclusivity within buildings and public spaces. Furthermore, we must continuously research, design, and test out ideas before implementing them to real life in order to create effective inclusively designed products and environments.

Overall, this thesis personally impacts me in many ways as a niece to my uncle who has Down syndrome, an architecture student, and a designer. I experience the built environment like anyone else, but as an individual in this field, I observe extra details within buildings. From an architect's perspective, it brings great shame when some people cannot access many poorly designed buildings. Today, I have gained more knowledge and experience within ID. This knowledge is power, which gives me a voice to be heard representing groups of people who continue to experience barriers within the physical environment. As a designer, I can apply my knowledge by considering diverse target users groups to create innovative solutions for fully inclusive buildings and public spaces. When a little girl with poor vision touches the surface of a wall and smells flowers while walking towards it safely and independently, I know I have done my job well. Though, when I continue to see the same results within the built environment, my goal is to raise awareness and become an advocate for change. I hope my thesis project opens many eyes for people and not just those within the design industry because inclusion is not considered an option in how buildings and public spaces are designed, but a basic necessity. 


\title{
APPENDIX A
}

\section{RE: Ryerson Masters Thesis on Inclusive Design}

\author{
From: Amy Pothier(APothier@quadrangle.ca) \\ Sent: October-25-13 10:53:14 AM \\ To: Hong-Li Wong (hongli.wong@ryerson.ca) \\ 2 attachments \\ Clear Floor Area.pdf(631.7 KB), Removing Barriers to Health Clubs and Fitness Facilities- \\ North Carolina State University 2008.pdf(3.2 MB)
}

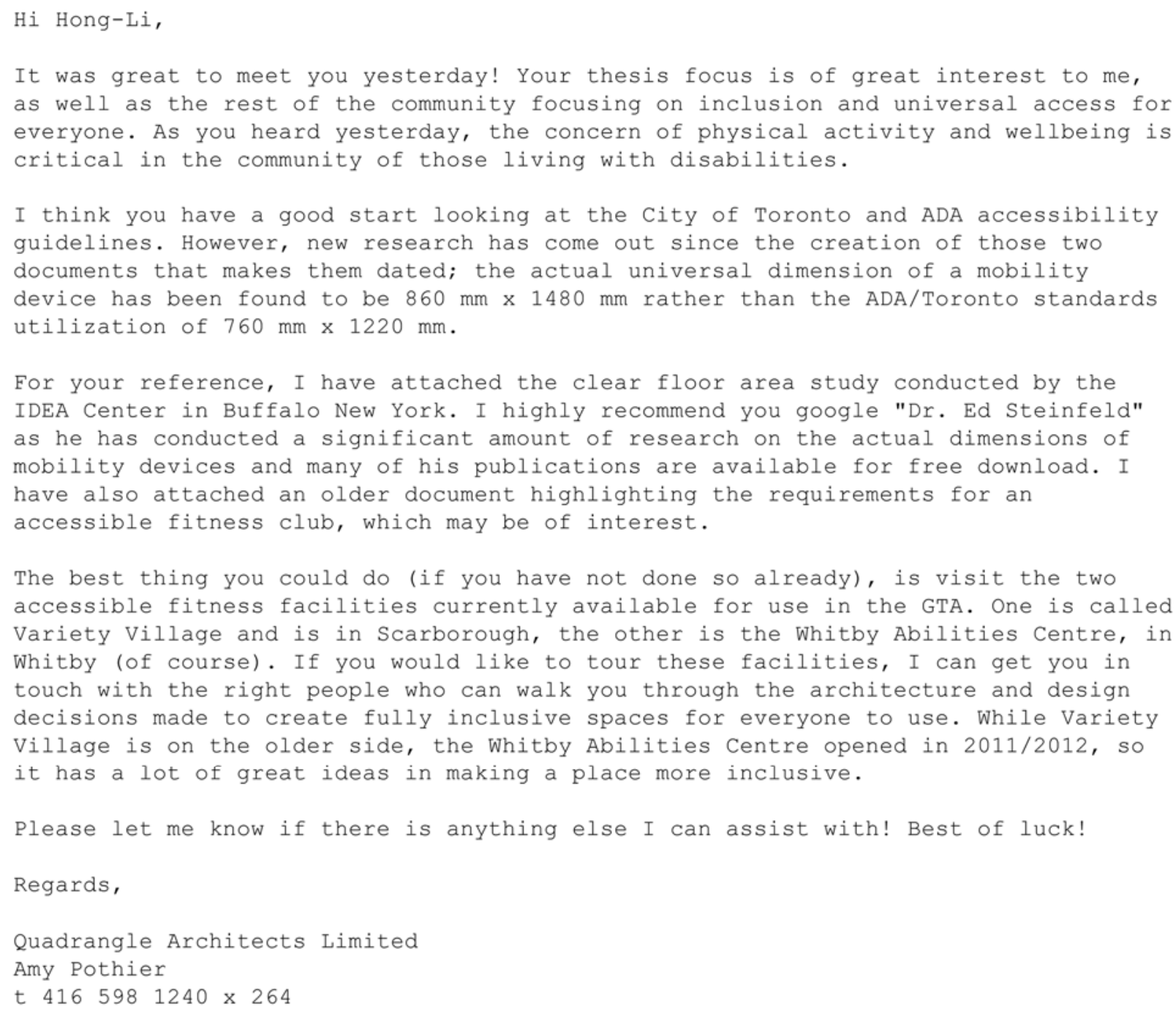




\section{APPENDIX B}

Facility Listing and Permits. (n.d.). FUN Guide Fall 2013/Winter 2014. Retrieved July 9, 2014, from http://www1.toronto.ca/parks/pdf/facility_map.pdf

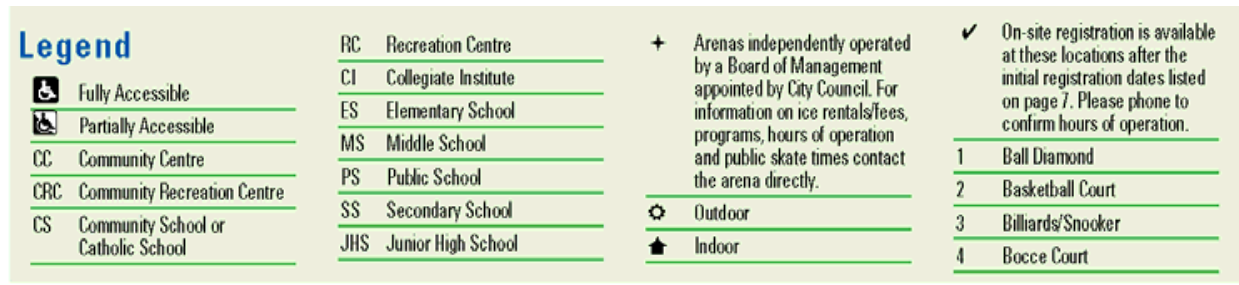

\section{Parks, Forestry and Recreation Operated Facilities}

\begin{tabular}{|c|c|c|c|c|c|c|c|c|c|c|c|c|c|c|c|}
\hline \multicolumn{3}{|c|}{ FACILITY INFORMATION } & & \multicolumn{11}{|c|}{ FACILITY DESCRIPTION } & \multirow[b]{2}{*}{ 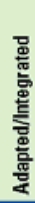 } \\
\hline 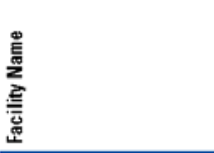 & 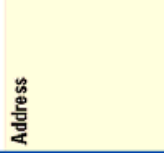 & $\begin{array}{l}\text { 节 } \\
\text { 产 }\end{array}$ & 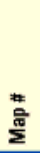 & 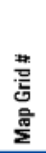 & 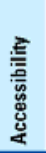 & 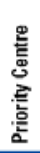 & 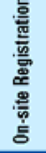 & 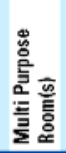 & 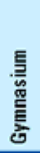 & 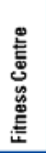 & 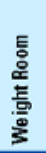 & 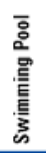 & 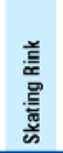 & 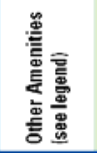 & \\
\hline Toronto City Hall & 100 uneen St W & 311 & $\bar{A}$ & 66 & $\bar{b}$ & & $\checkmark$ & & & & & & & & \\
\hline East York Civic Centre & 850 Coxwell Ave & 311 & $B$ & D11 & B & & & & & & & & & & \\
\hline Adam Beck CC & 79 Laystor Ave & $416-392-0741$ & 1 & $\mathrm{~F} 13$ & 图 & & & & - & & & & & 812 & \\
\hline Allan A. Lamport Stadium & 1151 King StW & $416-392 \cdot 1366$ & 2 & H2 & 图 & & & & & & & & & 12 & \\
\hline Balny Beach CC & 14 Pine Ave & $416-392-6972$ & 3 & 613 & 图 & & & & - & & & & & 12 & \\
\hline Beaches RC & 6WWiliamson Rd & $416-392.0740$ & 4 & 612 & 图 & & $v$ & $\bullet$ & $\bullet$ & $\bullet$ & $\bullet$ & 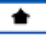 & & & $n$ \\
\hline Bob Abate CRC & 485 Montrose Ave & $416-392-0744$ & 5 & $E_{4}$ & 因 & & & - & $\bullet$ & & & & & 8 & 2 \\
\hline Brown CC & 454 Avenue Pd & $416-3922-6826$ & 6 & 65 & 田 & & & - & - & & & - & & & n \\
\hline DA Morrison JHS & 211Gledhill Ave & $416-392-1950$ & 7 & D12 & 8 & & & & - & & & 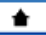 & & & \\
\hline Earl BeattyCC & 455Glebeholme Blvd & $416-392-0752$ & 8 & G11 & 因 & & & & - & & & 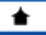 & & & $n$ \\
\hline East York CC & 10811/2 Pape Ave & $416-396-2880$ & 9 & E8 & 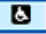 & & $v$ & & - & $\bullet$ & - & 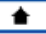 & & 8 & 22 \\
\hline East York Menmorial Arena & æs Cosburn Ave & $416-396-2869$ & 10 & D9 & b & & & & & & & & t & & \\
\hline Fairmount Park CC & 1757 Gerrard StE & $416-392.7060$ & 11 & 610 & 因 & & $v$ & - & - & & & 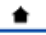 & & $1 / 8 / 12 / 13$ & $n$ \\
\hline Frankland CC & $816 \log a n$ Ave & $416-392-0749$ & 12 & $F_{8}$ & 图 & & & $\bullet$ & $\bullet$ & & & + & & & \\
\hline Gordon A. Brown MS & 2800 St. Clair Ave E & $416392-1950$ & 13 & C13 & 图 & & & & - & & & - & & & \\
\hline Harrison Pool & 15 Stephanie St & $416-392-7984$ & 14 & 65 & 因 & $\bullet$ & & & & & & + & & & \\
\hline Hillcrest CC & 1339 Bathurst St & $416-392-0746$ & 15 & A4 & 国 & & $\checkmark$ & - & - & $\bullet$ & - & - & & & 2 \\
\hline Holy Family CC & 141Close Ave & 4163922.6695 & 16 & 62 & 因 & & & - & - & & & & & & \\
\hline Jimmie Simpson RC:Park & 8700 ueen StE & $416-392-0751$ & 17 & 68 & 图 & $\bullet$ & & - & $\bullet$ & & & - & 0 & $\$ 10$ & 2 \\
\hline John Innes CAC & 150 Sherboume St & $416-392-6779$ & 18 & $\mathrm{H} 7$ & 圈 & $\bullet$ & $\checkmark$ & & - & & $\bullet$ & - & & $1 / 8 / 12 / 13 / 16$ & $n$ \\
\hline Main Square CRC & 245 Main St & $416-392-1070$ & 19 & $\mathrm{E} 12$ & $\theta$ & & $v$ & - & & $\bullet$ & - & - & & 8 & 2 \\
\hline Maple Cottage & 62 Laing St & $416-392-0734$ & 20 & 610 & $\Delta$ & & & & & & & & & & 23 \\
\hline Mary McCormick RC & 66 Sheridan Ave & 416.392 .0742 & 21 & $\mathrm{~F}_{2}$ & 图 & & $\checkmark$ & & $\bullet$ & $\bullet$ & - & - & & 816 & 23 \\
\hline Masaryk-Cowan CRC & 220 Cowan Ave & 4163926.6928 & 22 & 62 & 因 & - & $v$ & & - & & - & & & 8 & 23 \\
\hline Matty Eckler CRC & 963Gerrard StE & $416-392-0750$ & 23 & 610 & 因 & & $v$ & - & - & $\bullet$ & $\bullet$ & + & & 8 & \\
\hline Maurice CodyCC & 181 Cleveland St & $416-392.0777$ & 24 & B7 & 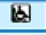 & & $v$ & & $\bullet$ & & & & & 8 & 23 \\
\hline McCormick Arena & 179 Brock Ave & $416-3922.0607$ & 25 & $\mathrm{~F}_{2}$ & 因 & & & & & & & & ++ & 1 & \\
\hline Moss Park Arena & 140 Sherboume St & $416-392-1060$ & 18 & $\mathrm{H} 7$ & 因 & & & & & & & & $t+$ & $1 / 12$ & \\
\hline Parkdale CRC & 75 Lansdowne A & $416-392-6696$ & 26 & 62 & d & & $\checkmark$ & - & - & & & t & & & \\
\hline Phil White Arena & 443 Arlington Ave & $416-394-2734$ & 23 & C3 & 因 & & & & & & & & $\star$ & & 23 \\
\hline Regent Park Aquatic Centre & 640 Dundas $\mathrm{StE}$ & 4163392237 & 29 & 67 & $\mathbf{B}$ & $\bullet$ & & & & & & - & & & \\
\hline Regent Park North BC & 415 Gerrard StE & $416-3922.0753$ & 28 & $\mathrm{Fl}$ & & $\bullet$ & & & $\bullet$ & & & & & $1 / 3$ & \\
\hline Regent Park South CC & 203 Sackille Green & $416392-5490$ & 29 & 67 & 因 & $\bullet$ & & - & - & & - & & & $3 / 8$ & \\
\hline Riverdale Farm.Park & 201 Winchester St & $416-392-6794$ & 30 & 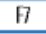 & 因 & & & & & & & & & & \\
\hline $\mathrm{g} C \mathrm{CRC}$ & 56 Woodfield PAd & $416-392-0734$ & 31 & 69 & 娄 & & & - & $\bullet$ & & & - & & 8 & \\
\hline Scadding Court CC & 707 Dundas St W & $416.392-0335$ & 32 & $\mathrm{H} 3$ & 因 & $\bullet$ & $\checkmark$ & & $\bullet$ & & & - & & & \\
\hline
\end{tabular}




\section{APPENDIX C}

Universal Design Guidelines (Commercial Buildings). (2006, October 4). Building and
Construction Authority, 11-14. Retrieved July $9, \quad$ 2014, from

http://www.bca.gov.sg/BarrierFree/others/ud_guides.pdf

- Infants and Children

In public buildings, particularly shopping centres and recreation centres, facilities should be "family friendly". Provision of play equipment and nursing spaces is highly recommended. Consideration should also be given to the special needs of and the appropriate scale for children. In the micro design, the material and the design detail need to be non-hazardous such as the use of non-toxic and non-breakable materials and the avoidance of sharp corners. Appropriate height for furniture, sanitary equipment, grab bars and drinking fountains is also an important aspect.

\section{- Expectant Mothers}

Expectant mothers also have special needs. Therefore priority in the use of facilities such as the lifts and rest areas should be accorded to them.

\section{- Elderly}

Today, there is a greater proportion of elderly living independently. The main concerns are their reduced mobility, limited strength, range of reach, poor eyesight and hearing, etc. Walking may no longer be easy. This may be aggravated by less stable gait, poorer eyesight and hence changes in floor level may not be easily discerned.

\section{- Wheelchair Users}

Wheelchair users should be able to access all public places. There are two categories of wheelchair users: those who are able to move independently and others who require assistance. In the design of the built environment, consideration should be given to better facilitate the independent wheelchair users such as the provision of gentler ramps and more easily operated doors and equipment to ease their mobility.

\section{- Physically Injured Persons}

A physical injury suffered could be temporary or permanent and in most instances, likely to result in unstable and slow movement. The person may need crutches or other aids. Provisions such as automatic doors and sensor control tabs would be desirable.

\section{- Sightless or Partially Sighted Persons}

All people with vision impairment will rely on whatever vision they have as well as other aids to find their way around. Provision of physical and other sensory cues such as touch, sound, smell as well as tactile or audible information are therefore important aids for them to move independently.

\section{- Hearing Impaired Persons}

It is important to understand the unique needs of the deaf or hearing impaired. Since they are unable to receive audio information, all information should be transmitted through other means, for example substituting audio alerts with visual alerts and allowing users to configure frequency and volume of audible cues. 


\section{Chart Outlining the Profile of People of}

Different Abilities

\begin{tabular}{|c|c|c|c|c|c|c|c|}
\hline \multirow[t]{2}{*}{ User Group } & \multicolumn{4}{|c|}{ Special Characteristics Requiring Attention } & \multirow[b]{2}{*}{$\begin{array}{l}\text { Prevalence of Poor } \\
\text { Coordination and } \\
\text { Orientation }\end{array}$} & \multirow[b]{2}{*}{$\begin{array}{l}\text { Poor or Inability } \\
\text { in Handling and } \\
\text { Fingering }\end{array}$} & \multirow[b]{2}{*}{$\begin{array}{l}\text { Poor or Inability } \\
\text { in using Upper } \\
\text { Extremities }\end{array}$} \\
\hline & $\begin{array}{l}\text { Difficulty in } \\
\text { Interpreting } \\
\text { Information }\end{array}$ & $\begin{array}{l}\text { Poor or } \\
\text { Complete } \\
\text { Degradation } \\
\text { of Sight }\end{array}$ & $\begin{array}{l}\text { Poor or } \\
\text { Complete } \\
\text { Degradation } \\
\text { of Hearing }\end{array}$ & $\begin{array}{l}\text { Prevalence } \\
\text { of Poor } \\
\text { Balance }\end{array}$ & & & \\
\hline \multicolumn{8}{|l|}{$\begin{array}{l}\text { Infants and Children } \\
\text { (up to } 8 \text { years old) }\end{array}$} \\
\hline \multicolumn{8}{|l|}{ Expectant Mothers } \\
\hline \multicolumn{8}{|l|}{$\begin{array}{l}\text { Elderly } \\
\text { (>50 years old) }\end{array}$} \\
\hline \multicolumn{8}{|l|}{$\begin{array}{l}\text { Hearing Impaired } \\
\text { Persons }\end{array}$} \\
\hline \multicolumn{8}{|l|}{$\begin{array}{l}\text { Sightless or } \\
\text { Partially Sighted } \\
\text { Persons }\end{array}$} \\
\hline \multicolumn{8}{|l|}{\begin{tabular}{|l|} 
Physically Injured \\
Persons (upper and \\
lower body) \\
\end{tabular}} \\
\hline Wheelchair Users & & & & & & & \\
\hline
\end{tabular}

\begin{tabular}{|c|c|c|c|c|c|c|c|c|}
\hline \multicolumn{9}{|l|}{ User Group } \\
\hline & $\begin{array}{l}\text { Poor or Inability } \\
\text { n using Lower } \\
\text { Extremities }\end{array}$ & $\begin{array}{l}\text { Limitations } \\
\text { of Stamina }\end{array}$ & $\begin{array}{l}\text { Limitations } \\
\text { of Strength }\end{array}$ & $\begin{array}{l}\text { Vertically and } \\
\text { Horizontally } \\
\text { Challenged } \\
\text { (in terms of } \\
\text { height or size) }\end{array}$ & \begin{tabular}{|l|} 
Require \\
Physical \\
Assistance/ \\
Supervision
\end{tabular} & $\begin{array}{l}\text { Require Family- } \\
\text { friendly Facilities }\end{array}$ & $\begin{array}{l}\text { Use of } \\
\text { Movement Aids }\end{array}$ & Others \\
\hline \multicolumn{9}{|l|}{$\begin{array}{l}\text { Infants and Children } \\
\text { (up to } 8 \text { years old) }\end{array}$} \\
\hline \multicolumn{9}{|l|}{ Expectant Mothers } \\
\hline $\begin{array}{l}\text { Elderly } \\
\text { ( }>50 \text { years old })\end{array}$ & & & & & & & & $\begin{array}{l}\text { Increased } \\
\text { visit to toilets }\end{array}$ \\
\hline \multicolumn{9}{|l|}{$\begin{array}{l}\text { Hearing Impaired } \\
\text { Persons }\end{array}$} \\
\hline $\begin{array}{l}\text { Sightless or } \\
\text { Partially Sighted } \\
\text { Persons }\end{array}$ & & & & & & & & $\begin{array}{l}\text { Use of } \\
\text { walking cane } \\
\text { to detect } \\
\text { obstructions }\end{array}$ \\
\hline \multicolumn{9}{|l|}{$\begin{array}{l}\text { Physically Injured } \\
\text { Persons (upper and } \\
\text { lower body) }\end{array}$} \\
\hline Wheelchair Users & & & & & & & & \\
\hline
\end{tabular}




\section{APPENDIX D}

Physical Model
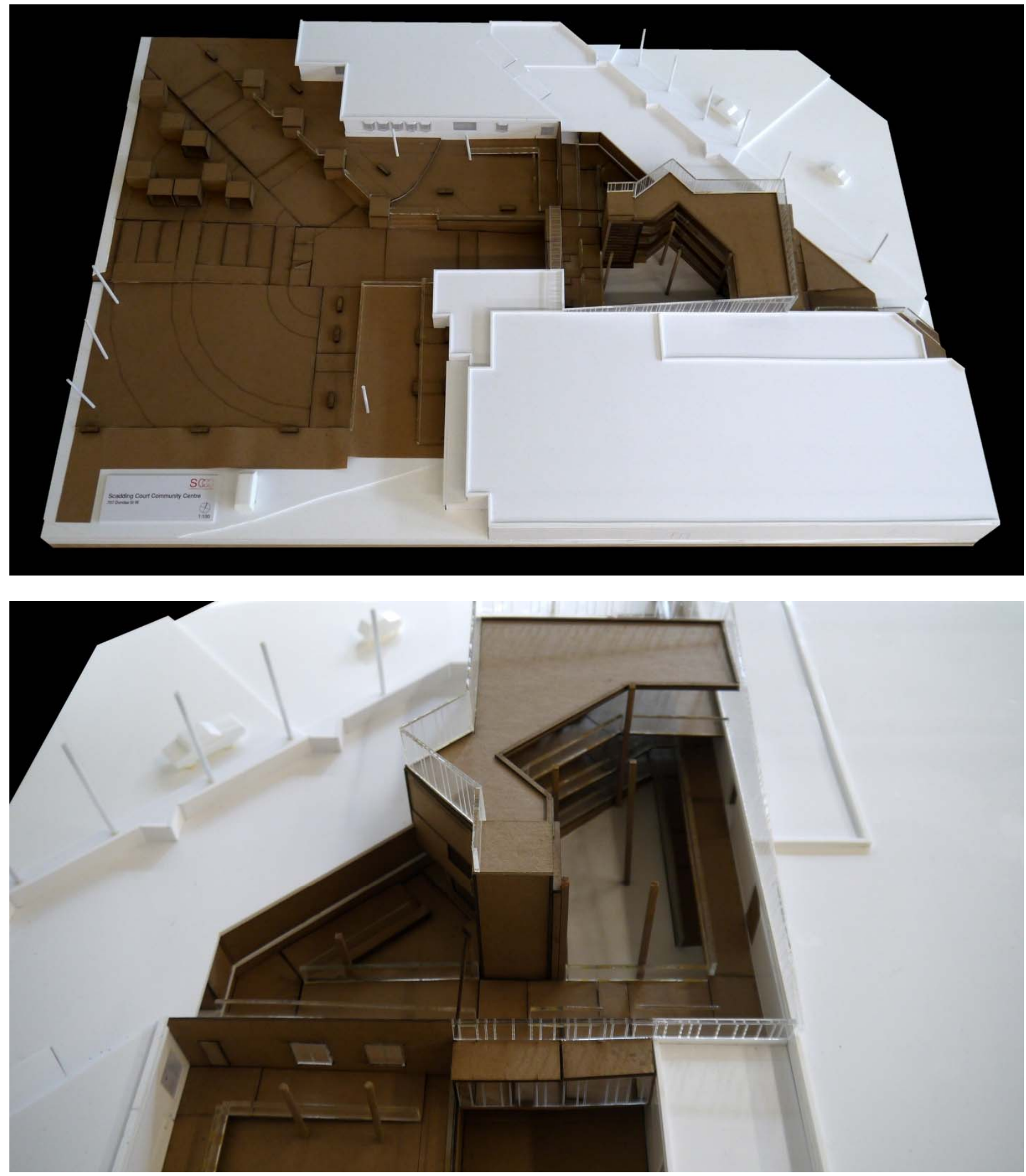

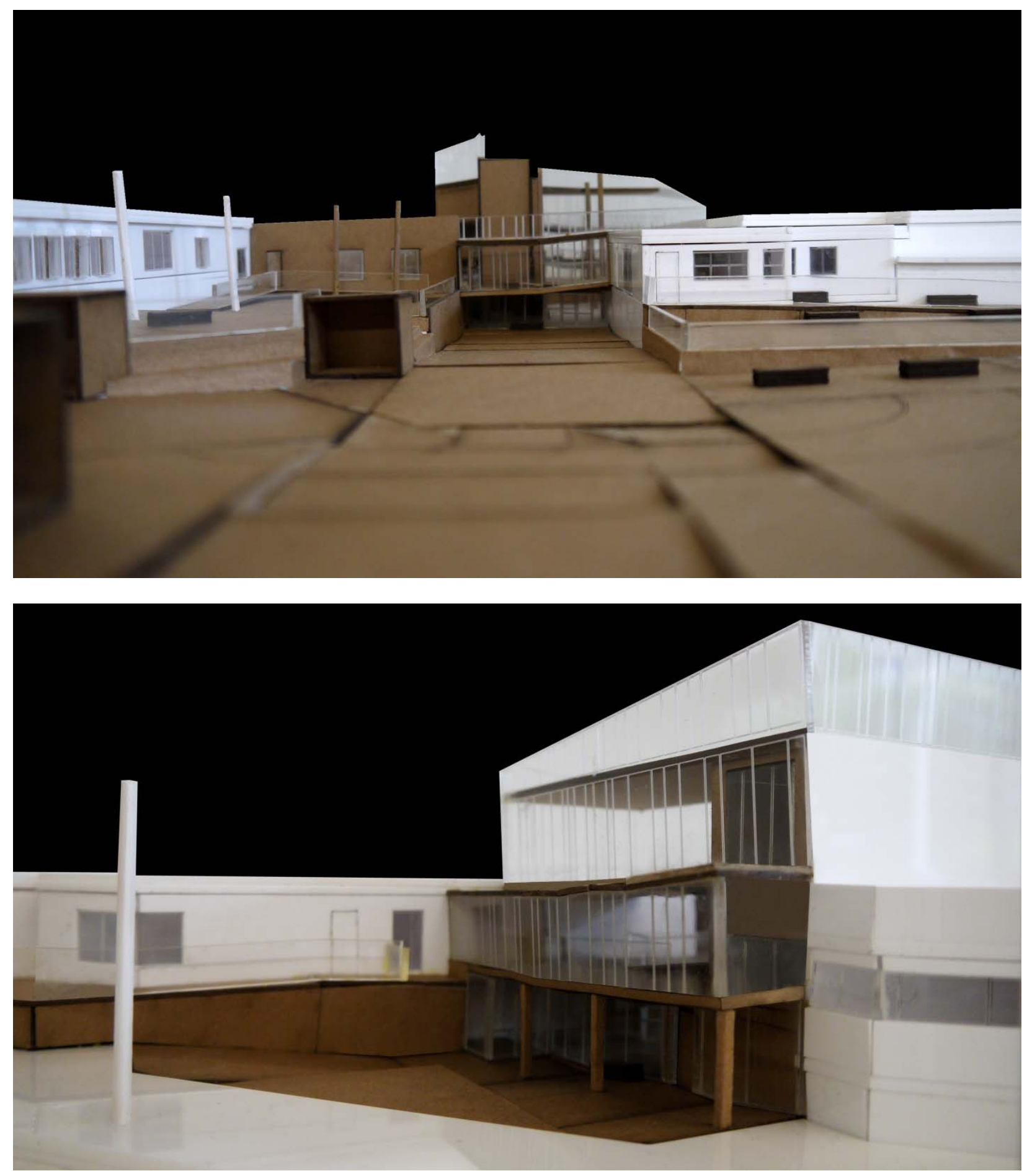


\section{Design Concept}
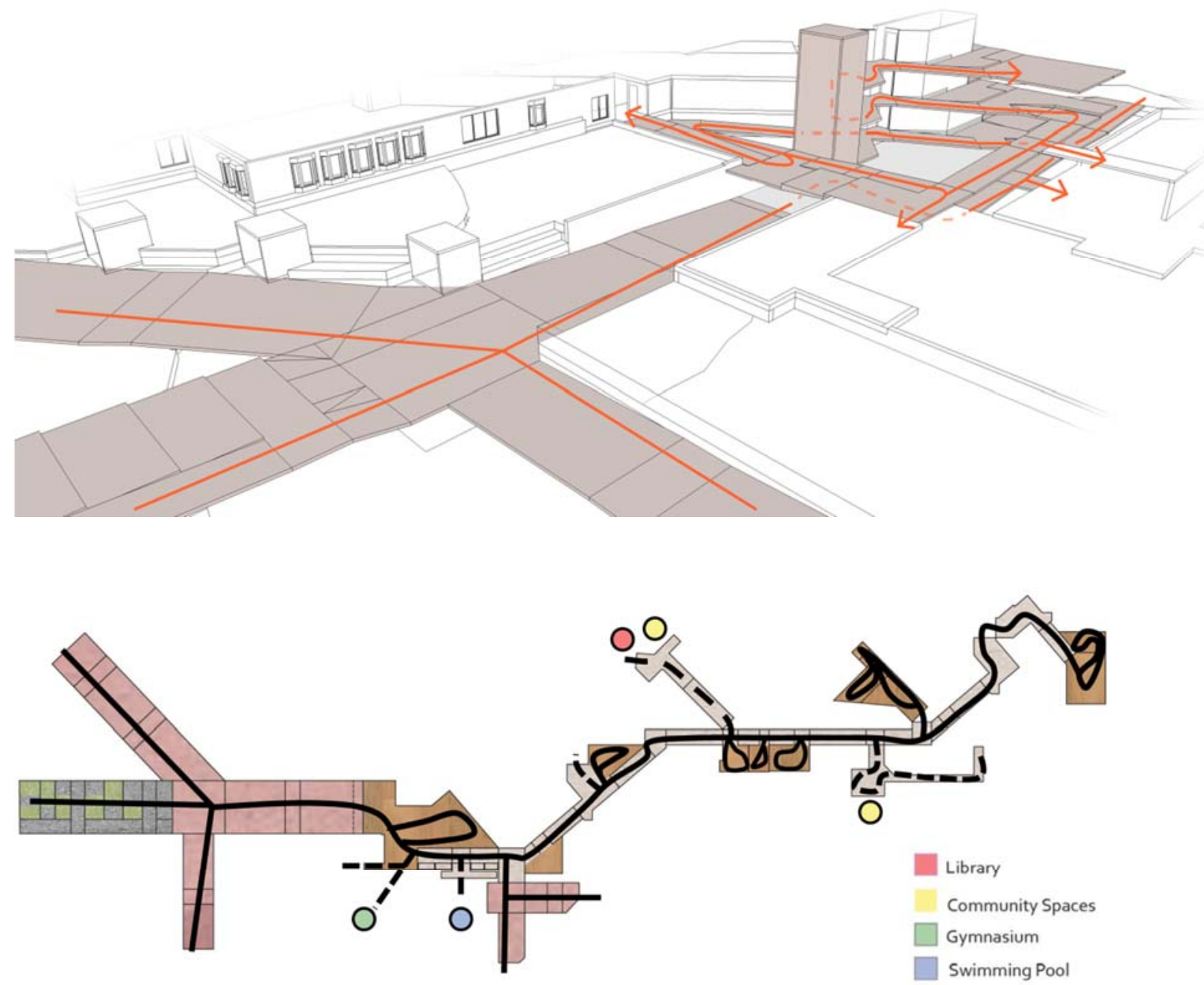

\begin{tabular}{|c|c|c|c|c|c|c|c|c|}
\hline & & $\begin{array}{c}\text { Central } \\
\text { Commons }\end{array}$ & & Exercise & & & Kitchen & \\
\hline Street & Entrance & & Bar & Room & Library & Theatre & 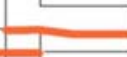 & $\begin{array}{l}\text { Third Floor } \\
\text { Second Floor }\end{array}$ \\
\hline
\end{tabular}


Site Plan

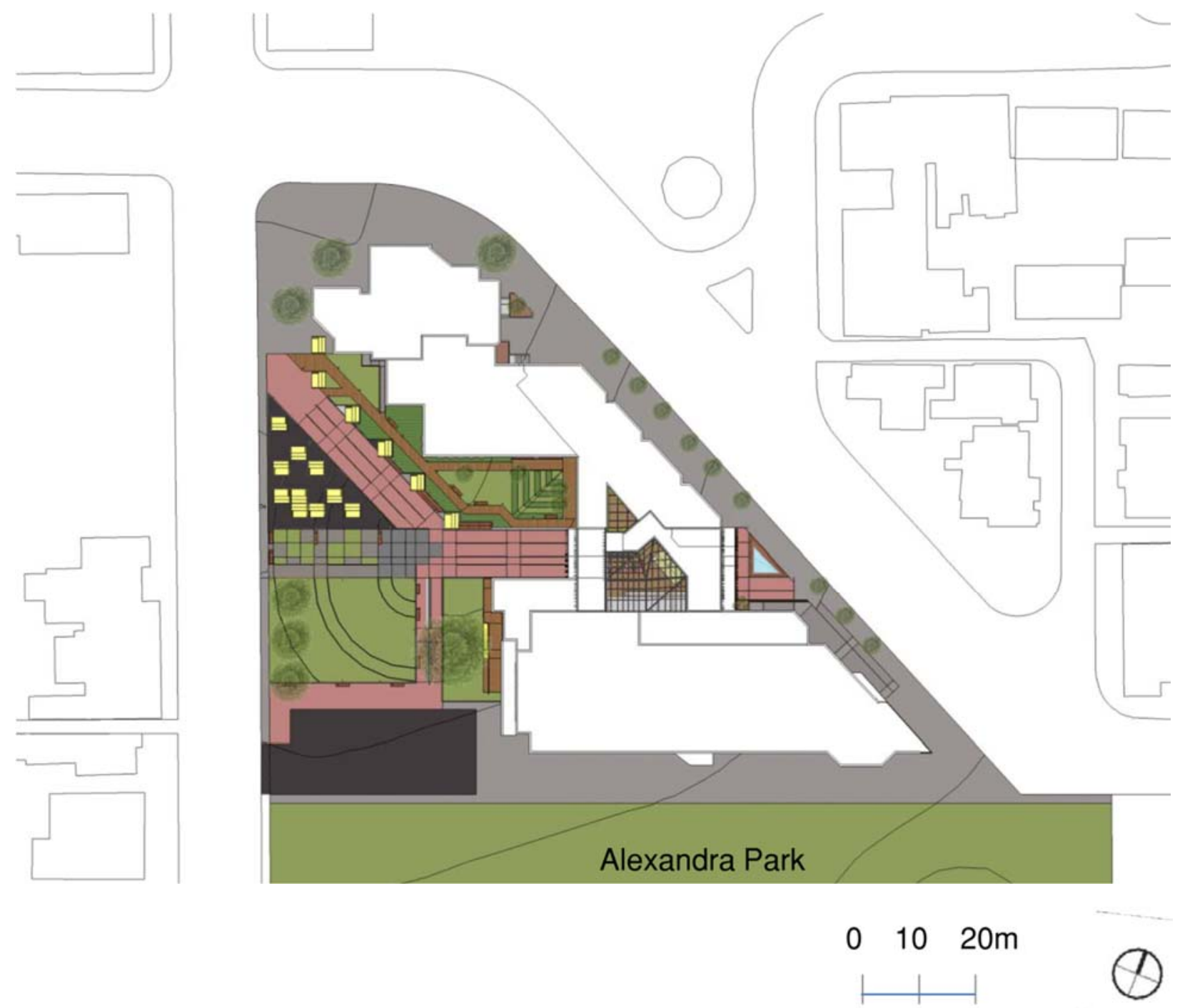




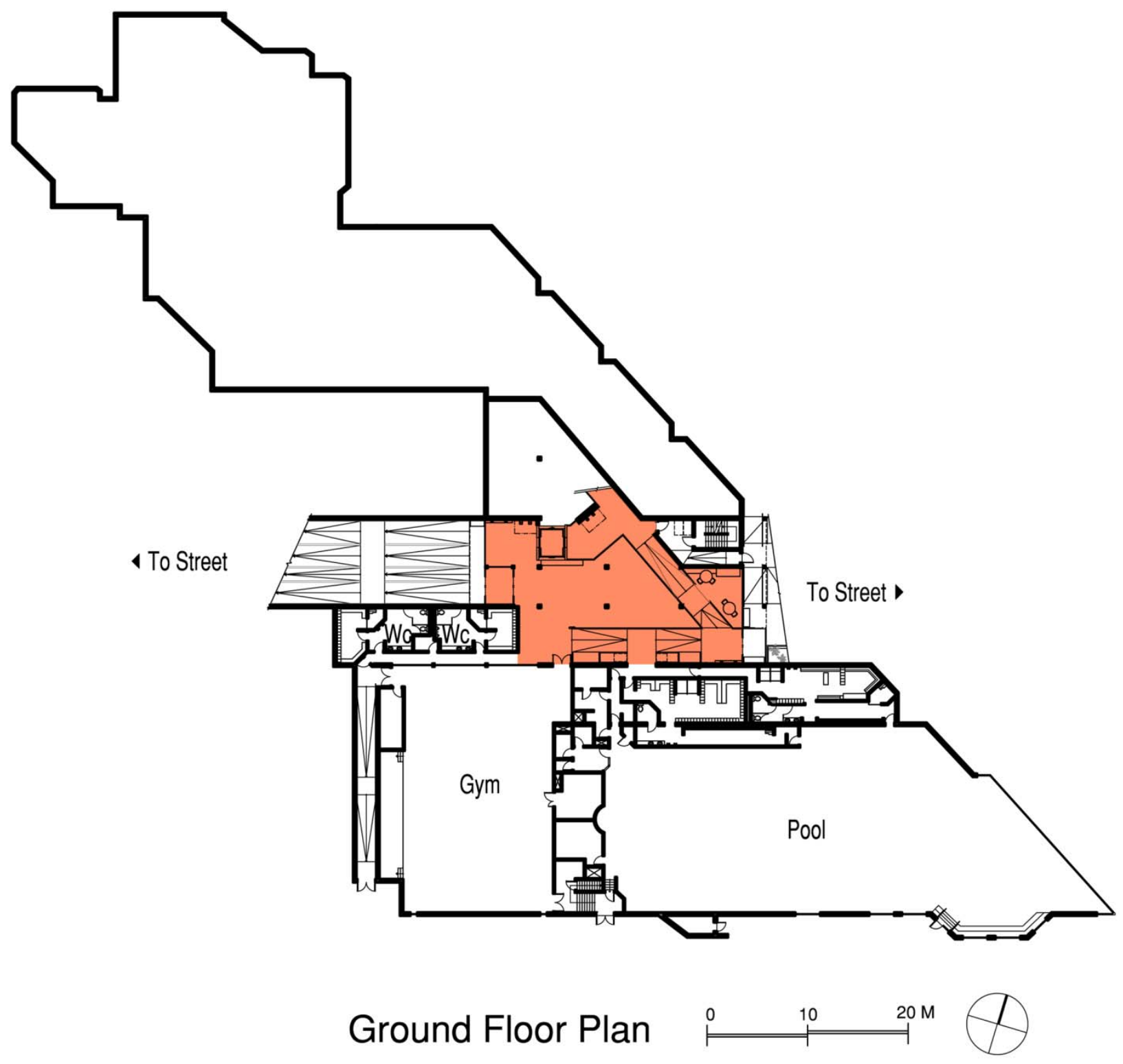



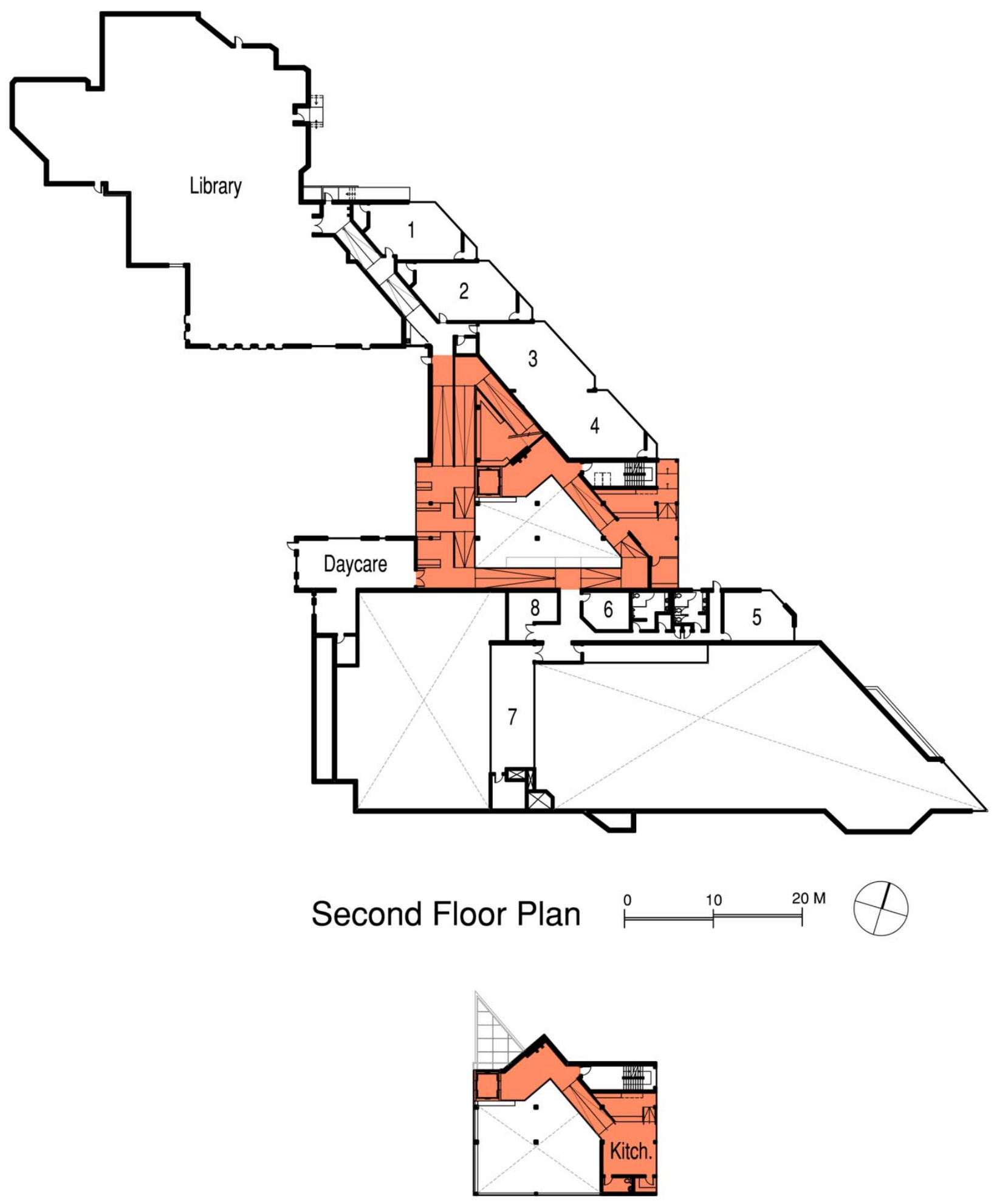

\section{Third Floor Plan}

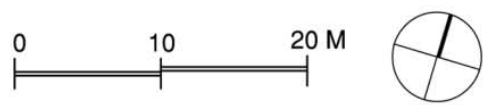


Building Sections

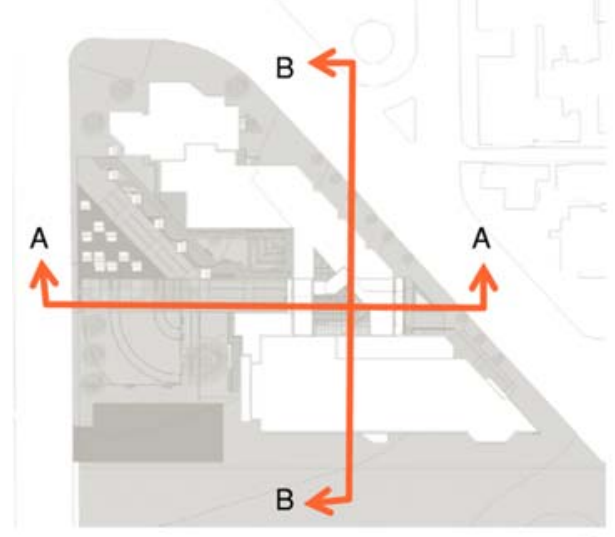

Key Plan

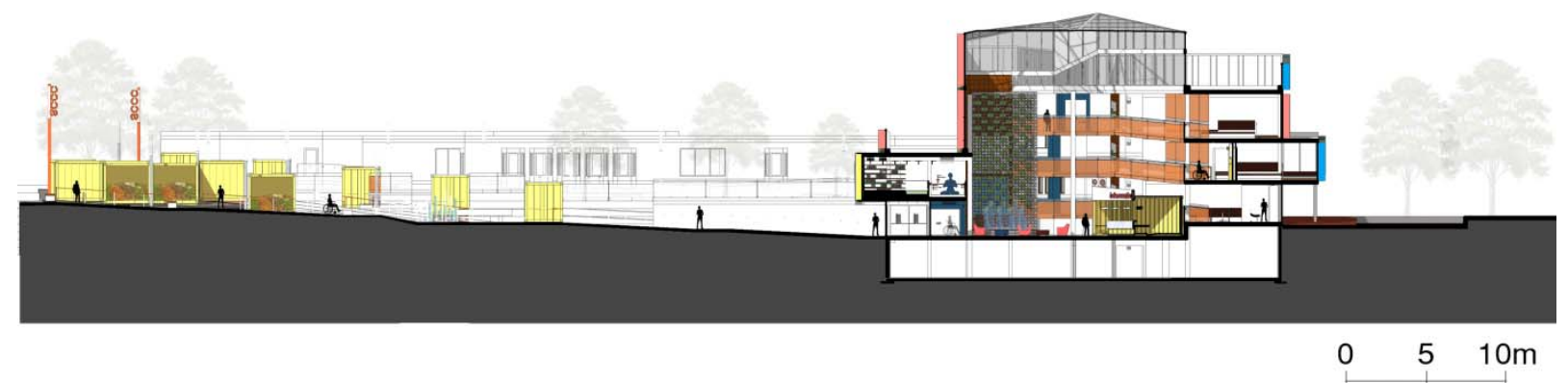

Section A-A

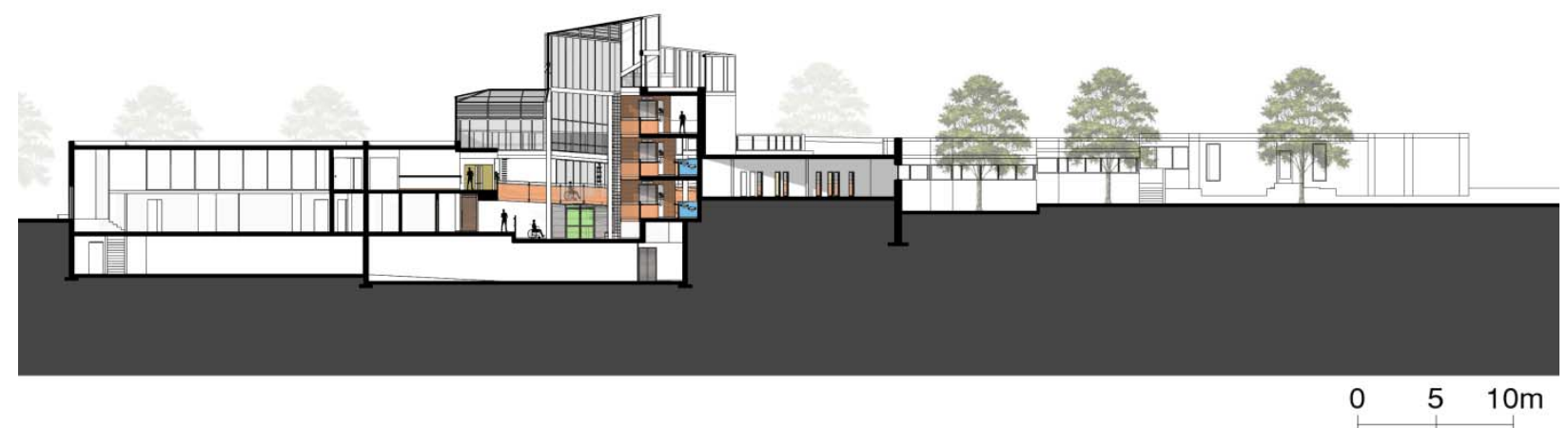

Section B-B 
Signage System

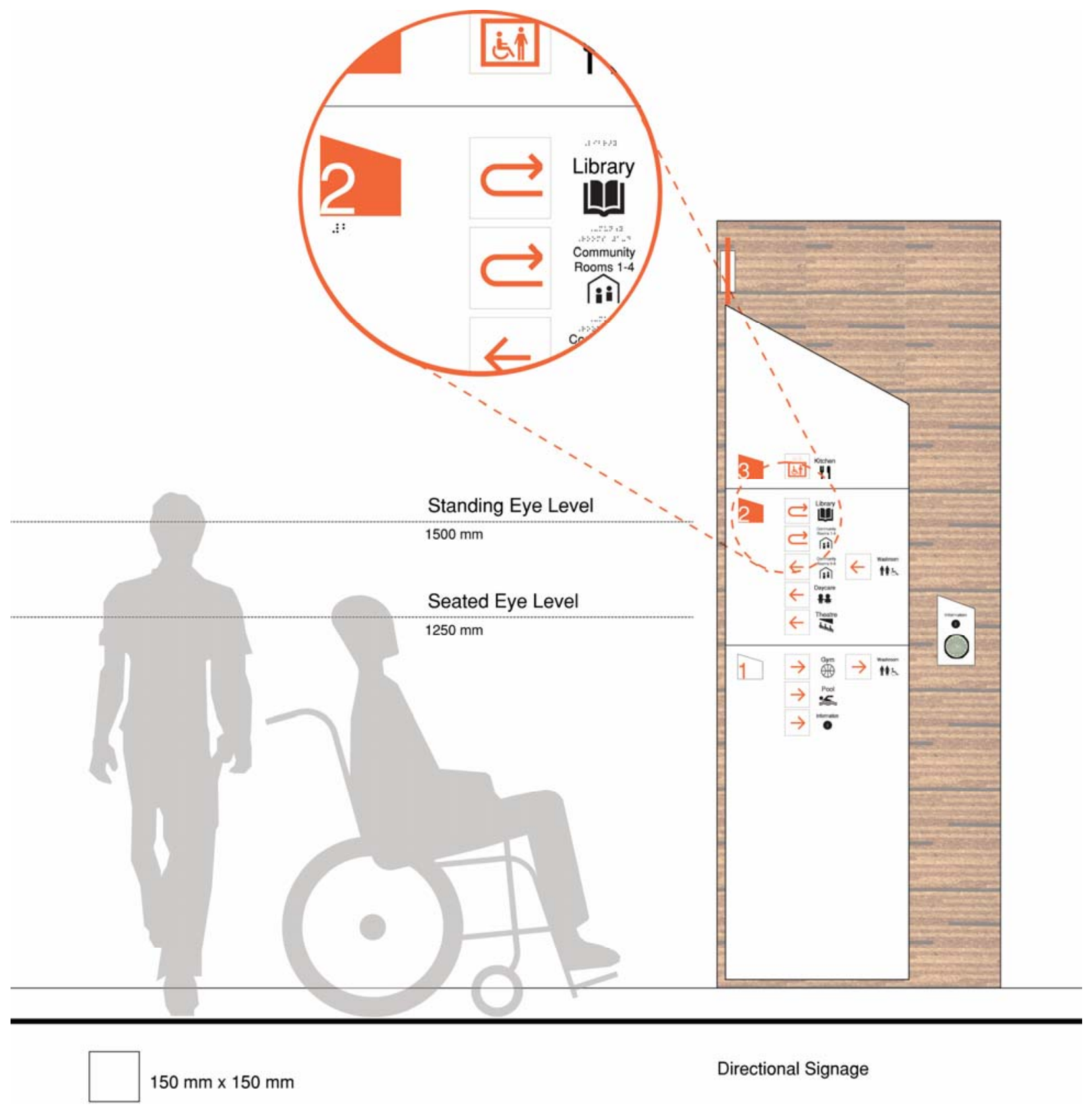


Materials and Finishes
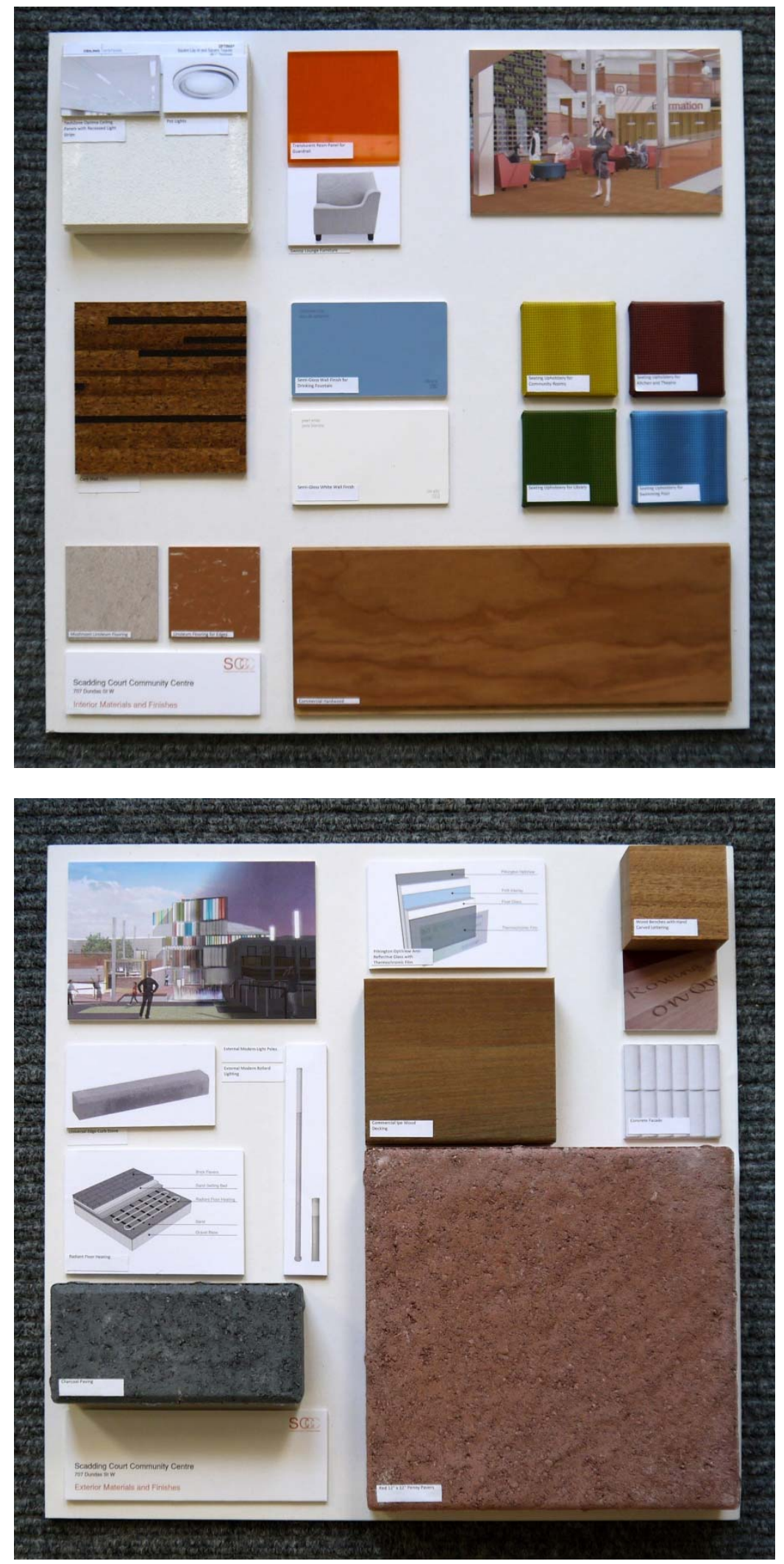

Interior Materials and Finishes

Exterior Materials and Finishes 


\section{ACRONYMS}

AODA Accessibility for Ontarians with Disabilities Act

AD Accessible Design

CABE Commission for Architecture and the Built Environment

DAT Digital Accessibility Team

ID Inclusive Design

PALS Participation and Activity Limitation Survey

POE Post Occupancy Evaluation

PWD People With Disabilities

SCCC Scadding Court Community Centre

UD Universal Design 


\section{REFERENCE LIST}

10 Reasons to Use Color. (2014).Understanding Graphics Design for the Human Kind.

Retrieved July 7, 2014, from http://understandinggraphics.com/design/10-reasons-to-usecolor/

Alexander, C., Ishikawa, S., \& Silverstein, M. (1977). A Pattern Language: Towns, Buildings, Construction. New York: Oxford University Press.

Annual Report. (2010). Scadding Court Community Centre. Retrieved July 10, 2014, from http://www.scaddingcourt.org/pdflibrary/sccc_ar2010_web.pdf

Arthur, P., \& Passini, R. (2002).Wayfinding: People, Signs, and Architecture. New York: McGraw-Hill Book Company.

At Home with Michael Graves. (n.d.). Traditional Home. Retrieved July 17, 2014, from http://www.traditionalhome.com/design/beautiful-homes/home-architect-michael-graves

Biography. (2009). Chris Downey Architect. Retrieved June 19, 2014, from http://www.arch4blind.com/bio.html

Brawley, E. (1997). Designing for Alzheimer's Disease: Strategies for Creating Better Care Environments. New York: Wiley.

Bright, K., \& Cook, G. (2010). The Colour, Light, and Contrast Manual: Designing and Managing Inclusive Built Environments. Chichester, West Sussex: Wiley-Blackwell.

Bright, K., \& Egger, V. (2008). Using Visual Contrast for Effective, Inclusive, Environments. Information Design Journal, 16(3), 178-189. 
Center for Inclusive Design and Environmental Access. (2010). Design Resources: Architectural Wayfinding. Center for Inclusive Design and Environmental Access. Retrieved June 26, 2014, from http://udeworld.com/documents/designresources/pdfs/ArchitecturalWayfinding.pdf

Choosing Durable Wood for a Garden Bench and Outdoor Furniture. (n.d.). Today's Homeowner. Retrieved July 15, 2014, from http://www.todayshomeowner.com/choosingdurable-wood-for-a-garden-bench-and-outdoor-furniture/

Cities for People. (2010). Alexandra Park. Spacing Toronto. Retrieved July 9, 2014, from http://spacing.ca/toronto/2010/06/22/cities-for-people-alexandra-park/

Creating a Sense of Adventure. (2009). ID/Lab. Retrieved June 9, 2014, from http://blog.idlab.com.au/creating-a-sense-of adventure/?doing_wp_cron=1401815173.1130859851837158203125

Dundas Street West Final Design Report. (2011). regionalArchitects + Corban and Goode + ERA Architects + planningAlliance + Poulos and Chung. Retrieved July 10, 2014, from http://www1.toronto.ca/city_of_toronto/policy_planning_finance_administration/public_c onsultation_unit/transportation_office/dundas_west/files/pdf/dundas_5.pdf

Facility Listing and Permits. (n.d.). FUN Guide Fall 2013/Winter 2014. Retrieved July 9, 2014, from http://www1.toronto.ca/parks/pdf/facility_map.pdf

Facio, A. \& Morgan, M. (2009). Equity or Equality for Women? Understanding CEDAW's Equality Principles. CEDAW. Retrieved June 23, 2014, from http://www.law.ua.edu/pubs//rarticles/Volume\%2060/Issue\%205/faciot.pdf

Fontys Sports College Eindhoven Scores With Bolidt. (n.d.). Archello. Retrieved July 18, 2014, from http://www.archello.com/en/project/fontys-sports-college 
Fontys Sports College / Mecanoo. (2012). ArchDaily. Retrieved July 18, 2014, from http://www.archdaily.com/287078/fontys-sports-college-mecanoo/

Fontys Sports College. (n.d.). World Buildings Directory. Retrieved July 18, 2014, from http://www.worldbuildingsdirectory.com/project.cfm?id=5025

Fontys School of Sport Studies. (n.d.). Mecanoo. Retrieved July 18, 2014, from http://www.mecanoo.nl/Default.aspx?tabid=116\&DetailId=834\&pcode=A489

Gehl, J. (1987). Life Between Buildings: Using Public Space. New York: Van Nostrand Reinhold.

Graves, M. (1999). Michael Graves: Selected and Current Works. Mulgrave, Vic.: Images Pub. Group.

Hazelwood ASN School. (n.d.). Scotland. Retrieved July 18, 2014, from http://www.scotland.gov.uk/Resource/Doc/920/0066326.pdf

Hazelwood School. (2009). Institute for Human Centered Design . Retrieved July 18, 2014, from http://www.dev.ihcdstore.org/?q=node/128\#top

Hazelwood School for the Multiple Sensory Impaired. (2009). Urbarama. Retrieved July 17, 2014, from http://es.urbarama.com/project/hazelwood-school-for-the-multiple-sensoryimpaired-1489

History. (2014). Sanderson Toronto Public Library. Retrieved July 10, 2014, from http://www.torontopubliclibrary.ca/detail.jsp?R=LIB085

Holl, S., Pallasmaa, J., \& Gómez, A. (2006). Questions of Perception: Phenomenology of Architecture. San Francisco: William Stout. 
IDeA. (2013). Center for Inclusive Design and Environmental Access. Retrieved June 9, 2014, from http://idea.ap.buffalo.edu/AboutUs/index.asp

Imrie, R. (2012). Disability and Rehabilitation. Universalism, Universal Design and Equitable Access to the Built Environment, 34(10), 873-882.

Inclusive Design Research Centre OCAD University. (2013). What is Inclusive Design.

Retrieved June 13, 2014, from http://idrc.ocad.ca/index.php/about-the-idrc/49resources/online-resources/articles-and-papers/443-whatisinclusivedesign

Ipe Wood. (n.d.). SwiftDeck. Retrieved July 15, 2014, from http://www.easydeckbuilding.com/decking_material_styles_swiftdeck.html

Jacobs, J. (1961). The Death and Life of Great American Cities. New York: Vintage Books Edition.

Kahn Building. (2014). Kimbell Art Museum. Retrieved June 28, 2014, from https://www.kimbellart.org/architecture/kahn-building

Kling, B., \& Krüger, T. (2013). Signage: Spatial Orientation. Germany: Walter de Gruyter.

Krupnick, E. (2013). 'Disabled' Mannequins Remind Us That Beautiful Doesn't Mean 'Perfect'. The Huffington Post. Retrieved July 20, 2014, from http://www.huffingtonpost.com/2013/12/03/disabled-mannequins-video_n_4379586.html

Lynch, K. (1960). The Image of the City. Cambridge: MIT Press.

MAH. (2005). Planning for Barrier-Free Municipalities: A Handbook \& Self Assessment Tool. Ontario. Retrieved November 18, 2013, from http://www.mah.gov.on.ca/Asset1059.aspx 
Market 707's New Public Patio. (n.d.).Projexity. Retrieved July 10, 2014, from https://projexity.com/projects/view/Market-707\%E2s-New-Public-Patio/2\#/main/designs

Marmorette with NATURCote. (n.d.).Armstrong Commercial Flooring: Linoleum / / Neutrals. Retrieved July 15, 2014, from http://www.armstrong.com/commflooringna/products/linoleum/marmorette-withnaturcote/neutrals/_N-67qZ1z141ymZ680

Myrvold, B. (1993). Historical Walking Tour of Kensington Market. Toronto Public Library. Retrieved July 10, 2014, from http://static.torontopubliclibrary.ca/da/pdfs/loc_his-w-16.pdf

Nielsen, J. (2008). Whiteness and Anti-Discrimination Law - It's in the Design.ACRAWSA ejournal, 4(2), 1-15. Retrieved June 23, 2014, from http://www.acrawsa.org.au/files/ejournalfiles/52NielsenInthedesignFINAL.pdf

Nussbaumer, L. (2012). Inclusive Design: A Universal Need. New York: Fairchild Books.

Ormerod, M. \& Newton, R. (2005, January). Moving Beyond Accessibility: The Principles of Universal (inclusive) Design as a Dimension in $\mathrm{nD}$ Modelling of the Built Environment. Architectural Engineering and Design Management, 1(2), 103-110.

Retrieved May 29, 2014, from http://journals2.scholarsportal.info.ezproxy.lib.ryerson.ca/pdf/17452007/v01i0002/103_mb atponmotbe.xml

Our History. (n.d.). Scadding Court Community Centre. Retrieved July 10, 2014, from http://www.scaddingcourt.org/our_history

Our Mission. (n.d.). Michael Graves Design Group. Retrieved June 19, 2014, from http://www.michaelgraves.com/design/mission.html 
Overview of Updated Accessibility Requirements. (n.d.). Ontario Ministry of Affairs and Housing. Retrieved June 12, 2014, from http://www.mah.gov.on.ca/Page10547.aspx

Pallasmaa, J. (2012). The Eyes of the Skin: Architecture and the Senses. Chichester: John Wiley and Sons Ltd.

Performance Plus. (n.d.). Commercial Hardwood Flooring by Armstrong. Retrieved July 15, 2014, from http://www.armstrong.com/commflooringna/products/commercial-hardwood

Pilkington OptiView. (n.d.). Pilkington . Retrieved September 3, 2014, from http://www.pilkington.com/northamerica/usa/english/products/bp/bybenefit/specialapplications/optiview/home.htm

Policy \& Projects Officer Community Services Division. (2013). Disability Discrimination Act Action Plan. Willoughby City Council 2012. Retrieved June 23, 2014, from https://www.google.ca/url?sa $=t \& r c t=j \& q=\& e s r c=s \&$ source $=$ web\&cd $=13 \&$ cad $=$ rja\&ved $=0$ CDUQFjACOAo\&url=http\%3A\%2F\%2Fwww.willoughby.nsw.gov.au\%2FDownloadDoc ument.ashx\%3FDocumentID\%3D8648\&ei=2ABfUpCkMOugyAHfiIGIBg\&usg=AFQjCN EpXu620D6wRAR_b7pJOmSzXwZL6A

Principles of Inclusive Design: They Include You. (n.d.). CABE. Retrieved July 17, 2014, from http://webarchive.nationalarchives.gov.uk/20110118095356/http:/www.cabe.org.uk/files/th e-principles-of-inclusive-design.pdf

Respecting Differences. (2009). Department of Education and Training. Retrieved June 23, 2014, from http://sielearning.tafensw.edu.au/MCS/CHCAOD402A/chcaod402a_csw/knowledge/differ ences/differences.htm

Roth, L. (1993). "Commoditie": How Does the Building Function?. Understanding Architecture: Its Elements, History, and Meaning (pp. 8-17). New York: Icon Editions. 
Scadding Court Community Centre. (2014). Scadding Court Community Centre. Retrieved July 9, 2014, from http://www.scaddingcourt.org/re_development

Schittich, C. (2013). Designing Circulation Areas: Stairs, Ramps, Lifts: Routing, Planning Principles. Germany: Birkhauser Architecture.

Schroeder, A. (2012). Space and Place.Andrew Schroeder. Retrieved July 8, 2014, from http://www.andrewschroeder.net/about/space-and-place/

Scutti, S. (2013). Wheelchair-Bound Michael Graves Designs People-Centric Healthcare Products. Medical Daily. Retrieved June 19, 2014, from http://www.medicaldaily.com/wheelchair-bound-michael-graves-designs-people-centrichealthcare-products-drawing-his-own-255136

Selwyn Goldsmith. (2011). The Telegraph. Retrieved July 20, 2014, from http://www.telegraph.co.uk/news/obituaries/technology-obituaries/8435991/SelwynGoldsmith.html

Social Profile \#2. (2007). Kensington-Chinatown (78). Retrieved July 9, 2014, from http://www1.toronto.ca/City\%20Of\%20Toronto/Social\%20Development,\%20Finance\%20 \&\%20Administration/Neighbourhood\%20Profiles/pdf/2006/pdf2/cpa78.pdf

Social Profile \#4. (2007). Kensington-Chinatown (78). Retrieved July 9, 2014, from http://www1.toronto.ca/City\%20Of\%20Toronto/Social\%20Development,\%20Finance\%20 \&\%20Administration/Neighbourhood\%20Profiles/pdf/2006/pdf4/cpa78.pdf

Sokol, D. (2014). Extra Sensory Perception.Architectural Record. Retrieved July 4, 2014, from http://archrecord.construction.com/schools/08_Extra_Sensory.asp 
Sokol, D. (n.d.). Pavilion in a Park .Architectural Record. Retrieved July 17, 2014, from http://archrecord.construction.com/schools/08_Hazelwood.asp

Standards Development Committee. (2010). AODA. Final Proposed Accessible Built Environment Standard, 1-193.

Steinfeld, E. \& Maisel, J. L. (2012).Universal Design: Creating Inclusive Environments. Hoboken, NJ: Wiley.

Story, M. F., Mueller, J. L., \& Mace, R. L. (1998). The Universal Design File: Designing for People of all Ages and Abilities (Rev. ed.). North Carolina State University : The Center for Universal Design.

The Place Diagram. (2012). Jane Jacobs` “Eyes on the Street” Concept. Retrieved July 8, 2014, from http://blogs.brandeis.edu/city/2012/09/10/placemaking-inspired-by-jane-jacobs-eyes-onthe-street-concept/place_diagram-2/

The Warehouse. (n.d.). Michael Graves and Associates. Retrieved July 17, 2014, from http://www.michaelgraves.com/architecture/project/the-warehouse.html

Treviranus, J. (2012). Planning a Universally Hospitable Museum. The Canadian Museum for Human Rights. Retrieved July 9, 2014, from http://humanrights.ca/explore/blog/guest-postplanning-universally-hospitable-museum\#.U71mOfldW9V

Universal Design New York. (2001). Center for Inclusive Design and Environmental Access. Retrieved June 12, 2014, from http://idea.ap.buffalo.edu//Publications/pdfs/udny1.pdf

Week 13: Function in Architecture. (n.d.).ARCH 121 - Introduction to Architecture I . Retrieved June 27, 2014, from http://arch121.cankaya.edu.tr/uploads/files/Week\%2013-lecture\%20notes07-jan-2014.pdf

What is Inclusive Design. (2013). Inclusive Design Toolkit. Retrieved June 25, 2014, from http://www.inclusivedesigntoolkit.com/betterdesign2/whatis/whatis.html 